\title{
MASBAL: A Computer \\ Program for Predicting the \\ Composition of Nuclear \\ Waste Glass Produced by a \\ Slurry-Fed Ceramic Melter
}

P. W. Reimus

July 1987

Prepared for the U.S. Department of Energy under Contract DE-AC06-76RLO 1830

Pacific Northwest Laboratory

Operated for the U.S. Department of Energy by Battelle Memorial Institute 


\section{DISCLAIMER}

This report was prepared as an account of work sponsored by an agency of the United States Government. Neither the United States Government nor any agency thereof, nor Battelle Memorial Institute, nor any of their employees, makes any warranty, expressed or implied, or assumes any legal liability or responsibility for the accuracy, completeness, or usefulness of any information, apparatus, product, or process disclosed, or represents that its use would not infringe privately owned rights. Reference herein to any specific commercial product, process, or service by trade name, trademark, manufacturer, or otherwise, does not necessarily constitute or imply its endorsement, recommendation, or favoring by the United States Government of any agency thereof, or Battelle Memorial Institute. The views and opinions of authors expressed herein do not necessarly state or reflect those of the United States Government or any agency thereof, or Battelle Memorial Institute.

\section{PACIFIC NORTHWEST LABORATORY operated by BATTELLE MEMORIAL INSTITUTE for the UNITED STATES DEPARTMENT OF ENERGY under Contract DE-AC06-76RLO 1830}

\begin{tabular}{|c|c|}
\hline \multicolumn{2}{|c|}{ Printed in the United States of America } \\
\hline \multirow{2}{*}{\multicolumn{2}{|c|}{$\begin{array}{c}\text { Available from } \\
\text { National Technical Information Service }\end{array}$}} \\
\hline & \\
\hline \multirow{3}{*}{\multicolumn{2}{|c|}{$\begin{array}{c}\text { National Technical Information Service } \\
\text { United States Department of Commerce } \\
5285 \text { Port Royal Road } \\
\text { Springfield, Virginia } 22161\end{array}$}} \\
\hline & \\
\hline & \\
\hline \multirow{2}{*}{\multicolumn{2}{|c|}{$\begin{array}{l}\text { NTIS Price Codes } \\
\text { Microfiche A01 }\end{array}$}} \\
\hline & \\
\hline \multicolumn{2}{|c|}{ Printed Copy } \\
\hline & Price \\
\hline Pages & Codes \\
\hline $001-025$ & A02 \\
\hline $026-050$ & $\mathrm{~A} 03$ \\
\hline $051-075$ & $\mathrm{~A} 04$ \\
\hline $076-100$ & A05 \\
\hline $101-125$ & $A 06$ \\
\hline $126-150$ & A07 \\
\hline $151-175$ & A08 \\
\hline $176-200$ & $\mathrm{~A} 09$ \\
\hline $201-225$ & A010 \\
\hline $226-250$ & A011 \\
\hline $251-275$ & $\mathrm{~A} 012$ \\
\hline $276-300$ & A013 \\
\hline
\end{tabular}


MASBAL: A COMPUTER PROGRAM FOR PREDICTING THE COMPOSITION OF NUCLEAR WASTE GLASS PRODUCED BY A SLURRY-FED CERAMIC MELTER

P. W. Reimus

July 1987

Prepared for the U.S. Department of Energy under Contract DE-ACU6-76RLO 1330

Pacific Northwest Laboratory Richland, Washingt on 99352 


\section{SUMMARY}

This report serves as a user's manual for the MASBAL computer program. MASBAL has three overall objectives: 1) to predict the composition of nuclear waste glass produced by a slurry-fed ceramic melter based on a knowledge of process conditions; 2) to generate simulated data that can be used to estimate the uncertainty in the predicted glass composition as a function of process uncertainties; and 3) to generate simulated data that can be used to provide a measure of the inherent variability in the glass composition as a function of the inherent variability in the feed composition. These three capabilities are important to nuclear waste glass producers because there are constraints on the range of compositions that can be processed in a ceramic melter and on the range of compositions that will be acceptable for disposal in a geologic repository.

MASBAL was developed specifically to simulate the operation of the West Valley Component Test System, a commercial-scale ceramic melter system that will process high-level nuclear wastes currently stored in underground tanks at the site of the Western New York Nuclear Services Center (near West Valley, New York). The program is flexible enough, however, to simulate any slurry-fed ceramic melter system.

MASBAL simulates the flow of material through the melter feed tank and melter of the vitrification system. The program can track as many as 100 constituents through the system. These constituents are assumed to be inert at all points in the system (i.e., concentrations are specified on an oxide basis). Material enters the system by way of the feed tank (slurry transfer from the makeup tank), and it leaves the system by going out either the off-gas system or into a canister. MASBAL can simulate the addition of glass-forming compounds directly to either the feed tank or the melter (these actions may be taken if the feed or glass composition deviates significantly from the target composition). The off-gas system is modeled as a sink for components that have finite melter decontamination factors. The primary outputs of MASBAL are the composition of the glass exiting the melter as a function of time and the average composition of the glass in each glass pour. 
Because the mixing characteristics of the West Valley melter are currently unknown, MASBAL provides several options for modeling flow of material through the melter. The melter can be modeled as 1) a single ideally-mixed tank, 2) two to five ideally-mixed regions in series, or 3 ) a plug flow region followed by one or two ideally-mixed regions in series. The best modeling approach will be decided by the best fit to experimental data. The relative volumes of each region are adjustable for use in calibration/validation activities.

MASBAL is designed to be operated in three modes. The first mode provides deterministic predictions of the glass composition exiting the melter as a function of time. The key inputs to the program when it is operated in this mode are the values of process measurements taken at appropriate times during the operation of the systen (i.e., actual process data).

The second mode generates simulated glass composition data that can be used to estimate the uncertainty in the deterministic predictions provided by the first mode. The process data required as inputs for the first mode are also required for the second mode. The parameters of statistical distributions that define uncertainties in the process measurements are also required as inputs for the second mode. Each process measurement is treated as the mean or mode of a statistical distribution that is assumed to contain the true value of the variable being measured. Measurement errors are simulated by randomly sampling these distributions; the values returned from the distributions are used in subsequent mass balance calculations as the true values of the measured variables. MASBAL can be run repeatedly in this mode to generate glass composition data that are distributed randomly about the deterministic predictions of mode 1 . The absolute differences between the data generated in mode 2 and the predictions of mode 1 provide a measure of the uncertainty in the deterministic predictions.

When MASBAL is run in the third mode, the program generates its own feed composition data by randomly selecting the composition of successive batches of feed from statistical distributions defined by the user (the concentration of each constituent in the feed will be taken from a distribution that has a mean or mode of the target concentration). All process measurements are simulated 
by randomly sampling statistical distributions that have means or modes equal to the simulated values of the process variables being measured. The simulated fluctuations in the feed composition and errors in process measurements cause the calculated glass composition to fluctuate randomly about the target composition. If the process measurements are treated deterministically (i.e., if the standard deviations describing the measurement errors are set to zero), then the absolute differences between the stochastically generated data and the target glass composition will provide a measure of the inherent variability in the composition of the glass as a function of the variability in the feed composition. If, on the other hand, the composition of successive batches of feed is treated deterministically, then the differences between the stochastically generated composition data and the target glass composition will provide the same information that is provided by the second mode of MASBAL. The advantage of running MASBAL in the third mode is that the user can cun the program without having to supply process data (all that is required are the parameters of distributions that describe feed composition variability and uncertainties in process measurements). This feature gives MASBAL the capability to simulate thousands of hours of operation of the melter system, and thus makes it possible to generate enough simulated data to make reasonable estimates of the confidence limits associated with either the predicted or the target glass composition.

MASBAL consists of PNL-developed FORTRAN subroutines that are integrated with the SIMAN simulation language. SIMAN offers 1) a differential equation solving algorithm for solving the mass balance differential equations that describe the time dependent concentrations in the system, 2) the capability to model discrete events that interact with or change the values of state variables in the system (e.g., the starting or stopping of the flow of feed to the melter, and 3) the capability to randomly sample statistical distributions. The random sampling of statistical distributions is an essential feature of MASBAL when it is operated in modes 2 or 3. 
This report provides a complete description of the features of MASBAL. Each of the input and output files is thoroughly described, and instructions on how to run the program are provided. Examples of each of the input and output files are included in appendices. 


\section{CONTENTS}

SUMMARY

1.0 INTRODUCTION $\ldots \ldots \ldots \ldots \ldots \ldots \ldots \ldots \ldots \ldots \ldots \ldots \ldots \ldots \ldots \ldots \ldots \ldots \ldots \ldots \ldots \ldots \ldots \ldots \ldots \ldots . . \ldots$

2.0 SOFTWARE DESIGN $\ldots \ldots \ldots \ldots \ldots \ldots \ldots \ldots \ldots \ldots \ldots \ldots \ldots \ldots \ldots \ldots \ldots \ldots \ldots \ldots \ldots \ldots \ldots . \ldots \ldots$

2.1 DESCRIPTION OF THE PHYSICAL SYSTEM ...................... 2.1

2.2 ASSUMPTIONS AND BASES $\ldots \ldots \ldots \ldots \ldots \ldots \ldots \ldots \ldots \ldots \ldots \ldots \ldots \ldots \ldots \ldots \ldots \ldots \ldots \ldots . \ldots \ldots \ldots$

2.3 MODES OF OPERATION $\ldots \ldots \ldots \ldots \ldots \ldots \ldots \ldots \ldots \ldots \ldots \ldots \ldots \ldots \ldots \ldots \ldots \ldots \ldots$

2.4 MASS BALANCE EQUATIONS $\ldots \ldots \ldots \ldots \ldots \ldots \ldots \ldots \ldots \ldots \ldots \ldots \ldots \ldots \ldots \ldots$

2.4.1 Mass Balance Equations for Ideally-Mixed Regions ....... 2.9

2.4.2 Mass Balance Equations for Plug Flow Region in Melter .........................................2.10

2.4.3 Changes in Mass of Melter Regions as a Function of Feed Rate ....................................2.11

2.4 .4 off-Gas Calculations ............................ 2.14

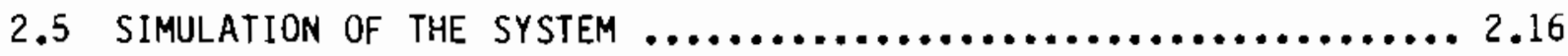

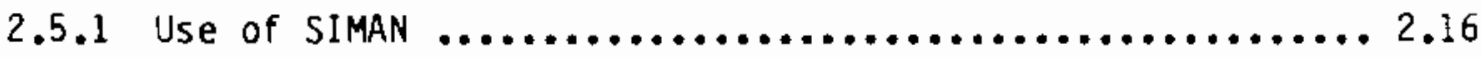

2.5 .2 MASBAL Implementation $\ldots \ldots \ldots \ldots \ldots \ldots \ldots \ldots \ldots \ldots \ldots \ldots \ldots \ldots$

2.5 .3 State Variables ................................ 2..24

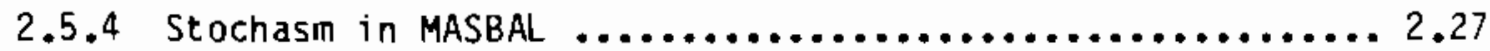

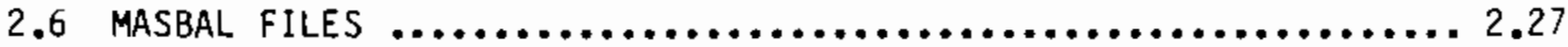

2.6 .1 Special SIMAN Files $\ldots \ldots \ldots \ldots \ldots \ldots \ldots \ldots \ldots \ldots \ldots \ldots \ldots \ldots \ldots . . \ldots \ldots$

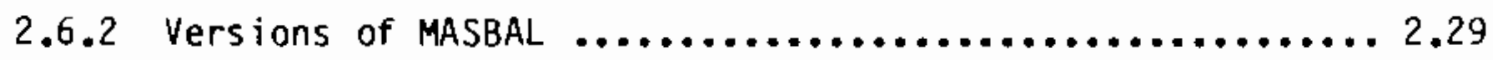

3.0 INPUT FILES $\ldots \ldots \ldots \ldots \ldots \ldots \ldots \ldots \ldots \ldots \ldots \ldots \ldots \ldots \ldots \ldots \ldots \ldots \ldots \ldots \ldots \ldots \ldots \ldots \ldots \ldots . \ldots . \ldots$

3.1 MODE.DAT $\ldots \ldots \ldots \ldots \ldots \ldots \ldots \ldots \ldots \ldots \ldots \ldots \ldots \ldots \ldots \ldots \ldots \ldots \ldots \ldots \ldots \ldots \ldots . \ldots . \ldots \ldots$

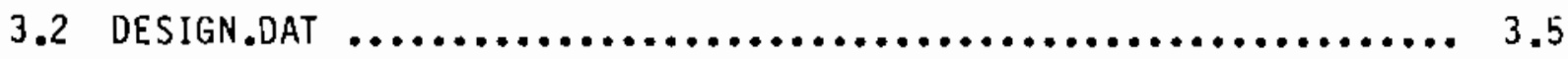

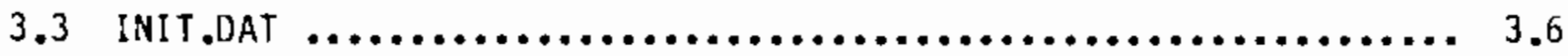




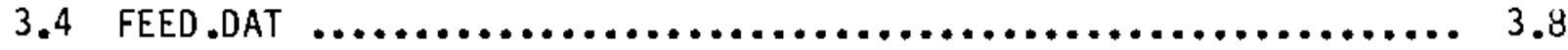

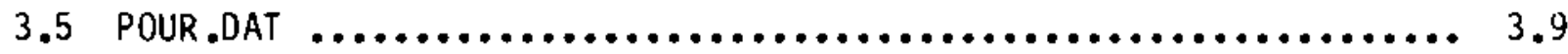

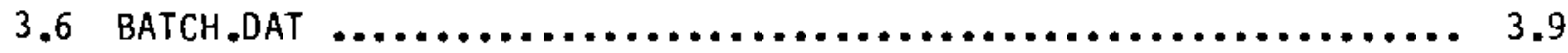

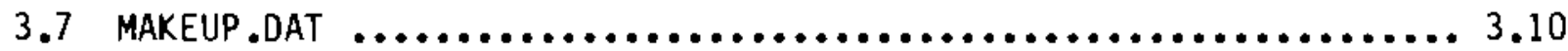

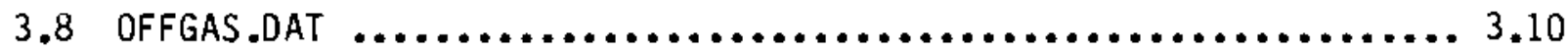

3.9 FSHIM.DAT $\ldots \ldots \ldots \ldots \ldots \ldots \ldots \ldots \ldots \ldots \ldots \ldots \ldots \ldots \ldots \ldots \ldots \ldots, \ldots \ldots \ldots, 11$

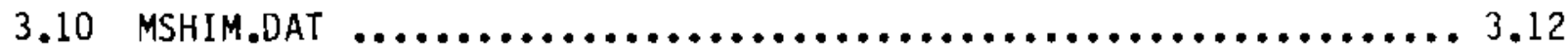

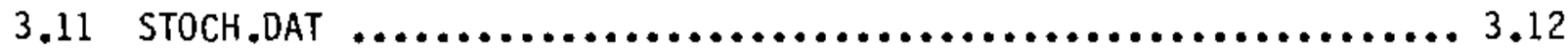

3.11 .1 Statistical Distributions $\ldots \ldots \ldots \ldots \ldots \ldots \ldots \ldots \ldots \ldots .12$

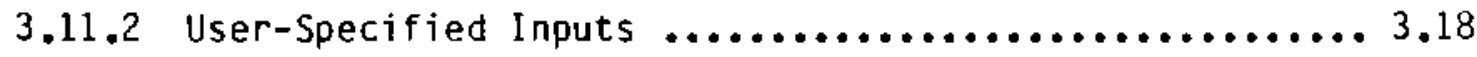

4.0 OUtPUt files $\ldots \ldots \ldots \ldots \ldots \ldots \ldots \ldots \ldots \ldots \ldots \ldots \ldots \ldots \ldots \ldots \ldots \ldots \ldots, 4.1$

4.1 OUTPUT FILES GENERATED BY PRODUCTION VERSION $\ldots \ldots \ldots \ldots \ldots \ldots \ldots . .1$

4.2 OUtPut files generated by debug Version $\ldots \ldots \ldots \ldots \ldots \ldots \ldots \ldots . .2$

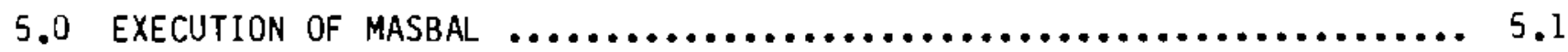

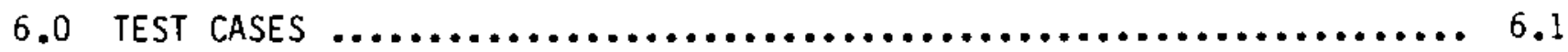

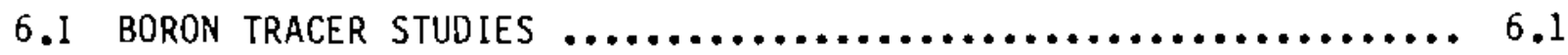

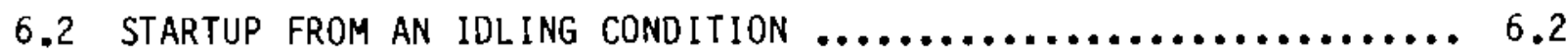

6.3 VARIABILITY IN GLASS COMPOSITION AS A FUNCTION OF
VARIABILITY IN FEED COMPOSITION $\ldots \ldots \ldots \ldots \ldots \ldots \ldots \ldots \ldots \ldots \ldots \ldots . \ldots \ldots$

6.4 VARIABILITY IN PREDICTED GLASS COMPOSITION AS A

FUNCTION OF SAMPLING AND ANALYTICAL ERRORS $\ldots \ldots \ldots \ldots \ldots \ldots \ldots .6 .6$

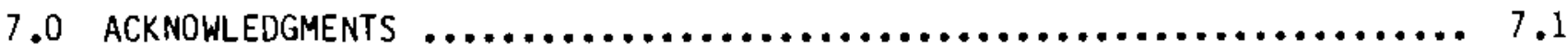

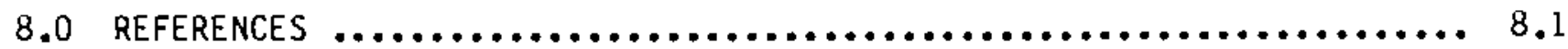

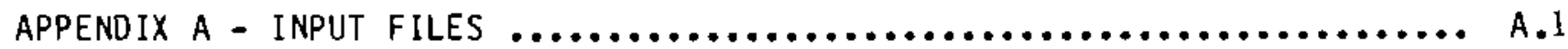

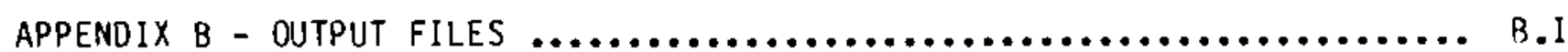




\section{FIGURES}

2.1 West Valley Component Test System Schematic .................... 2..2

2.2 Mode 1 of MASBAL $\ldots \ldots \ldots \ldots \ldots \ldots \ldots \ldots \ldots \ldots \ldots \ldots \ldots \ldots \ldots \ldots \ldots \ldots \ldots \ldots \ldots \ldots \ldots$

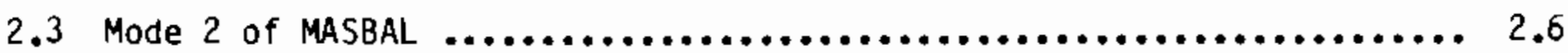

2.4 Mode 3 of MASBAL $\ldots \ldots \ldots \ldots \ldots \ldots \ldots \ldots \ldots \ldots \ldots \ldots \ldots \ldots \ldots \ldots \ldots \ldots \ldots \ldots \ldots \ldots . \ldots \ldots \ldots$

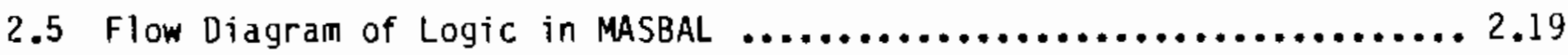

2.6 Correspondence Between State Variables and Physical

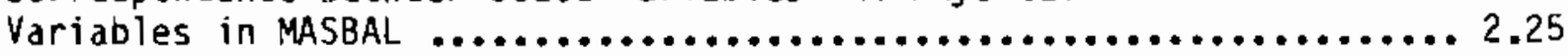

3.1 Probability Density Function for Symmetrical

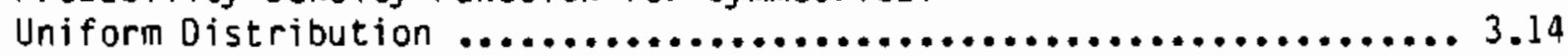

3.2 Probability Density Function for Symmetrical

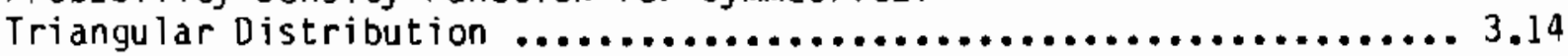

3.3 Probability Density Function for Nonsymmetrical

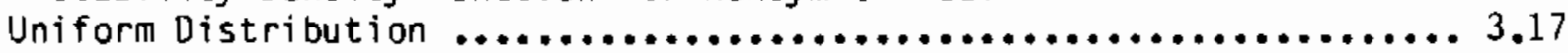

3.4 Probability Density Function for Nonsymetrical

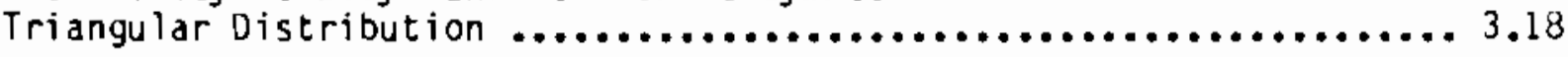

6.1 Responses to Step Change in B203 Concentration when Modeling

Melter as Ideally-Mixed Regions in Series ..................... 6.3

6.2 Responses to Step Change in B203 Concentration when Modeling

Melter as Plug Flow and Ideally-Mixed Regions in Series ............ 6.4

6.3 Change in Mass of Melter Regions when Starting from an

Idling Condition (Two Ideally-Mixed Regions in Series) ........... 6.5

6.4 Variability in Glass Composition as a Result of a $5 \%$

Batch-to-Batch Variability in Feed Composition ................. 6.7

6.5 Variability in Predicted Glass Composition as a Result of

5\% Errors in Sampling and Analyzing the Feed - One Sample and

One Analysis of Each Sample ................................ 6..9

6.6 Variability in Predicted Glass Composition as a Result of 5\% Errors in Sampling and Analyzing the Feed - Three Samples and Three Analyses of Each Sample 


\section{TABLES}

2.1 Discrete Events in the West Valley Component Test System .......... 2.17

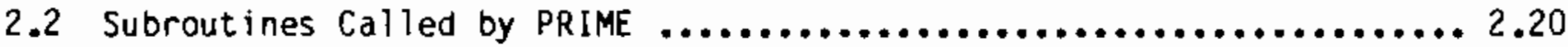

2.3 MASBAL Event Subroutines $\ldots \ldots \ldots \ldots \ldots \ldots \ldots \ldots \ldots \ldots \ldots \ldots \ldots \ldots \ldots \ldots \ldots \ldots . \ldots 21$

2.4 Key to Figure $2.6 \ldots \ldots \ldots \ldots \ldots \ldots \ldots \ldots \ldots \ldots \ldots \ldots \ldots \ldots \ldots \ldots \ldots \ldots \ldots \ldots \ldots \ldots \ldots . \ldots . \ldots \ldots$

3.1 MASBAL Input Files and Modes of Operation in which They Are Used ........................................... 3.1 


\subsection{INTRODUCTION}

This report serves as a user's manual for the MASBAL computer program. MASBAL has three primary objectives: 1) to predict the composition of nuclear waste glass produced by a slurry-fed ceramic melter based on a knowledge of process conditions, 2) to generate simulated data that can be used to estimate the uncertainty in the predicted glass composition as a function of process uncertainties, and 3) to generate simulated data that can be used to provide a measure of the inherent variability in the glass composition as a function of the inherent variability in the feed composition.

MASBAL was developed at Pacific Northwest Laboratory (PNL) ${ }^{(a)}$ for West Valley Nuclear Services (WVNS) Company, Inc. WVNS is responsible for management of the site of the Western New York Nuclear Services Center, the only commercial nuclear fuel reprocessing plant to have operated in the United States. Underground tanks at the site contain high-level waste (HLW) produced in part by a commercial fuel reprocessing campaign. The State of New York has assumed responsibility for these wastes. The U.S. Department of Energy (DOE) is assisting, through the West Valley Demonstration Project (WVDP), in the retrieval and solidification of these wastes.

The planned method of solidification of the HLW is incorporation into a vitreous glass matrix. The waste slurry from the storage tanks will be combined with appropriate glass-forming compounds, concentrated, and then fed to a ceramic melter operated at $1100^{\circ}$ to $1250^{\circ} \mathrm{C}$. Water from the slurry will be driven off immediately, and the remaining components will gradually melt into a molten glass phase in the melter. Glass will be poured from the melter into canisters, where it will cool and solidify. The canisters will eventually be sealed and shipped to a high-level nuclear waste repository for disposal.

The ability to predict the glass composition in the canisters and the uncertainty in the glass composition is important for two reasons: 1) there are constraints on the range of compositions that can be processed in a ceramic

(a) Operated for the U.S. Department of Energy by Battelle Memorial Institute. 
melter, and 2) there are constraints on the range of compositions that will be acceptable for disposal in a geologic repository.

The first set of constraints arises because the composition of the glass affects key processing parameters such as the melting point, melting rate, viscosity, electrical conductivity of the mixture, and the tendency of the mixture to foam. The second constraint arises because composition is an important parameter affecting the durability of the glass to aqueous attack, one of the key measures of the acceptability of any waste form for geologic disposal. Because of the dependence of durability on composition, WVNS will probably be required to provide the DOE Office of Civilian Radioactive Waste Management (OCRWM) or perhaps a regulatory agency with an estimate of the composition of the glass in each canister that is produced.

MASBAL provides WVNS with the capability to predict the composition of the glass in each canister based on process measurements taken upstream of the canisters. It also provides

? the capability to estimate the uncertainty in the predicted glass composition as a function of 1) uncertainties in process measurements, and 2) the number of replicate feed samples taken and the number of replicate analyses performed on each sample

- the capability to estimate the variability in the actual glass composition as a function of the inherent variability in the feed composition.

Chapter 2.0 of this report provides a detajled description of the design of MASBAL. The input files and the input data that they contain are discussed in Chapter 3.0. Because the input files represent the only interface between the user and the program, Chapter 3.0 is extremely important to the user. A description of the output files is provided in Chapter 4.0 . Chapter 5.0 provides instructions on how to execute MASBAL. Results from some of the test cases that were run during the development of MASBAL are presented in Chapter 6.0. These test cases illustrate some of the capabilities of the program. Examples of input and output files are provided in Appendices $A$ and $B$, respectively. 


\subsection{SOFTWARE DESIGN}

MASBAL is a computer program that simulates the operation of a slurry-fed ceramic melter system. The primary inputs to the program are 1) the design parameters of the melter system, 2) the process measurements taken during operation of the system, and 3) the parameters of statistical distributions that describe uncertainties in the process measurements and inherent fluctuations in the feed composition. The primary output of the program is the calculated glass composition exiting the melter as a function of time.

\subsection{DESCRIPTION OF THE PHYSICAL SYSTEM}

A schematic drawing of the West Valley Component Test System (CTS) is shown in figure 2.1. The following operating scenario was assumed for the purposes of the simulation: (a) During a vitrification campaign, waste slurry is pumped from the high-level waste feed tank to the concentrator feed nlakeup tank, where it is sampled. The apparent composition of the samples is used to calculate the amount of various glass forming compounds that should be added to the waste to obtain a slurry of the desired feed composition. These chemicals are added first to a cold chemical makeup tank, where they are blended. They are then transferred to the concentrator feed makeup tank, where they are combined with the waste. After addition of the glass formers, the slurry in the makeup tank is concentrated until the solids loading is at some specified level. The slurry is then transferred to the feed tank, where it is continuously fed to the melter. When the slurry enters the melter, the water quickly evaporates and goes to the off-gas system, leaving the less volatile constituents behind to gradually melt into the molten glass phase. Small amounts of each of these less volatile constituents will go to the off-gas system as a result of being entrained in the exiting gases or because of partial volatilization in the melter. The purpose of the off-gas system is to remove the radioactive constituents from the gas so that the gas can be exhausted to the environment. Glass is poured out of the melter either continuously or in batches into metal canisters.

(a) This operating strategy reflects current plans at West Valley. 


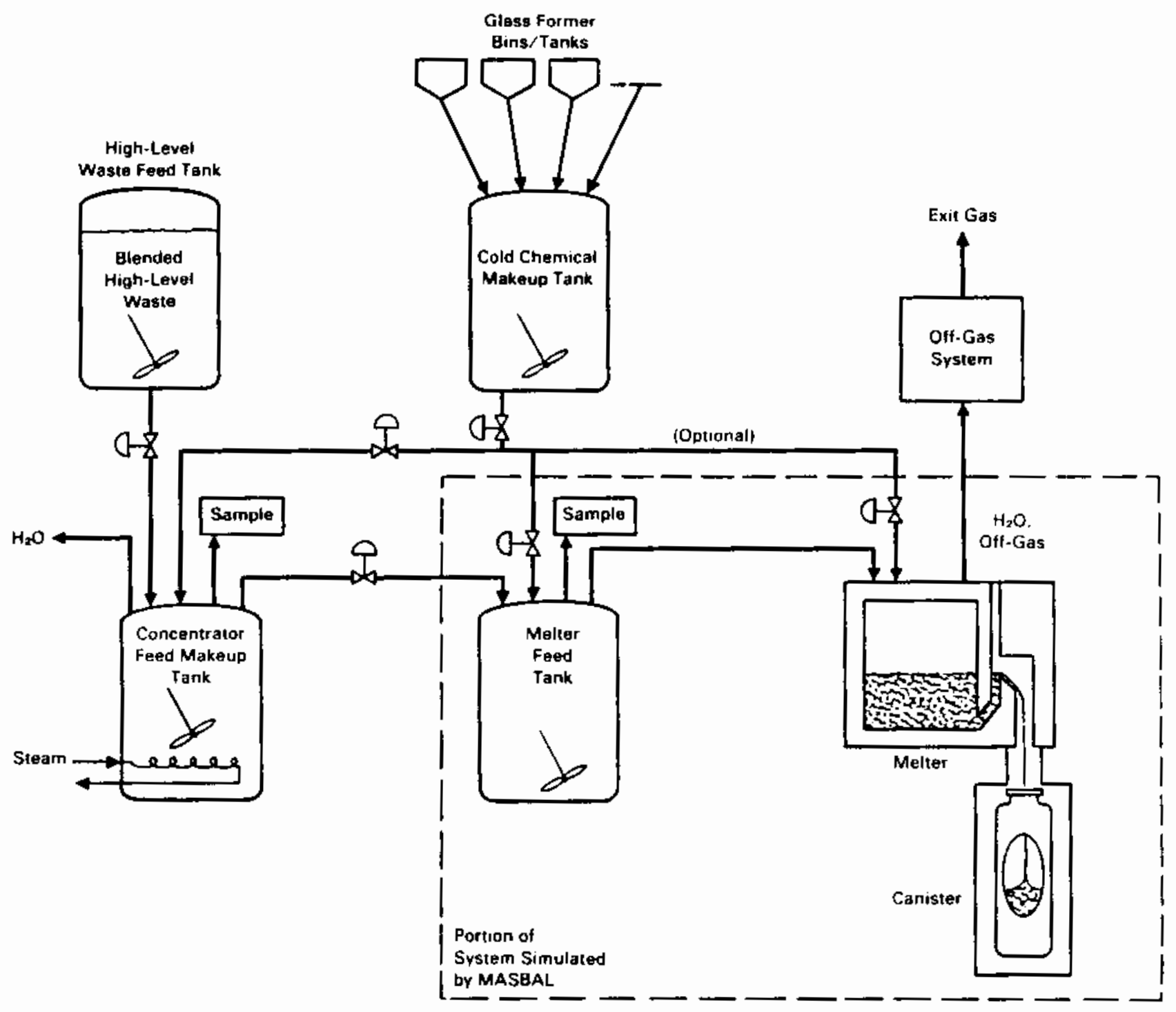

FIGURE 2.1. West Valley Component Test System Schematic

MASBAL simulates only the part of the system that is contained within the dashed line in Figure 2.1. The makeup tank is excluded because WVNS plans to sample the feed tank after each transfer of slurry from the makeup tank. Therefore, the glass compositions calculated by MASBAL are based on the analyses of samples from the feed tank rather than from the makeup tank.

The slurry lines that run from the cold chemical makeup tank to the feed tank and melter in Figure 2.1 could be used to add glass formers directly to the latter two tanks. This action might be taken if a sample from the feed tank indicates that the feed composition is out of tolerance and must be 
corrected. The West Valley CTS currently does not have a line running from the cold chemical makeup tank to the melter, but such a line is included in MASBAL for completeness.

The off-gas system is excluded from MASBAL because the objective of MASBAL is to calculate the composition of the glass poured into the canisters, not the composition in the off-gas system. However, the amount of each constituent that is collected in the off-gas system is a necessary input to MASBAL because the composition of the glass is calculated by differencing between the feed composition and the off-gas composition.

\subsection{ASSUMPTIONS AND BASES}

MASBAL was developed under the following set of assumptions and bases:

- The model includes a provision for as many as 100 chemical constituents.

- The model assumes that all chemical constituents are inert at all points in the system (chemical reactions are not modeled). The concentration of each chemical constituent is specified as a mass of oxide (or other final glass form) per unit volume. Each constituent that appears in the glass is treated as a separate inert component. water is the only component that does not appear in the glass.

- The main feed tank is modeled as an ideally-mixed tank. Based on studies at PNL, this assumption should be valid if sufficient power is supplied to the tank in the form of agitation (Peterson et al. 1986).

- The melter can be modeled as an ideally-mixed tank, as a plug flow region followed by one or two ideally-mixed regions in series, or as two to five ideally-mixed regions in series.

- There is no holdup in lines between tanks (i.e., the volume of slurry in pipes is negligible compared to the volume in tanks).

- The rate of volatilization of constituents in the melter is modeled as constant from one of $f$ gas sampling time to another. No attempt is made to model off-gas surges or fluctuations. If the off-gas is not 
sampled or if no sampling information is available, losses due to volatilization are modeled using a constant decontamination factor for each constituent.

- Batch glass pours are modeled as having a constant flow rate for a specified time period.

\subsection{MODES OF OPERATION}

MASBAL is designed to be operated in three modes. The first mode provides deterministic predictions of the glass composition as a function of time. The second and third modes generate simulated glass composition data that can be used to estimate the uncertainty in the deterministic predictions provided in mode 1 , or to estimate the variability in the glass composition as a function of the inherent variability in the feed composition.

When MASBAL is operated in the first mode, the key program inputs are process measurements and control actions taken at appropriate times during the operation of the system. The program takes these inputs and simulates the system deterministically to calculate the composition of the glass exiting the melter as a function of time. The operation of the program in this mode is depicted in Figure 2.2a. A typical plot of output from mode 1 is provided in Figure 2.2b, which shows the predicted mass fraction of $\mathrm{B}_{2} \mathrm{O}_{3}$ in the glass as a function of time. The fluctuations in the glass composition are primarily a result of fluctuations in the measured feed composition, which are input to the program. Figure 2.2b does not represent actual output from a MASBAL run; it is simply a schematic drawing showing how the output from mode 1 is expected to look.

In the second mode, the key inputs to MASBAL are the parameters of statistical distributions that define uncertainties in process measurements. The inputs used in the first mode are also required as inputs in the second mode, but they are now used as the "most likely" values of distributions rather than as deterministic values. A statistical distribution is randomly sampled each time there is a process measurement. The value returned from the distribution is treated as the "true" or actual value of the measurement. Because the returned value is usually different from the "most likely" value, this 


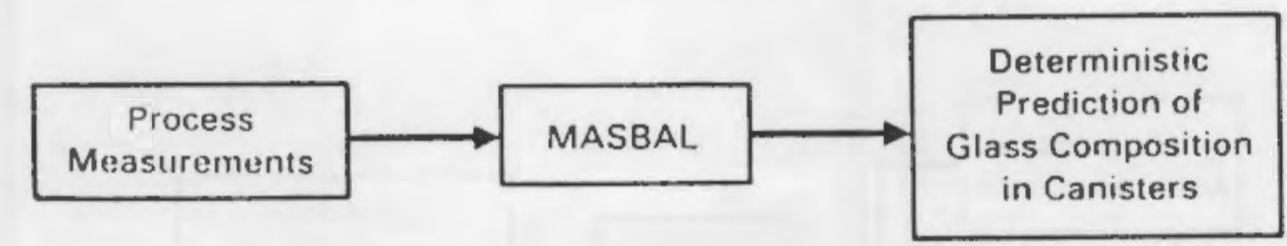

(a) Block Diagram Depicting Operation

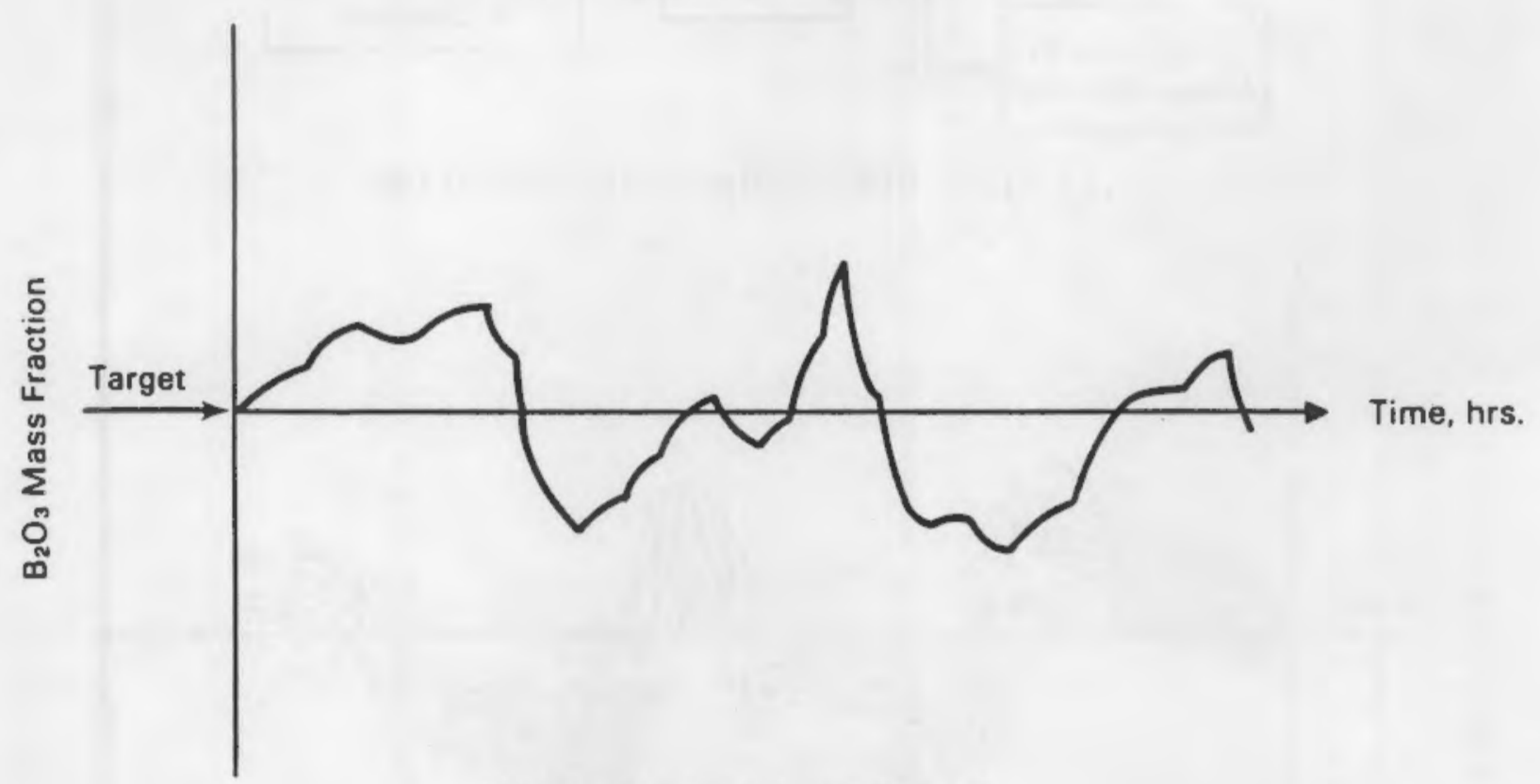

(b) Typical Plot of Output

FIGURE 2.2. Mode 1 of MASBAL (a) Block Diagram Depicting Operations; (b) Typical Plot of Dutput

procedure simulates errors in the process measurements. If a number of runs are performed using the same set of inputs (with a different random number stream for each run), a population of simulated glass compositions that are randomly distributed about the deterministic composition calculated in mode 1 will be obtained.

A block diagram depicting the operation of MASBAL in mode 2 and a typical plot showing output from mode 2 are provided in Figure 2.3. Each of the 1ight solid lines in Figure 2.36 represents the output from one run in mode 2 . The dark solid line represents the output from mode 1. It appears that the output from mode 2 forms an envelope about the mode 1 predictions. The width of this envelope provides a qualitative measure of the uncertainty associated with the composition predicted in mode 1. The absolute differences between the glass 


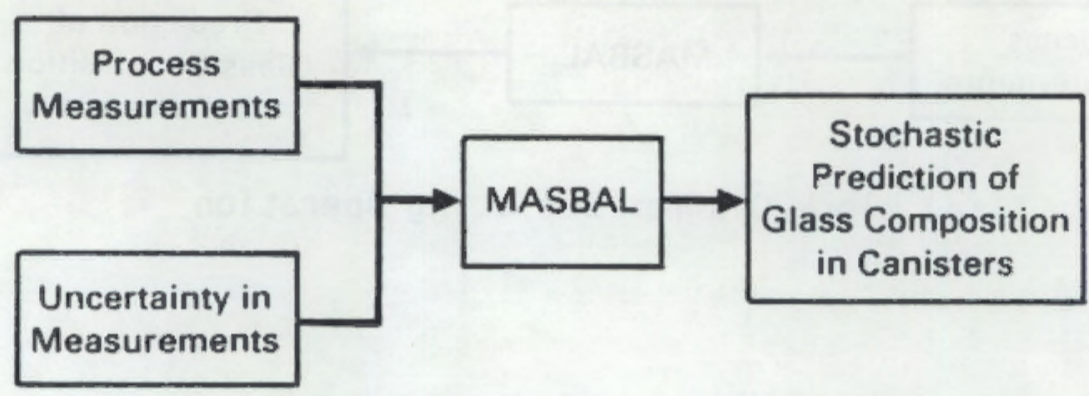

(a) Block Diagram Depicting Operation

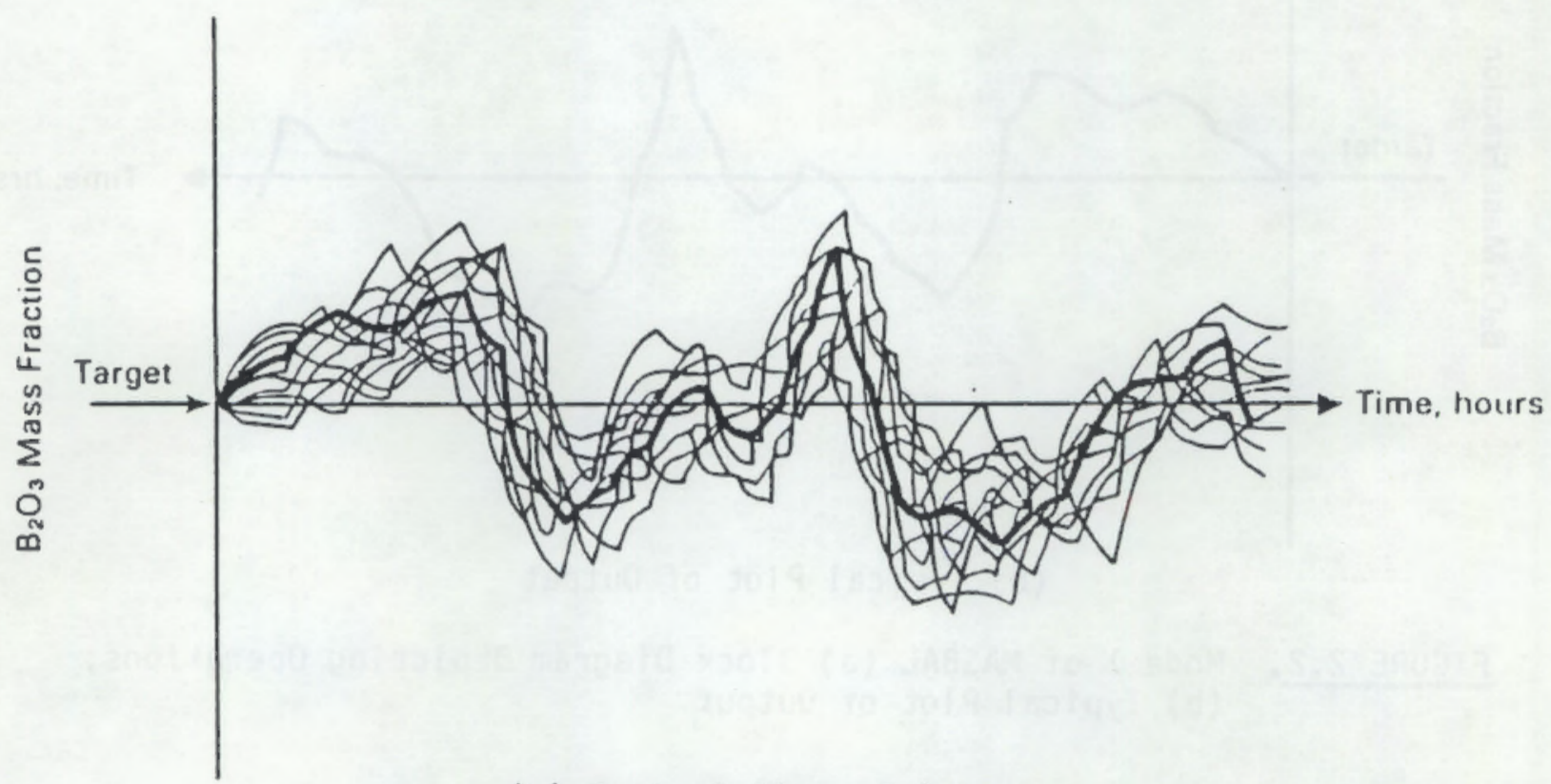

(b) Typical Plot of Output

FIGURE 2.3. Mode 2 of MASBAL (a) Block Diagram Depicting Operation;

(b) Typicl Plot of Output

compositions calculated in modes 2 and 1 can be used to construct confidence intervals about the mode 1 predictions, which provide a quantitative measure of the uncertainty in the deterministic predictions.

When MASBAL is run in the first or second mode, the simulation is driven by process data that are provided as input to the program. These data include information on what has happened in the system prior to the current time, but they contain no information about future events. Because it may be of interest to predict the composition of the glass that will be poured in the next several canisters (based on the current composition in the feed tank and melter), 
MASBAL continues to simulate the system by generating its own data for future process data. The user is given two options for continuing execution of the program: 1) all batches of feed following the last batch will be given the target composition, or 2) the next $N$ batches of feed will be given the same composition as the last batch, where $N$ is specified by the user. When MASBAL is run in mode 1 , the compositions of succeeding feed batches are deterministic. When the program is run in mode 2 , the compositions are stochastic, and the mean composition is either the target composition or the composition of the most recent batch, depending on the option selected. The melter feed rate and the rate of volatilization of constituents to the off-gas system are kept constant (equal to the design feed and volatilization rates). Also, glass is poured at the design frequency and duration throughout the remainder of the simulation. The user must specify how long (in simulated time) the simulation is to continue before terminating.

When MASBAL is run in the third mode, the program generates its own feed composition data by randomly selecting the composition of successive batches of feed from statistical distributions defined by the user (the concentration of each constituent in the feed will be taken from a distribution that has a mean or mode of the target concentration). All process measurements are simulated by randomly sampling a statistical distribution that has a mean or mode equal to the simulated value of the process variable being measured. The simulated fluctuations in the feed composition and the errors in process measurements cause the calculated glass composition to fluctuate randomly about the target composition. If the process measurements are treated deterministically (i.e., if the standard deviations describing the measurement errors are set to zero), then the absolute differences between the stochastically generated data and the target glass composition will provide a measure of the inherent variability in the composition of the glass as a function of the variability in the feed composition. If, on the other hand, the composition of successive batches of feed is treated deterministically, then the differences between the stochastically generated composition data and the target glass composition will provide the same information that is provided by the second mode of MASBAL. The advantage of running MASBAL in the third mode is that the user can run the program without having to supply process data; only the parameters of distributions that 
describe feed composition variability and uncertainties in process measurements are required. This feature gives MASBAL the capability to simulate thousands of hours of operation of the melter system, and thus makes it possible to generate enough simulated data to make reasonable estimates of the confidence limits associated with either the predicted or the target glass composition.

A block diagram depicting the operation of MASBAL in mode 3 and a typical plot of output from mode 3 are shown in Figure 2.4. Each of the lines in Figure 2.4b represents the output from one run in mode 3 . The straight,

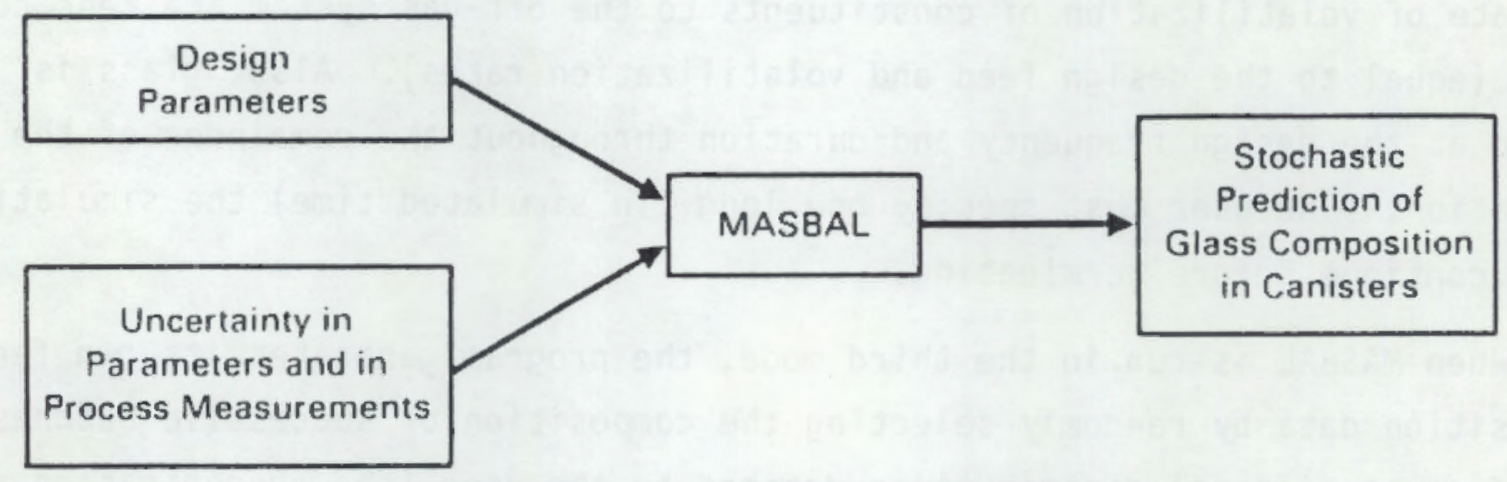

(a) Block Diagram Depicting Operation

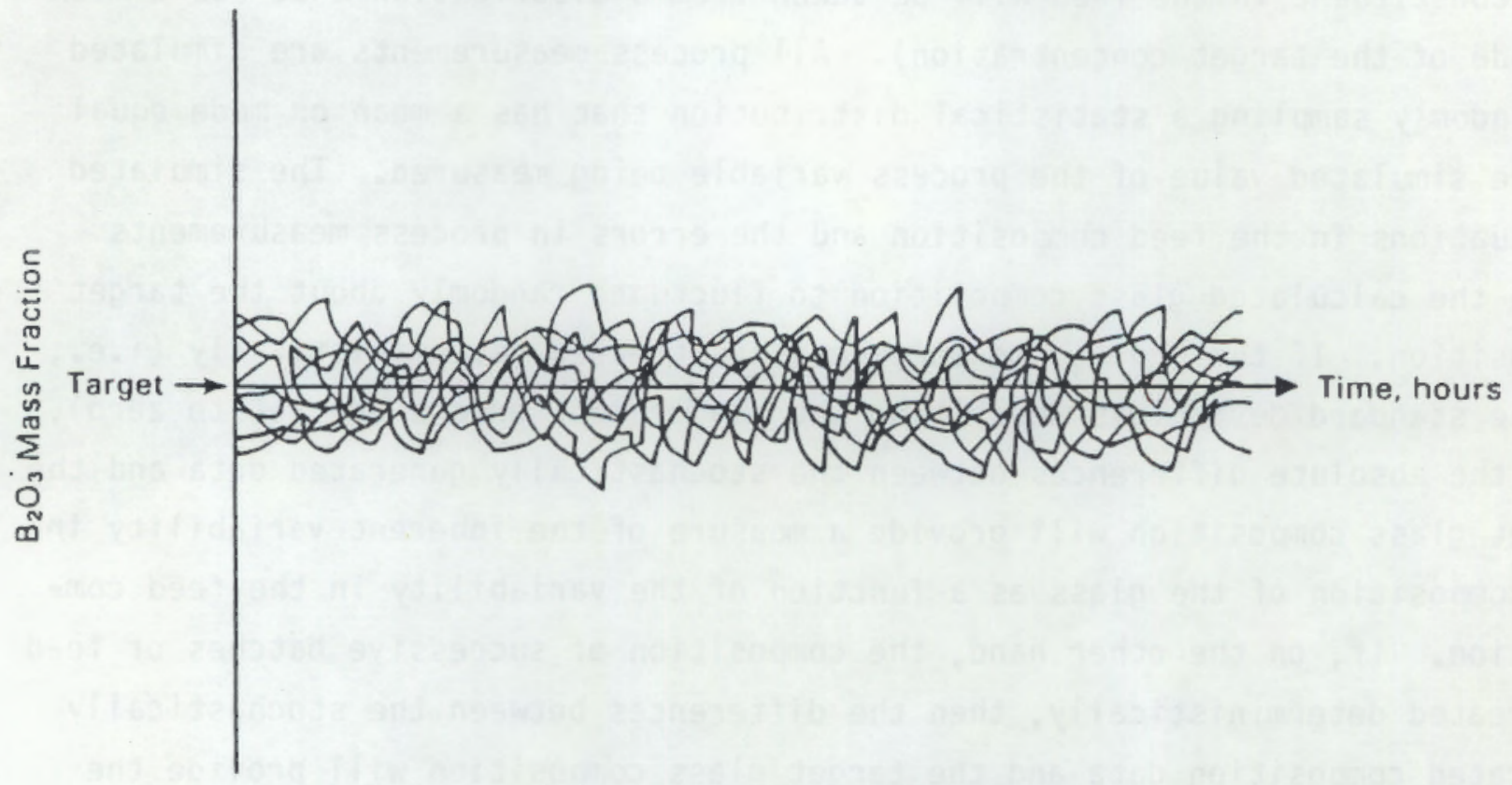

(b) Typical Plot of Output

FIGURE 2.4. Mode 3 of MASBAL (a) Block Diagram Depicting Operation; (b) Typical Plot of Output 
horizontal line represents the target composition. The output is very similar to the output from mode 2, except that the glass composition fluctuates about the target composition rather than the composition calculated by mode 1 .

\subsection{MASS BALANCE EQUATIONS}

The key equations in MASBAL are the differential and state equations that describe the change of mass with time of each constituent in the feed tank, melter, and canisters. The feed tank in MASBAL is modeled as an ideally-mixed tank. The user is given the option of modeling the melter in one of three ways:

1. as an ideally-mixed tank

2. as a combination of one plug flow and up to two ideally-mixed regions in series - The plug flow region is the first region in the series, followed by the smaller of the two ideally-mixed regions (if there are two). The user must specify the percentage of melter volume that is plug flow and the percentage that constitutes each of the ideallymixed regions. These percentages will apply when the melter is operated at steady state.

3. as two to five ideally-mixed regions in series - The user must specify the volume percentages of each of the regions at steady state.

Each glass pour into a canister is treated as a pour into an ideally-mixed tank that has no out let stream.

\subsubsection{Mass Balance Equations for Ideally-Mixed Regions}

The overall mass balance equation around an ideally-mixed region is given by

$$
d W / d t=Q_{f}-Q_{p}
$$

where $W=$ mass or volume of the ideally-mixed region, $\mathrm{kg}$ or $\mathrm{L}$

$t=t i m e, h r$

$Q_{f}=$ flow rate into region, $\mathrm{kg} / \mathrm{hr}$ or $\mathrm{L} / \mathrm{hr}$

$Q_{p}=$ flow rate into region, $\mathrm{kg} / \mathrm{hr}$ or $\mathrm{L} / \mathrm{hr}$ 
The equation describing the change in mass over time of an individual constituent in an ideally-mixed region is

$$
d\left(M_{\mathbf{i}}\right) / d t=Q_{f} \star X_{i f}-Q_{p} \star X_{i p}
$$

where $M_{j}=$ mass of constituent $i$ in the ideally-mixed region, $k g$

$x_{i f}=$ concentration of constituent $i$ in inlet stream, mass fraction or $\mathrm{kg} / \mathrm{L}$

$x_{i p}=$ concentration of constituent $i$ in outlet stream, mass fraction or $\mathrm{kg} / \mathrm{L}$.

By convention, concentrations in the aqueous feed slurry are generally expressed as $\mathrm{kg}$ oxide/L, while concentrations in the molten glass are generaliy expressed as mass fractions. Equations (2.1) and (2.2) also hold for individual glass pours into canisters, except that Qp for these "regions" is zero.

The instantaneous concentration or mass fraction of a constituent in an ideally-mixed region is given by

$$
x_{i p}=M_{i} / W
$$

Because ideal mixing implies that the concentration at every point in the reyion is the same, $x i p$ is also the concentration in any stream that exits the ideally-mixed region.

\subsubsection{Mass Balance Equations for Plug Flow Region in Melter}

By definition, all elements of mass in the plug flow region must exit in the same order that they entered (i.e., there is no mixing). The cumulative mass that enters the plug flow region and the cumulative mass that exits the region are both continuously monitored by MASBAL. The program periodically records the composition of mass elements that enter the region. The composition of a mass element exiting the region is then set equal to the composition of a mass element that entered the region at the time when the total cumulative 
mass having entered the region (minus the initial mass) was equal to the total cumulative mass that has now exited the region. This situation is expressed mathematically as

$$
x_{i O Z}=x_{i f(z-z i)}
$$

where $x_{i o z}=$ mass fraction of constituent $i$ in a mass element exiting the region after $Z \mathrm{~kg}$ of cumulative mass have exited the region $x_{\text {if }(Z-Z i)}=$ mass fraction of constituent $i$ in a mass element entering the region after ( $Z-Z i) \mathrm{kg}$ of cumulative mass have entered the region

$$
\mathrm{Zi}=\text { initial mass in plug flow region, } \mathrm{kg} \text {. }
$$

The composition of mass elements entering the plug flaw region are updated once each hour of simulated time or whenever the concentration of a constituent in the inlet stream changes by $1 \%$ (to adequately model the plug flow region when the composition is changing rapidly). The composition of a mass element that enters the region between two consecutive updating times is calculated by linear interpolation of the compositions recorded at the two times.

\subsubsection{Changes in Mass of Melter Regions as a Function of Feed Rate}

When the melter is not modeled as a single ideally-mixed region, the user must specify the percentage of the total mass that is allocated to each region (the inputs are actually entered as volume percentages). MASBAL assumes that these percentages are valid only when the feed rate is equal to the design feed rate. If the feed rate drops below the design feed rate, the mass of all regions except the last region will drop proportionately (i.e., a 10\% drop in feed rate will result in a 10\% drop in these volumes). The rate at which the mass changes is modeled as an exponential decay with a time constant proportional to the steady-state mass in the melter divided by the design feed rate (in $\mathrm{kg} \mathrm{oxides/hr).} \mathrm{The} \mathrm{last} \mathrm{two} \mathrm{sentences} \mathrm{are} \mathrm{expressed} \mathrm{mathematically} \mathrm{in}$ Equations (2.5) through (2.7).

$$
Q_{i}=Q_{d} * W_{i} / W_{d}
$$




$$
\begin{gathered}
W_{f}=W_{d} \star Q_{f} / Q_{d} \\
d W / d t=-\left(Q_{i}-Q_{f}\right) \star B W_{d} / W_{s} \star \exp \left(-t /\left(W_{s} / B Q_{d}\right)\right)
\end{gathered}
$$

where $Q_{j}=$ equivalent feed rate before change in feed rate, $\mathrm{kg}$ oxides $/ \mathrm{hr}$

$Q_{f}=$ new feed rate, $\mathrm{kg}$ oxides $/ \mathrm{hr}$

$Q_{d}=$ design feed rate, $\mathrm{kg}$ oxides $/ \mathrm{hr}$

$W_{i}=$ instantaneous mass of region before change in feed rate, $\mathrm{kg}$

$W_{f}=$ steady-state mass of region at new feed rate, $\mathrm{kg}$

$W_{d}=$ steady-state mass of region at design feed rate, $\mathrm{kg}$

$B=$ user-specified parameter for adjustment of time constant

$W_{S}=$ steady-state mass of all regions in melter at the design feed rate, $\mathrm{kg}$

$W=$ instantaneous mass of region, $\mathrm{kg}$

$t=$ time since change in feed rate occurred, hr.

The integrated form of Equation (2.7), which gives the actual mass of melter regions (other than the last region) as a function of time after a change in feed rate, is

$$
W=W_{i}-W_{d}\left(Q_{i}-Q_{f}\right) / Q_{d} *\left[1-\exp \left(-t\left(W_{s} / B Q_{d}\right)\right)\right]
$$

Equations (2.7) and (2.8) work well when the feed rate is within a factor of two or three of the design feed rate, but they tend to overpredict the increase in mass of the region(s) whenever the feed rate is more than an order of magnitude greater than the design feed rate. This situation can physically arise when glass formers are added directly to the melter from the cold chemical makeup tank, because the transfer of slurry can be very rapid. In this case, the equation used to calculate the change in mass of all regions (except the last region) in the melter is

$$
d w / d t=-\left(Q_{i}-Q_{f}\right) /(N-1) * \exp \left[-t /\left((N-1) w_{d} / Q_{d}\right)\right.
$$


where $N$ is the number of regions in the melter.

The integrated form of Equation (2.9) is

$$
W=W_{i}-W_{d}\left(Q_{i}-Q_{f}\right) / Q_{d} *\left[1-\exp \left[-t /\left((N-1) W_{d} / Q_{d}\right)\right]\right.
$$

Equations (2.9) and (2.10) are used to describe the change in mass of all melter regions (except the last region) whenever glass formers are being added directly to the melter.

The change in mass of the last region in the melter is determined from a mass balance around the last region:

$$
d W_{L} / d t=Q_{f}-\sum_{j=1}^{N-1} d W_{j} / d t-p
$$

$$
\text { where } \begin{aligned}
W_{L} & =\text { mass of last region in melter, } \mathrm{kg} \\
W_{j} & =\text { mass of jth region in melter, } \mathrm{kg} \\
N & =\text { total number of regions in melter } \\
P & =\text { pouring rate of glass into canister, } \mathrm{kg} / \mathrm{hr} .
\end{aligned}
$$

Equation (2.11) ensures that the mass balance around the entire meiter remains as

$$
\mathrm{dW}_{\mathrm{t}} / \mathrm{dt}=\mathrm{Q}_{\mathrm{f}}-\mathrm{P}
$$

where $W_{t}$ is the total mass of glass $(\mathrm{kg})$ in the melter

The approach outlined above ensures that when the feed rate, $Q_{f}$, is zero (i.e., the melter is idling), the melter will approach an ideally-mixed state rather than remain in a non-ideal state. This situation is believed to be realistic for idling melters. When the feed rate increases, the volume of all regions except the last region will increase proportionately and at an 
exponential rate. (a) If the time-averaged glass pouring rate is increased along with the feed rate (as it should be unless it is desired to raise the level of glass in the melter), the last region in the melter will decrease in mass at a rate equal to the sum of the rates of increase for the other regions.

\subsubsection{Off-Gas Calculations}

Losses to the off-gas system are modeled by splitting the melter inlet stream into two streams, one going directly to the off-gas system and the other going to the first region in the melter. Assuming that the of $f$ gas has been sampled and that information is available regarding the mass of each constituent that has been collected in the off-gas system (over a certain period of time), the following equations apply:

$$
\begin{gathered}
Q_{i 0}=M_{i 0} / t \\
Q_{i f}=Q_{e} \star x_{i e}-Q_{i 0} \\
Q_{0}=\sum_{i=1}^{N} Q_{i 0} \\
Q_{f}=\sum_{i=1}^{N} Q_{i f}
\end{gathered}
$$

(a) It should be recognized that as the feed rate is increased or decreased, the power to the melter is generally increased or decreased. Because an increase in power generally increases the amount of natural convection in the melter (and vice-versa), the volume of the plug flow and smaller wellmixed regions may not necessarily change in proportion to the feed rate. However, until data become available that suggest otherwise, the plug flow and smaller well-mixed regions will be modeled as stated above. 
where $Q_{i 0}=f$ low rate of constituent $i$ into off-gas system, $\mathrm{kg}$ oxide/hr

$M_{i o}=$ mass of constituent $i$ collected in off-gas system, $\mathrm{kg}$

$\mathrm{t}=\mathrm{time}$ duration over which mass $M_{i o}$ was collected, hr

$Q_{\text {if }}=$ flow rate of constituent $\mathrm{i}$ into lst melter region, $\mathrm{kg}$ oxide/hr

$Q_{e}=$ total flow rate entering melter, $\mathrm{kg}$ oxide/hr

$x_{i e}=$ mass fraction of constituent $i$ in stream entering melter

$Q_{0}=$ total flow rate into off-gas system, $\mathrm{kg}$ oxide/hr

$Q_{f}=$ total flow rate into lst melter region, $\mathrm{kg}$ oxide/hr

$\mathrm{N}=$ number of constituents.

If no data are available from the off-gas system, decontamination factors are used to calculate the amount of material going to the off-gas system. Under these circumstances, Equations (2.13) and (2.14) are replaced with

$$
\begin{gathered}
Q_{i o}=Q_{e} \star x_{i e} \star\left(1 / D F_{i}\right) \\
Q_{i f}=Q_{e} \star x_{i e} \star\left(D F_{i}-1\right) / D F_{i}
\end{gathered}
$$

where $D F_{i}$ is the melter decontamination factor of constituent $i$.

It should be recognized that Equations (2.17) and (2.18) do not properly account for losses to the off-gas system during periods of melter idling or low feed rates. For example, according to these equations, there are no losses when the feed rate is zero. Equations (2.13) and (2.14) will model losses at low or zero feed rates, but the losses will be constant over time rather than varying with feed rate; i.e., when the feed rate is zero, losses will be nonzero and will come from the first region in the melter. This part of MASBAL may require refinement at some future date when more is known about off-gas losses as a function of feed rate. However, the errors introduced by Equations (2.13) and (2.14) or (2.17) and (2.18) are small for most constituents because the amount of material going to the off-gas system is generally small relative to the amount going to the glass. 


\subsection{SIMULATION OF THE SYSTEM}

MASBAL treats the operation of the vitrification system as a classical simulation problem. The state of the system at any point in time is defined by the values of the state variables in the system. The state variables include all the masses, concentrations, and flow rates in the system. These variables must be initialized at the start of the simulation, and their values change during the simulation according to the differential and state equations in Section 2.4. The equations are solved simultaneously using a numerical differentiation algorithm.

The differential and state equations alone, however, do not completely describe the behavior of the system. During the operation of the vitrification plant, many events occur that cause instantaneous changes in the state of the system. In simulation jargon, these events are called "discrete events" because they occur at discrete points in time. Examples of discrete events are the starting or stopping of a slurry transfer from the makeup tank to the feed tank, the sampling of the feed tank, and the starting or stopping of a glass pour. Discrete events are triggered either by a condition on time or by a condition on one or more of the state variables. An example of the former is the starting of a batch glass pour every 2 hours. An example of the latter is stopping the flow of feed to the melter when the glass level in the melter exceeds some maximum level. The discrete events that occur when the West Valley CTS is operated are listed in Table 2.1. When these events occur, they alter either the state of the system or the rate of change of the state of the system.

To properly simulate the vitrification system, a model must be capable of simulating both the continuous and the discrete changes in the state of the system. MASBAL makes use of the SIMAN simulation language, a FORTRAN-based software package, to provide these capabilities.

\section{5 .1 Use of SIMAN}

The SIMAN simulation language offers 1) a variable-step, fourth-fifth order Runge-Kutta-Fehlberg numerical differentiation algorithm for solving the mass balance differential equations describing the vitrification system; 2) the 
IABLE 2.1. Discrete Events in the West Valley Component Test System

1. Start the flow of slurry from the makeup tank to the feed tank (i.e., the initiation of a batch transfer of feed slurry)

2. Stop the flow of slurry from the makeup tank to the feed tank

3. Change the slurry feed rate to the melter (includes starting or stopping the feed)

4. Start the flow of slurry from the cold chemical makeup tank to the feed $\tan x$

5. Stop the flow of slurry from the cold chemical makeup tank to the feed tank

6. Start the flow of slurry from the cold chemical makeup tank to the melter

7. Stop the fiow of slurry from the cold chemical makeup tank to the melter

8. Start a glass pour

9. Stop a glass pour

capability to model discrete events that interact with or change the values of state variables in the system; and 3) the capability to introduce stochasm into the simulation. The first capability is essential to the operation of MASBAL because the continuous behavior of the vitrification system is described by a large number of coupled differential equations (see Section 2.4). The second capability is desirable because it simplifies the modeling of discrete behavior in the system (see Table 2.1). The third capability, is essential when MASBAL is run in the second or third modes described in Section 2.3.

SIMAN enables the development of a simulation model that has all these capabilities with a minimum of programming effort. The programmer has only to develop subroutines that describe system-specific behavior. These subroutines are then linked with the main SIMAN subprogram library to create an executable image that draws on the SIMAN software to perform essentially all of the complicated operations associated with simulating the system. The SIMAN software is available from Systems Modeling Corp., State College, Pennsylvania. 


\subsubsection{MASBAL Implementation}

MASBAL consists of FORTRAN subroutines that are integrated with the SIMAN simulation language. During a run, MASBAL reads several input files that contain data that drive the simulation. Once a run is initiated, there are no interfaces between the program and the user other than the error messages that appear if erroneous input is detected (i.e., the program does not have interactive features).

The overall logic in MASBAL is depicted in Figure 2.5. When MASBAL is executed, the simulation clock is initially set to zero and a call is made to the PRIME subroutine. This subroutine calls several subroutines that open input files and read data from these files. These data include 1) parameters specifying various options for running the program, 2) design parameters for the melter system, 3) initial values of state variables in the system, 4) the times at which the initial discrete events occur in the system, and 5) the parameters of statistical distributions that describe uncertainties in process measurements. The names of the subroutines that PRIME calls and brief descriptions of their functions are provided in Table 2.2.

After PRIME has completed execution, control is passed to the differential equation solving algorithm of SIMAN. This algorithm makes frequent calls to the STATE subroutine, which contains the FORTRAN-coded differential and state equations that describe the flow of mass through the vitrification system. SIMAN advances the simulation clock and updates the values of the state variables (as dictated by the equations in STATE) with each time step.

During each time step, SIMAN checks conditions on time and on the state of the system to see if a discrete event is to occur. SIMAN keeps track of the discrete events that are conditional on time by maintaining a special file called the event calendar. This file contains an ordered list of all events that are scheduled to occur in the future and the exact time at which they are to occur. The user specifies all the information needed to schedule these events by setting up the MASBAL input files described in Chapter 3.0. SIMAN also keeps track of events that are conditional on the state of the system. These events occur only when the values of certain state variables cross threshold values that are specified by the user in the MASBAL input files. For 


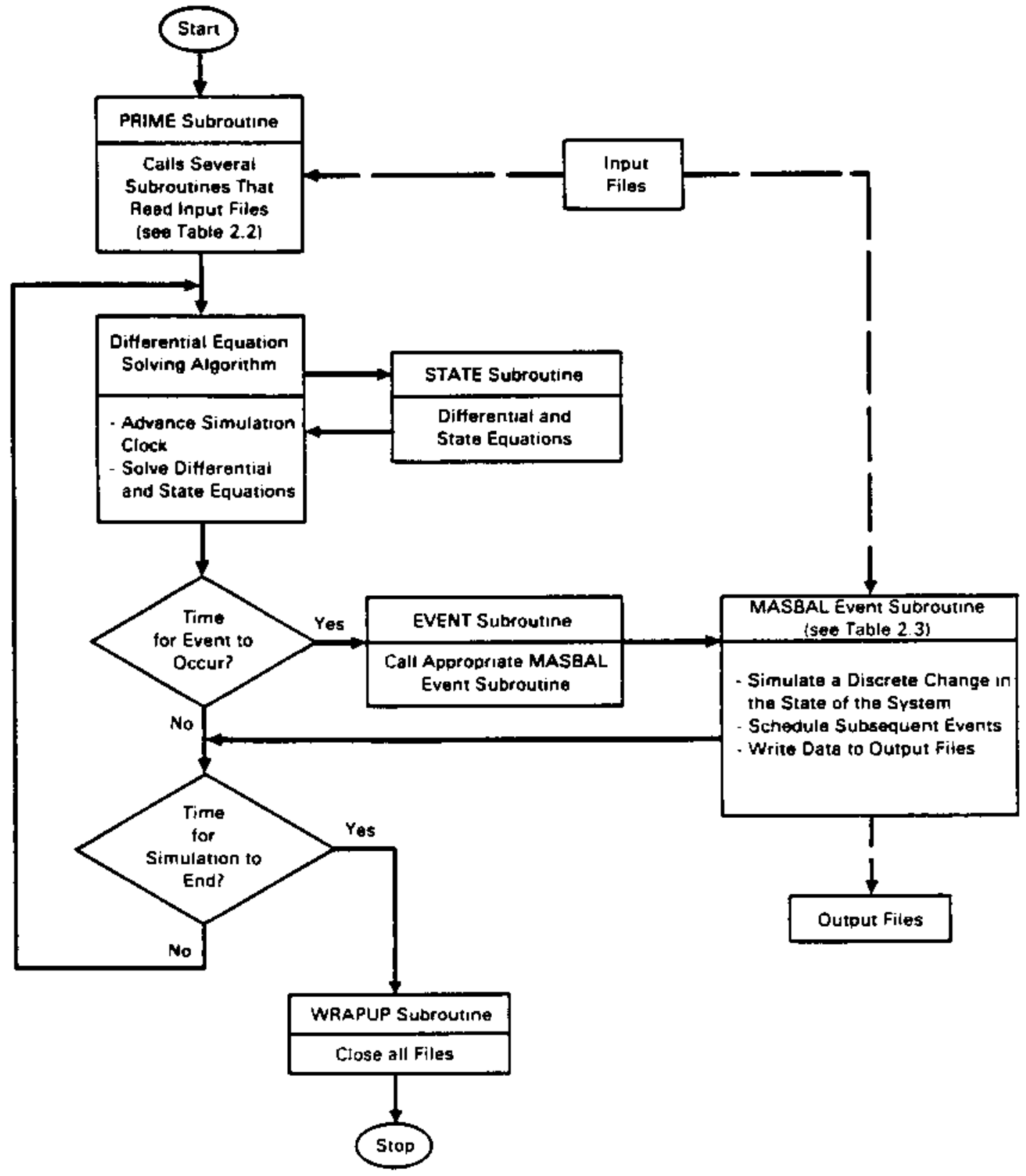

FIGURE 2.5. Flow Diagram of Logic in MASBAL

example, a discrete event that corresponds to shutting off the flow of feed to the melter will occur when the mass of glass in the melter exceeds some maximum value specified by the user (this event will not occur if the feed is scheduled to be shut of at a later time).

If a discrete event is to occur during a time step, the size of the step is adjusted so that it ends when the event is to begin. After the time step is taken, a call is made to the EVENT subroutine. This subroutine passes control to the appropriate MASBAL subroutine that contains logic describing the event 
TABLE 2.2. Subroutines Called by PRIME

Name

MODERD

DSNRD

INITRD

FEEDRD

POURRD

BATRD

OFFRD

FSHRD

MSHRD

STOCRD

Description

Reads in all the data from the input file MODE.DAT

Reads in all the data from the input file DESIGN.DAT

Reads in all the data from the input file INIT.DAT, and initializes all the state variables in the system

Reads in the first set of data from the input file FEED.DAT, and schedules the first change in the feed rate to the melter (called only in modes 1 and 2 )

Reads in the first set of data from the input file POUR.DAT, and schedules the first glass pour (called only in modes 1 and 2)

Reads in the first set of data from the input file BATCH.DAT, and schedules the first transfer of slurry from the makeup tank to the feed tank (called only in modes 1 and 2)

Reads in the first set of data from the input file OFFGAS.DAT, and schedules the first change in the volatilization rate to the offgas system (called only in modes 1 and 2)

Reads in the first set of data from the input file FSHIM.DAT, and schedules the first transfer of slurry from the cold chemical makeup tank to the feed tank (called only in modes 1 and 2)

Reads in the first set of data from the input file MSHIM.DAT, and schedules the first transfer of slurry from the cold chemical makeup tank to the melter (called only in modes 1 and 2)

Reads in all the data from the input file STOCH.DAT (called only in modes 2 and 3 )

(e.g., a change in the feed rate to the melter, the initiation of a glass pour). In a strict sense, it is not necessary that an event change the state of the system. For example, an event may do nothing more than write the value of a state variable to an output file. The names of the MASBAL event subroutines and brief descriptions of their functions are provided in Table 2.3.

As Table 2.3 indicates, subsequent events are often scheduled from within event subroutines. The times at which the events are scheduled to occur are either read directly from the MASBAL input files, or determined indirectly from 
TABLE 2.3. MASBAL Event Subroutines

Name

FUTBAT

FUBSTP

STOPFD

STRTFD

STDPPR
Description

Starts the transfer of slurry from the makeup tank to the feed tank on the condition that the level in the feed tank is below some value specified by the user. When MASBAL is run in modes 1 or 2, this subroutine is called only after all the data in the input file BATCH.DAT has been exhausted. When MASBAL is run in mode 3 , FUTBAT is called for all transfers of slurry from the makeup tank to the feed tank. FUTBAT simulates batch-to-batch variability in the feed composition if MASBAL is run in modes 2 or 3 .

Stops the transfer of slurry from the makeup tank to the feed tank on the condition that the level in the feed tank is above some value specified by the user. When MASBAL is run in modes 1 or 2, this subroutine is called only after all the data in the input file BATCH.DAT has been exhausted. When MASBAL is run in mode 3 , FUBSTP is called for all transfers of slurry from the makeup tank to the feed tank.

Stops the flow of feed to the melter on the condition that the level of glass in the melter is above some value specified by the user. When MASBAL is run in modes 1 or 2 , this subroutine is called only after all the data in the input file FEED.DAT has been exhausted. When MASBAL is run in mode 3 , STOPFD is called whenever the melter level condition is met.

Starts the flow of feed to the melter (after a stoppage) on the condition that the level of glass in the melter is below some value specified by the user. When MASBAL is run in modes 1 or 2, this subroutine is called only after all the data in the input file FEED.DAT has been exhausted. When MASBAL is run in mode 3 , STRTFD is called whenever the melter level condition is met.

Stops a glass pour on the condition that the level of glass in the melter is below some value specified by the user. Writes the mass and composition of the pour to the appropriate output files. When MASBAL is run in modes 1 or 2 , this subroutine is called only after all the data in the input file POUR.DAT has been exhausted. When MASBAL is run in mode 3 , STOPPR is called whenever the melter level condition is met. 
TABLE 2.3. (contd)

Name

STRTPR

FUTPOR

FUPSTP

BSTART

BSTOP

CHFEED

PSTART

PSTOP
Description

Starts a glass pour (after a stoppage) on the condition that the level of glass in the melter is above some value specified by the user. When MASBAL is run in modes 1 or 2 , this subroutine is called only after all the data in the input file POUR.DAT has been exhausted. When MASBAL is run in mode 3 , STRTPR is called whenever the melter level condition is met.

Starts a glass pour that is scheduled to occur after all the data in the input file POUR.DAT has been exhausted. Schedules the subsequent stoppage of the pour.

Stops a glass pour that is scheduled to occur after all the data in the input file POUR. DAT has been exhausted. Writes the mass and composition of the pour to the appropriate output files. Schedules the next pour.

Starts a scheduled transfer of slurry from the makeup tank to the feed tank. Schedules the subsequent stoppage of the transfer. Reads either the measured composition in the feed tank (after the transfer) from the input file BATCH.DAT, or the apparent composition in the makeup tank (before the transfer) from the input file MAKEUP.DAT. Simulates sampling and analytical error if MASBAL is run in modes 2 or 3.

Stops a scheduled transfer of slurry from the makeup tank to the feed tank. Reads an additional line from the input file BATCH.DAT, and schedules a subsequent transfer.

Changes the flow rate of feed to the melter based on information in the input file FEED.DAT. Reads an additional line from FEED.DAT, and schedules the next change in the feed rate.

Starts a scheduled glass pour. Schedules the subsequent stoppage of the pour.

Stops a scheduled glass pour. Writes the mass and composition of the pour to the appropriate output files. Reads another line from the input file POUR.DAT, and schedules the next pour. 
TABLE 2.3. (contd)

Name

FSHIM

FSTOP

MSHIM

MSTOP

OFFGAS

RECORD
Description

Starts a scheduled transfer of slurry from the cold chemical makeup tank to the feed tank. Schedules the subsequent stoppage of the transfer. Reads the apparent composition in the cold chemical makeup tank from the input file FSHIM.DAT. Simulates sampling and analytical error or slurry preparation error if MASBAL is run in modes 2 or 3.

Stops a scheduled transfer of slurry from the cold chemical makeup tank to the feed tank. Reads an additional line of the input file FSHIM.DAT, and schedules the next transfer.

Starts a scheduled transfer of slurry from the cold chemical makeup tank to the melter. Schedules the subsequent stoppage of the transfer. Reads the apparent composition in the cold chemical makeup tank from the input file MSHIM.DAT. Simulates sampling and analytical error or slurry preparation error if MASBAL is run in modes 2 or 3 .

Stops a scheduled transfer of slurry from the cold chemical makeup tank to the melter. Reads an additional line of the input file MSHIM.DAT, and schedules the next transfer.

Changes the rate of volatilization (of each constituent) to the offgas system based on information in the input file OFFGAS.DAT. Simulates off-gas sampling and analytical errors if MASBAL is run in modes 2 or 3 . Reads an additional line of OFFGAS.OAT, and schedules the next change in the volatilization rate.

Writes the composition (mass fraction of each constituent) in the last region of the melter to the appropriate output files. This subroutine is called at regular intervals specified by the user. 
the design parameters specified by the user. The scheduling of discrete events is a function that is performed internally within MASBAL by making calls to appropriate SIMAN subroutines. The interested reader is referred to Pegden (1985) for a complete discussion of how discrete events are scheduled using SIMAN subroutines.

After a MASBAL event subroutine has completed execution, control is passed back to the differential equation-solving algorithm of SIMAN. The simulation resumes with calls to the STATE or EVENT subroutines as necessary. Each time the simulation clock is advanced, SIMAN checks to see if the new time is greater than or equal to the time specified for ending the simulation. If it is greater, the time step is adjusted so that it ends at the specified time. When the ending time is reached, the simulation is stopped and a call is made to the WRAPUP subroutine, which closes all input and output files. After the files are closed, a FORTRAN STOP is executed.

A listing of the MASBAL source code (excluding the proprietary SIMAN software) is provided on microfiche in a pocket on the inside of the front cover of this report. For those who are interested, a a hardcopy listing can be obtained directly from the author.

\section{5 .3 State Variables}

MASBAL contains over 1900 state variables that define the state of the simulated system at any point in time. The state variables correspond to the values of

- total volumes or masses in tanks or melter regions

- masses of individual constituents in tanks or melter regions

- concentrations or mass fractions of constituents in tanks, melter regions, and streams

- flow rates.

All of the state variables are contained in the array $S(I)$, which has 2000 locations. Figure 2.6 and Table 2.4 show the correspondence between the state variables and the physical variables in the vitrification system. It should be noted that not all of the state variables are used in every run of 


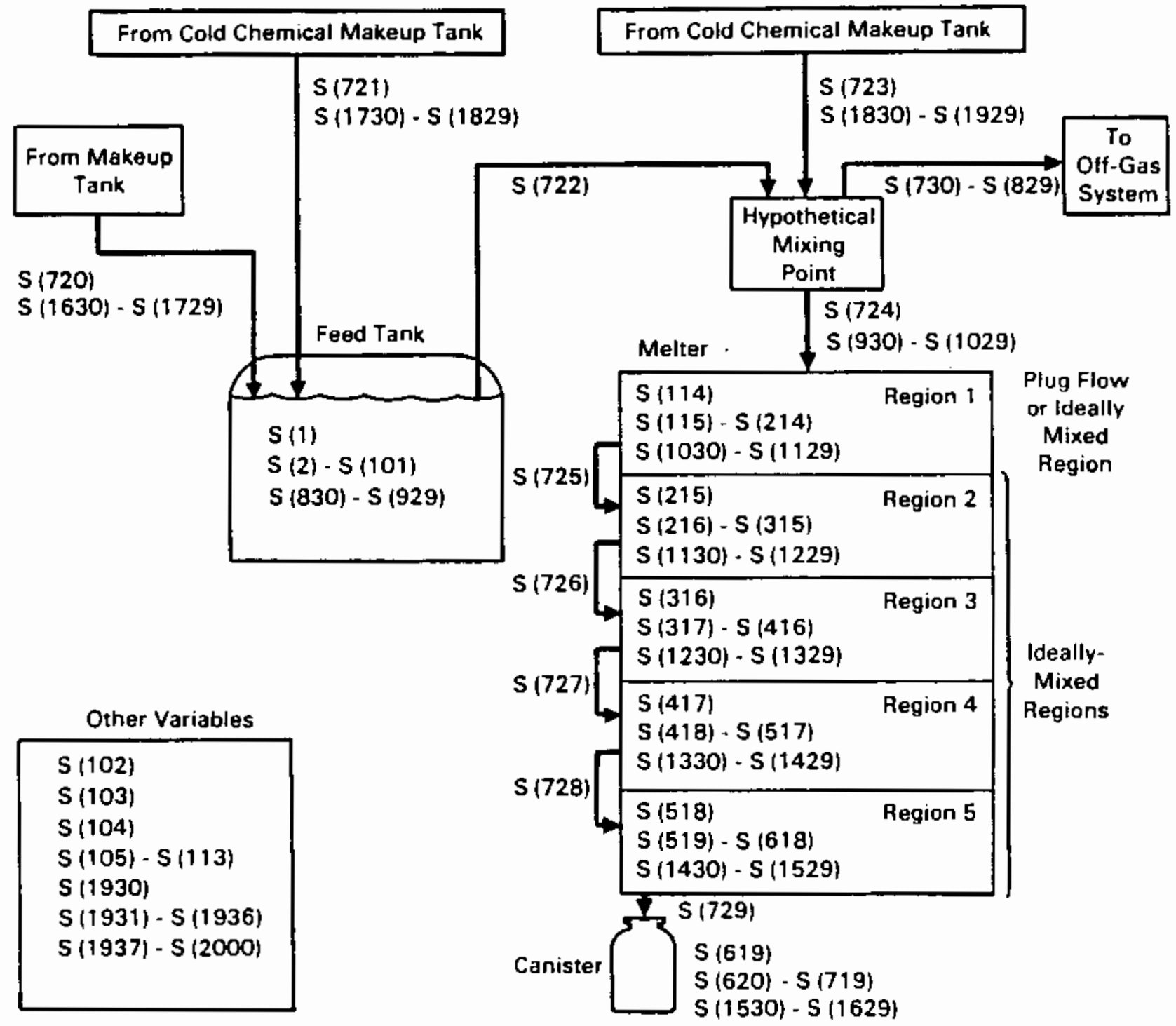

FIGURE 2.6. Correspondence Between State Variables and Physical Variables in MASBAL (NOTE: See Table 2.4 for Key)

MASBAL. If less than 100 constituents are specified, for example, many of the array locations corresponding to the masses and concentrations of constituents in the feed tank and the various regions in the melter will not be used. Also, if the melter is modeled as having less than five regions, only the variables for the specified number of regions will be used in the mass balance calculations. Any regions that are not used are bypassed in the mass balance calculations. 
TABLE 2.4. Key to Figure 2.6

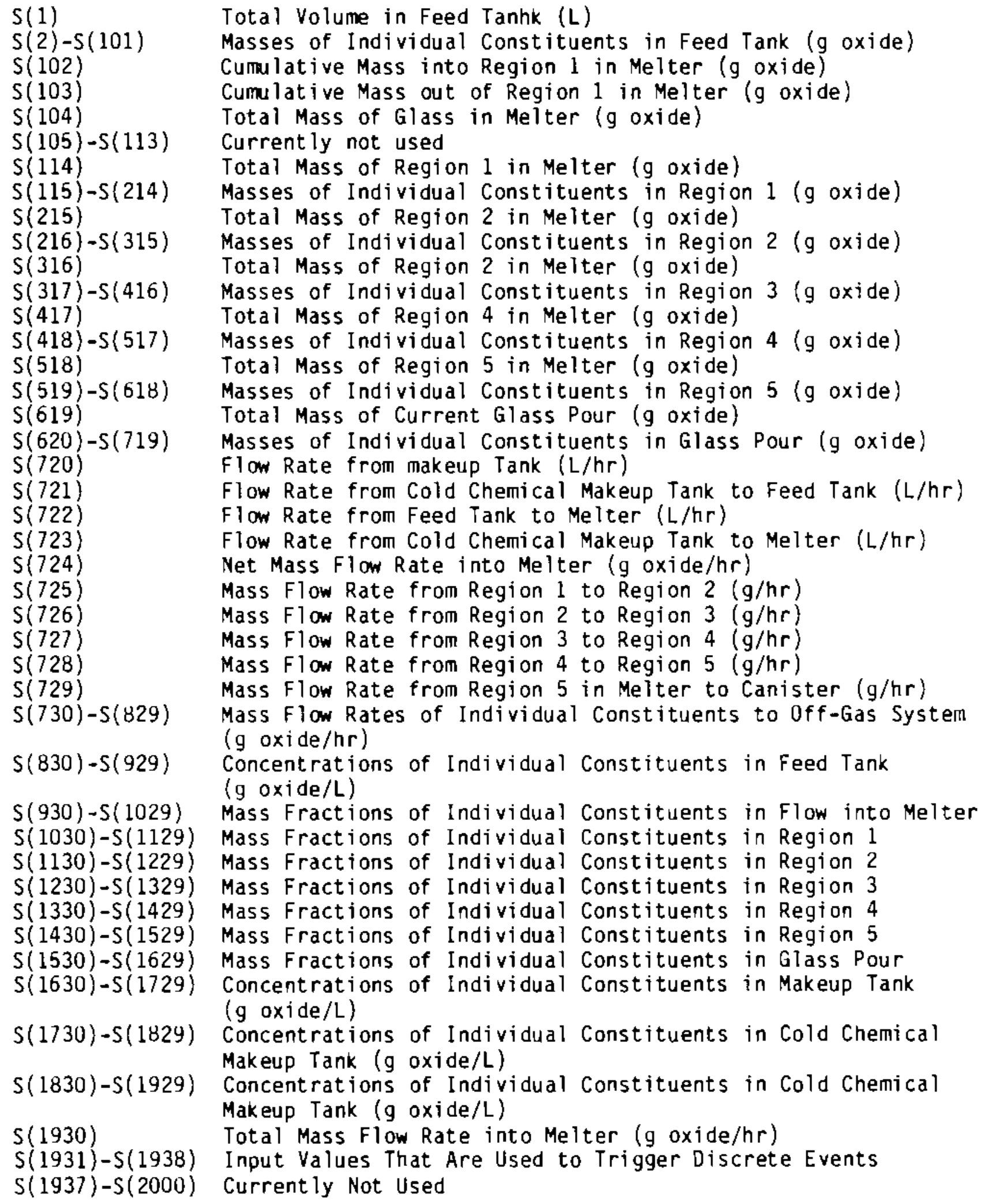


The values of the state variables can change during the simulation in two ways: 1) as prescribed by the differential and state equations in the STATE subroutine, and 2) as dictated by statements in MASBAL event subroutines. The first type of change is a continuous change, such as the gradual increase in mass fraction of a constituent in the melter after an increase in the concentration of the constituent in the feed. The second type of change is a discrete change, such as the stopping of a glass pour.

\subsubsection{Stochasm in MASBAL}

When MASBAL is run in either the second or the third mode (see Section 2.3), it simulates random errors in process measurements and inherent fluctuations in the feed composition (mode 3 only). MASBAL does this by randomly sampling statistical distributions that represent these errors or fluctuations. The most likely values of these distributions are either the actual values of process measurements (when simulating measurement errors) or the target or design concentrations of constituents in the feed (when simulating inherent fluctuations in the feed composition). The parameters that define the shapes of the distributions (e.g., standard deviations, minima, maxima) are specified by the user.

Random sampling of the statistical distributions is accomplished by calls to appropriate SIMAN subroutines. Whenever a distribution is to be sampled, the parameters that define the distribution (e.g., the mean and standard deviation for a normal distribution) are passed to SIMAN as arguments in a subroutine call list. Control is then passed to a SIMAN algorithm that generates random numbers. After a random number is generated, a special SIMAN function translates the number to a representative value from the specified statistical distribution. This value is then returned to MASBAL as either the value of a process measurement or the concentration of a constituent in the feed.

\subsection{MASBAL FILES}

The complete MASBAL software package consists of the following files:

- 35 fortran source (text) files 
- 11 text files containing MASBAL common blocks

- 35 fORTRAN object files (compiled source files)

- 2 special text files: the SIMAN experiment file (MASBAL.EXP) and the SIMAN model file (MASBAL.MOD)

- 2 special object files (MASBAL.E and MASBAL.M) created by "processing" the experiment file and the model file with SIMAN processing programs

- 1 special program file created by the SIMAN linker program (MASBAL.P)

- 2 executable images of MASBAL created by linking the 35 FORTRAN object files with 4 SIMAN object files - One image is the production version of MASBAL, and the other is the debug version

- 11 input files

- several output files (the number varies depending on which version and which mode of MASBAL is run)

- 6 VAX/VMS cormand files that facilitate the compiling, linking, and execution of MASBAL.

The special SIMAN files and the two versions of MASBAL are discussed in greater detail in this section. The input files are the topic of Chapter 3.0, and the output files are discussed in Chapter 4.0.

\subsubsection{Special SIMAN Files}

In addition to all the FORTRAN files that comprise MASBAL and SIMAN, two special text files are included as part of the MASBAL software package. These files are the SIMAN model file and the SIMAN experiment file. The model file (MASBAL.MOD) is an empty file that exists only because it is required for execution of SIMAN. The experiment file (MASBAL.EXP) contains some important parameters that specify 1) dimensions of internal SIMAN arrays; 2) the minimum and maximum time step sizes and the maximum absolute and relative truncation errors for each time step taken by the Runge-Kutta-fehlberg differential equation solving algorithm; and 3 ) conditions that trigger discrete events that are conditional on the state of the system. A listing of the MASBAL experiment 
file is included at the end of Appendix $A$. The reader is referred to Pegden (1985) for a complete explanation of each of the elements in this file. The casual MASBAL user need not be concerned with this file, as all the parameters have been adjusted for proper MASBAL execution.

Before MASBAL can be run, Doth the model file and the experiment file must be "processed" by SIMAN. The model file is processed by running a program called the SIMAN model processor, and the experiment file is processed by running the SIMAN experiment processor. These processors interpret the information in the respective text files and create object files called MASBAL.M and MASBAL.E. The two object files are then linked to create a file called MASBAL.P. This is accomplished by running a program called the SIMAN linker. MASBAL .? must reside in the same work area as the MASBAL executable image or MASBAL will not run. The casual user need not be concerned with processing and linking the model and experiment files, as the MASBAL.P file has already been created and is provided in the MASBAL software package.

\subsubsection{Versions of MASBAL}

Two versions of MASBAL are available to the user: a production version and a debug version. The only difference between the two versions is that the debug version generates more output files. The additional files are useful for determining the exact sequence of events that occurred during the simulation and for debugging the program. The production version runs somewhat faster than the debug version, because it does not access the disk as frequent Jy. The debug version should be used when setting up new problems, as it is much easier to find errors in the input files when this version is run. The production version should be used when relatively minor changes are made to the inputs from one run to the next, or when a simulation is repeated several times to obtain a distribution of results (i.e., modes 2 or 3 ). The output generated by the two versions is discussed in Chapter 4.0 .

The FORTRAN coding for the two versions of MASBAL is identical except for the value of the variable NDEBUG in the PRIME subroutine. NDEBUG is used as a flag that tells MASBAL which set of output files to generate. In the production version, NDEBUG is set equal to zero, while in the debug version it is set 
equal to 1. NDEBUG can be changed only by editing the source file PRIME.FOR;

it cannot be changed from outside the program (i.e., via an input file). Both versions of MASBAL are included in the MASBAL software package. 


\subsection{INPUT FILES}

The MASBAL input files represent the only interface between MASBAL and the user. Before each run of MASBAL, the input files must be modified to reflect the changes that the user wants to make since the previous run. The modifications should be made using a text editor such as the EDT editor (on DEC VAX computers running the VMS operating system). The program is then executed, and all input data are processed in the proper order.

MASBAL has a total of 11 input files. These files and the modes of operation in which they are used are listed in Table 3.1 .

TABLE 3.1. MASBAL Input Files and Modes of Operation in Which They Are Used

\begin{tabular}{lll}
\multicolumn{1}{c}{ File } & & Mode $(s)$ \\
\hline MODE.DAT & & $1,2,3$ \\
DESIGN.DAT & & $1,2,3$ \\
INIT.DAT & & $1,2,3$ \\
FEED.DAT & & 1,2 \\
POUR.DAT & 1,2 \\
BATCH.DAT & 1,2 \\
MAKEUP.DAT & 1,2 \\
OFFGAS.DAT & 1,2 \\
FSHIM.DAT & 1,2 \\
MSHIM.DAT & 1,2 \\
STOCH.DAT & 2,3
\end{tabular}

In the deterministic mode (mode 1), all files except STOCH.DAT are used. In mode 2, all files are used. In mode 3, only MOOE.DAT, DESIGN.DAT, INIT.DAT, and STOCH.DAT are used.

All of the input files are set up so that the user can quickly see where each input value is to be entered. The files are partially self-documenting, as they contain blocks of text. that describe the inputs. All input values are 
read from formatted fields. The formatting is indicated by asterisks and decimal points directly above the field from which the value is read. The following example serves to illustrate this.

Suppose a file contains these two lines:

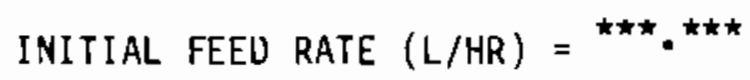

In this case, the user will know 1) the value is to be entered in units of liters/hr, 2) the format field is $F 7.3$ (for a real number with three places before and three places after the decimal point), and 3) the field starts in the second space after the equal sign. The user might enter the input value as follows:

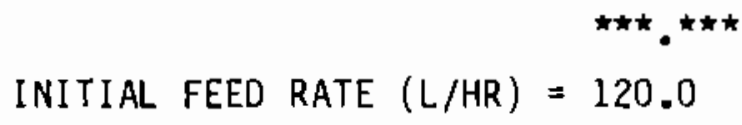

It is very important that the inputs in each file be properly formatted, or MASBAL will not run correctly.

Each input file and its contents are discussed in detail in this chapter. Examples of each file are provided in Appendix A (these are copies of printouts of input files that have been used in MASBAL runs).

\subsection{MODE.DAT}

This file contains input data that control the logic in the simulation. The inputs are:

- MODE - The user must choose 1, 2, or 3. The three modes are discussed in detail in Section 2.3. If the user chooses any number other than 1,2, or 3, the code will give an error message.

- LENGTH OF SIMULATION - The amount of real time that MASBAL simulates in a given run. The value must be specified in hours.

- NUMBER OF REPEAT SIMULATIONS - The number of repeat runs that MASBAL performs when the code is run in modes 2 or 3 . The runs will be 
identical except that each one will use a different random number stream for sampling statistical distributions. Each run, therefore, will give a slightly different set of results. The distribution of results over many runs can be used to establish confidence limits about the results obtained when the code is run in mode 1 . When MODE $=1$, the number of repeat simulations defaults to 1 .

- time interval fOR RECORDINg COMPOSITION IN MELTER - This input is used to specify the time interval (in hours) for writing the predicted composition in the melter to the output files COMPl.OUT through COMPX.OUT (see Chapter 4.0). The default value is 5 hours.

- COMPOSITION OF fUtURE BATChES OF FEED - The user must choose 1 or 2 ( 1 for target, 2 for same composition as last batch of feed). This input is used in modes 1 or 2 when the process data provided in the files BATCH.DAT and MAKEUP.DAT runs out before the simulation completes. For example, if the user provides data for only two batches of feed, but the simulation requires four batches in order to run the specified length of time, MASBAL will automatically set the composition of the last two batches of feed equal to either the target composition or the same composition as the last batch of feed. When the code is run in mode 3 , this input defaults to 1 (target).

- nUmBer of batches - This input is used only if 2 is chosen as the input for the COMPOSITION OF FUTURE BATCHES OF FEED; it is ignored otherwise. The value specifies the number of consecutive batches of feed that should have the same composition as the last batch. After this number of batches has been processed, all further batches will have the target composition.

- number of SAMPLes Of feEd PER BatCh - This input is used only if MODE $=2$ or 3, and only for "future" batches if $M O D E=2$. The value must be an integer between 1 and 5 . This value represents the number of replicate samples that are to be taken of the feed prior to transfer from the makeup tank to the feed tank. 
- Number of analyses per SAMPLE OF FEed - This input is used only if MODE $=2$ or 3, and only for "future" batches if MODE $=2$. The value must be an integer between 1 and 3. This value represents the number of replicate analyses that are performed on each sample of feed taken from the makeup tank prior to transfer to the feed tank.

- OPTION - This is the option for modeling the mixing behavior in the melter. The user must choose 1,2 , or 3 . If 1 is chosen, the melter will be modeled as a single ideally-mixed tank. If 2 is chosen, the melter will be modeled as a plug flow region followed by one or two ideally-mixed regions in series. If 3 is chosen, the melter will be modeled as two to five ideally-mixed regions in series. If the user chooses any number other than 1,2, or 3, the code will give an error message.

- NUMBER - This input reflects the number of ideally-mixed regions that are to be modeled in the melter. If OPTION $=1$, the input is ignored because this option pertains to only one ideally-mixed tank. If OPTION $=2$, the user must specify 1 or 2 . If OPTION $=3$, the user must specify 2 to 5 . Any numbers other than those mentioned here will give error messages.

- VOlUME PERCENTAGes OF REgions in MELTER - This input is the steadystate volume percentages of each region in the melter ( $i . e .$, when the melter is operating at the design feed rate and the design feed oxide loading). The entries must be consistent with the option and the number of ideally-mixed regions specified in the preceding two inputs. For example, if OPTION $=2$ and NUMBER $=2$ (one plug flow and two ideally-mixed regions), then a non-zero value should be specified under each of the first three locations. If OPTION $=2$, the first region is always considered to be the plug flow region. Ideally-mixed regions should always be ordered from smallest to largest volume percentage. The volume percentages must add up to 100.0 exactly or an error message will result. When OPTION $=1$, the input is ignored. 


\subsection{DESIGN.DAT}

This file contains all the design parameters for the vitrification system. The parameters can be modified to accommodate any change in the design of the system. The inputs are:

- CONSTITUENTS, tARget COMPOSITION, and DECONTAMINATION FACTOR - These inputs are entered in tabular form under the appropriate column headings near the top of the file ("Constituent", "Mass Frac.", and "Decon. Factor"). Each constituent must be specified as an alphanumeric character string not more than 8 characters in length. The alphanumeric string should always start under the first asterisk that specifies the "Constituent" format field. All constituents that are to be included in the model must appear in the constituent list in this file. The target glass composition (mass fraction) and the melter decontamination factor for each constituent should be entered to the right of the constituent name. The list of constituent names should always end with the string END. As MASBAL reads the input file, it looks for the string END to tell it when to stop reading constituent names. If END is not there, the run will terminate with error status.

- TARget OXIDE LOADING OF FEED - the target oxide loading of the feed siurry in grams per liter

- TARGet DENSITY OF FEED SLURRY - the target density of the feed slurry in grams per cubic centimeter

- taRget DENSITY Of GLASS - The target density of the glass in grams per cubic centimeter

- VOLUME CORRECTION fOR STEAM Jet - This input specifies a volume correction factor for the amount of water that is added to the feed during transfer from the makeup tank to the feed tank by steam jet. The units are liters of feed per liter of makeup tank slurry. The volume correction factor should always be greater than one.

- transfer rate from makeup tank to feed tank - the transfer rate in liters per hour 
- RATE OF ADOITION OF "SHIMS" - the rate of addition of glass formers to either the feed tank or the melter in liters per hour

- fEed RATE TO MELTER - the design feed rate to the melter in liters per hour

- GLASS POURING RATE - the design pouring rate of glass from the melter in kilograms per hour

- DURATION OF EACH GLASS POUR - the duration of each glass pour in hours

- TIME BETWEEN POURS - the duration between glass pours in hours

- VOLUME IN FEED TANK AFTER FILLING - the volume of slurry, liters, in the feed tank after each transfer from the makeup tank; this volume does not necessarily have to be the capacity of the feed tank.

- VOLUME OF HEEL IN FEED TANK - the volume of slurry, liters, in the feed tank prior to each transfer from the makeup tank (in liters)

- DESIGN WORKING VOLUME OF MELTER - the volume of glass, liters, that the melter is designed to hold

- MAXIMUM VOLUME OF GLASS ALLOWED IN MELTER - the maximum volume of glass, liters, that the melter will safely accommodate

- MiNIMUM VOLUME OF GLASS ALLOWED IN MELTER - the minimum volume of glass, liters, that the melter will safely accommodate.

- parameter fOR aDJUSTMENT OF TIME CONSTANT - the value of the parameter $B$ in Equations (2.7) and (2.8) of this report. This parameter is used to adjust the time that it takes for the mass of regions in the melter to respond to changes in the feed rate. A value from 1 to 5 is recommended.

\subsection{INIT.DAT}

This file is used to specify initial values for the simulation. The initial values are assumed to be based on process measurements that are taken prior to the start of a run. The inputs are: 
- INITIAL COMPOSITION IN FEED TANK - The inputs are entered in tabular form under the first set of column headings in the file. Alphanumeric constituent names are entered in the "Constituent" column. These constituent names must be identical to the names used in the constituent list in DESIGN.DAT. If a constituent name does not match up with any constituent in DESIGN.DAT, an error message will result (a typographical error could cause this to happen). If a constituent is omitted from the 1ist, MASBAL will assume that the initial composition of that constituent in the feed tank is zero. A constituent name may appear more than once in the "Constituent" column. Replicate constituent names indicate that replicate samples were taken of the feed. To the right of each constituent name, the user must enter the results of one to three analyses (for that constituent) in units of grams oxide/liter. The user should enter the number of analyses in the column labeled "No. Anal." (this must be an integer from 1 to 3). An example best illustrates this. Suppose the following lines are entered in the table:

\begin{tabular}{|c|c|c|c|c|}
\hline $\begin{array}{l}\text { CONST ITUENT } \\
\star \star \star \star \star \star \star \star\end{array}$ & $\begin{array}{l}\text { ANAL. } \\
\star\end{array}$ & $\begin{array}{l}\text { ANALYSIS } 1 \\
\star \star \star \star \star \star \star\end{array}$ & $\begin{array}{l}\text { ANALYSIS } 2 \\
\star \star \star \star \star \star \star\end{array}$ & $\begin{array}{l}\text { ANALYSIS } 3 \\
\star \star \star \star \star \star \star\end{array}$ \\
\hline SI02 & 3 & 157.5 & 162.5 & 162.5 \\
\hline $\mathrm{SIO2}$ & 2 & 152.5 & 154.5 & 151.5 \\
\hline
\end{tabular}

MASBAL will interpret these lines as follows: Two samples were taken from the feed tank. The first sample was analyzed three times for SI02, with the results of the analyses being $157.5,162.5$, and 162.5 goxide/liter, respectively. The second sample was analyzed twice for SI02, with the results of the analyses being 152.5 and 154.5 (the 151.5 is ignored in this case). The value taken as the initial composition in the feed tank will be the average of the five analyses. As with the constituent list in DESIGN.DAT, the constituent list here must end with the string END or else the run will terminate with errors. 
- INITIAL COMPOSITION IN MELTER - The inputs are entered in the same manner as for INITIAL COMPOSITION IN THE FEED TANK except that the values are in units of mass fraction.

- INITIAL VOLUME IN FEED TANK - the initial volume of slurry, liters, in the feed tank

- INITIAL VOLUME OF GLASS IN MELTER - the initial volume of glass, liters, in the melter

- initial feEd rate to MELTER - the initial feed rate to the melter, in liters per hour

- initial VOLUME PERCENTAges Of REgions in MELTER - The volume percentages of each region in the melter at the start of the simulation. The entries must be consistent with the OPTION and the NUMBER of ideally-mixed regions specified in MODE.DAT. The order of the regions must be the same as in MODE.DAT. The last ideally-mixed region is the only region that must be specified as having an initial volume greater than zero. If the melter is idling prior to the start of a run, it is probably in a relatively ideally-mixed state. This situation can be simulated by specifying that all regions in the melter except the last region have an initial volume percentage of zero. All initial volume percentages must add up to 100.0 exactly or an error message will result. When OPTION $=1$, the input is ignored.

\subsection{FEED.DAT}

This file contains input data specifying the times of changes in the feed rate and the new feed rate when these changes occur. The inputs must be ordered sequentially. Times (in hours) are entered in the "Time" column and rates (in liters per hour) are entered in the "Rate" column. The last line in the file should always be the last line of data; if the file ends with a blank line, the code will give unpredictable results. If there are no data, then the last line should be the line containing the asterisks that specify the format fields. In this case, the feed rate for the entire simalation will be equal to the initial feed rate specified in INIT.DAT. 


\subsection{POUR.DAT}

This file contains input data specifying the starting times, stopping times, and masses of each glass pour. The inputs must be ordered sequentially. Starting times (in hours) are entered in the "Start Time" column, stopping times (in hours) are entered in the "Stop Time" column, and masses (in kilograms) are entered in the "Mass of Pour" column. As in the case of FEED.DAT, the last line of data should always be the last line in the file; if this file ends with a blank line, the code will give unpredictable results. If there are no data, then the last line should be the line containing the asterisks that specify the format fields. If no data are specified, MASBAL will simulate glass pours that start and stop at regular intervals as specified by the values for the DURATION OF EACH GLASS POUR and TIME BETWEEN POURS in DESIGN.DAT. The pouring rate will default to the value specified for GLASS POURING RATE in DESIGN.DAT.

\subsection{BATCH.DAT}

This file contains input data specifying the starting and stopping times of batches to the feed tank and the volume in the feed tank at the beginning and end of each batch. It also contains data specifying the composition in the feed tank after each batch. With the exception of the first six lines in the file (which serve as a header), the entire file should appear as a series of repeated "blocks" of text that are identical except for the numerical values within each block. Each block should start with the line that contains the column headers "Start Time," "Stop Time," "Start Vol," "Stop Vol" and end with the line that has the string END in the "Constituent" column. The blocks should contain data for successive batches of feed (a new block should be added for each batch that is transferred from the makeup tank to the feed tank). The starting and stopping times should be specified in hours and the starting and stopping volumes in the feed tank should be specified in liters. The constituent names and the results of analyses of the samples should be entered exactly as they are in INIT.DAT (see INITIAL COMPOSITION IN FEED TANK in Chapter 3.3). Composition data should be provided for each batch of feed. The data may not be available for the last batch, however, because of the lag time in getting 
results back from the analytical laboratory (there may be as much as a 24 hour turnaround time for results from the analytical lab). If this is the case, the last line of the file should be the line containing the starting and stopping times of the last batch of feed (or any line between this line and the line that contains the asterisks used to specify format fields for the analytical results). If composition data are available for the last batch, the last line in the file should be the line that has the string END in the "Constituent" column.

\subsection{MAKEUP.DAT}

This file is used only if composition data for the last batch of feed to the feed tank are not yet available from the analytical laboratory. MAKEUP.DAT should contain data specifying the composition of the slurry in the makeup tank prior to the last transfer to the feed tank. MASBAL will use the composition in the makeup tank as the composition of the most recent batch (adjusted to account for water added by the steam jet during transfer to the feed tank) until the results from the analytical laboratory are available. The constituent names and the results of analyses of the samples should be entered exactly as they are in INIT.DAT (see INITIAL COMPOSITION IN FEED TANK in Chapter 3.3). This file should be updated every time another batch is transferred from the makeup tank to the feed tank. The last line in this file should always be the line that has the string END in the "Constituent" column.

\subsection{OFFGAS.DAT}

This file contains input data specifying the times at which samples are taken from the off-gas system and the analytical results from these samples. With the exception of the first five lines in the file (which serve as a header), the entire file should appear as a series of repeated "blocks" of text that are identical except for the numerical values within each block. Each block should start with the line that contains the asterisks specifying the format field for the time at which the sample(s) were taken and end with the line that has the string END in the "Constituent" column. The blocks should contain data for successive sets of samples from the off-gas system (a new 
block should be added for each sample or set of samples taken). The sampling times should be specified in hours. The constituent names and the results of analyses of the samples should be entered exactly as they are in INIT.DAT (see INITIAL COMPOSITION IN FEED TANK in Chapter 3.3), except that the values should be in units of grams instead of gram oxide/liter. The last line in this file should always be the line that has the string END in the "Constituent" column.

\subsection{FSHIM.DAT}

This file contains input data specifying the times at which glass formers are added to the feed tank and the volume and composition of each of these additions. With the exception of the first two lines in the file (which serve as a header), this file should consist of a series of "blocks" of text that are identical except for the numerical values within each block. Each block should contain data for a different addition of glass formers (sequentially ordered). All blocks should start with the line that contains the column headers "Time (hrs)" and "Volume (L)" and end with the line that has the string END in the constituent column. Times should be specified in hours and volumes in liters. For each addition, the user must specify a METHOD OF OETERMINATION of the slurry composition. This number should be specified as either 0 or 1 (the default is 1). The user should specify 1 if the composition of the added slurry is determined by taking samples of the slurry and analyzing these samples, and the user should specify 0 if the composition is known only to the extent that the user knows how the slurry was prepared (i.e., from knowing the amount of each glass former that was added to the slurry). Composition data should be specified in exactly the same way as it is in INIT.DAT (see INITIAL COMPOSITION IN FEED TANK in Chapter 3.3). If METHOO OF DETERMINATION $=1$, replicate constituent names may be used to indicate replicate samples, and the results of up to three analyses per sample can be specified in the "Analysis 1," "Analysis 2," and "Analysis 3" columns. If METHOD OF DETERMinATION = 0 , however, the user should not enter replicates in the constituent list. Also, when METHOD OF OETERMINATION $=0$, only the number in the "Analysis 1 " column will be read by MASBAL. The last line in this file should be the line containing the string END in the constituent column. If there are no data, the last line should be the line containing the asterisks that specify the format fields 
for "Time" and "Volume." If zero is specified as both the time and volume of the first addition, all other inputs will be ignored and MASBAL will assume that there are no glass former additions to the feed tank.

\subsection{MSHIM.DAT}

This file contains data specifying the times at which glass formers are added to the melter and the volume and composition of each of these additions. The file is structured exactly like FSHIM.DAT, so the reader is referred to Section 3.9 for a discussion of the inputs.

\subsection{STOCH.DAT}

This file contains data specifying the statistical distributions that are used to simulate errors in process measurements and inherent fluctuations in process variables. It also contains data specifying the parameters that define these distributions. The distributions and their parameters should be selected on the basis of information obtained from experiments aimed at characterizing the uncertainties in the process. STOCH.DAT is used only when MASBAL is run in modes 2 or 3 .

\subsubsection{Statistical Distributions}

MASBAL offers the user a choice of 10 statistical distributions for simulating errors in process measurements and inherent fluctuations in the feed composition. These distributions are described in detail in this section. (a) The numbers assigned to the distributions correspond to the numbers that the user must specify in STOCH.DAT when selecting a distribution. The first four distributions always have symmetrical probability density functions. The last six distributions can have either symmetrical or nonsymetrical distribution functions depending on the parameters that the user specifies. The distributions are:

(a) Additional information about the statistical distribution can be obtained from standard statistics texts such as Choi (1978) and Tsokos (1972). 
1. constant (point distribution) - This "distribution" is simply the deterministic value of a variable. It gives the user the option of treating some variables deterministically while treating others stochastically.

2. normal (Gaussian) - The probability density function for this distribution is

$$
f(x)=(1 / \sqrt{2 \pi \sigma}) * \exp \left\{-0.5 *[(x-\mu) / \sigma]^{2}\right\}
$$

$$
\text { where } \begin{aligned}
-\infty & <x<\infty \\
\mu & =\text { mean } \\
\sigma & =\text { standard deviation }
\end{aligned}
$$

The mean of the distribution is the value of the variable that is passed from MASBAL (i.e., the deterministic value).

3. uniform (symmetrical) - This distribution has a rectangular shaped probability density function, as shown in Figure 3.1. The distance between the maximum value of the distribution and the value of the variable that is passed from MASBAL is the same as the distance between the minimum value of the distribution and the value of the variable that is passed from MASBAL.

4. triangular (symmetrical) - This distribution has a triangular shaped probability density function, as shown in Figure 3.2. The distance between the maximum value of the distribution and the value of the variable that is passed from MASBAL is the same as the distance between the minimum value of the distribution and the value of the variable that is passed from MASBAL. The minimum and maximum values both have a probability of zero (thus defining the base of the triangle) and the value of the variable that is passed from MASBAL has the highest probability (thus forming the apex of the triangle).

5. lognormal - The probability density function for this distribution is 


$$
f(x)=(1 / x \sqrt{2 \pi \sigma}) * \exp \left\{-0.5 *[(\ln (x)-\mu) / \sigma]^{2}\right\}
$$

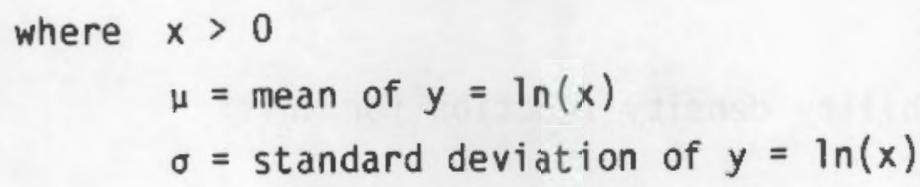

$f(x)$

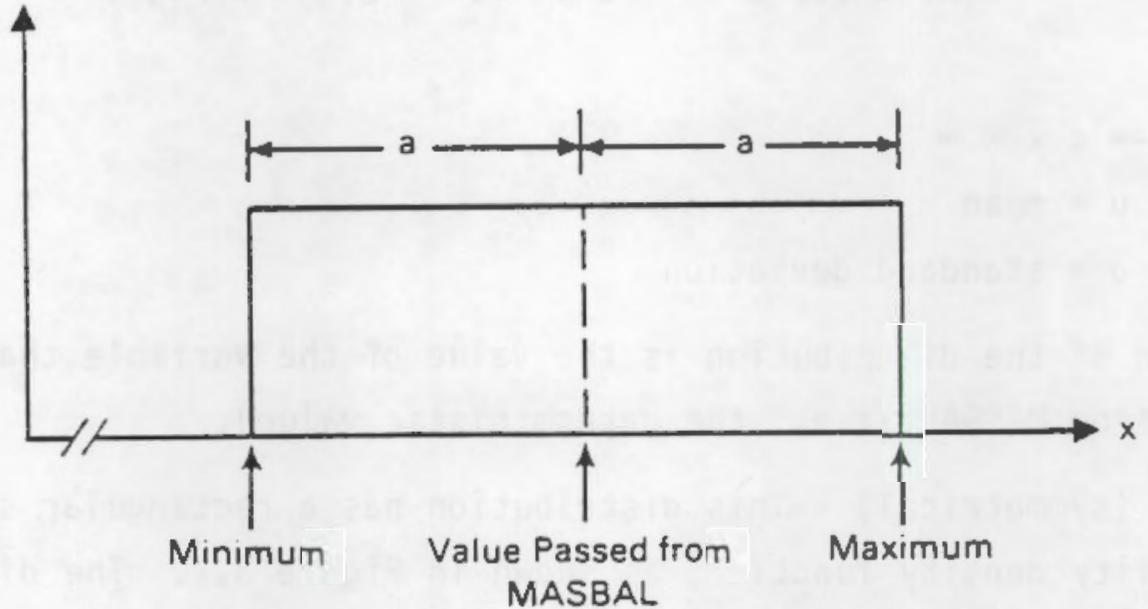

\section{FIGURE 3.1. Probability Density Function for} Symmetrical Uniform Distribution

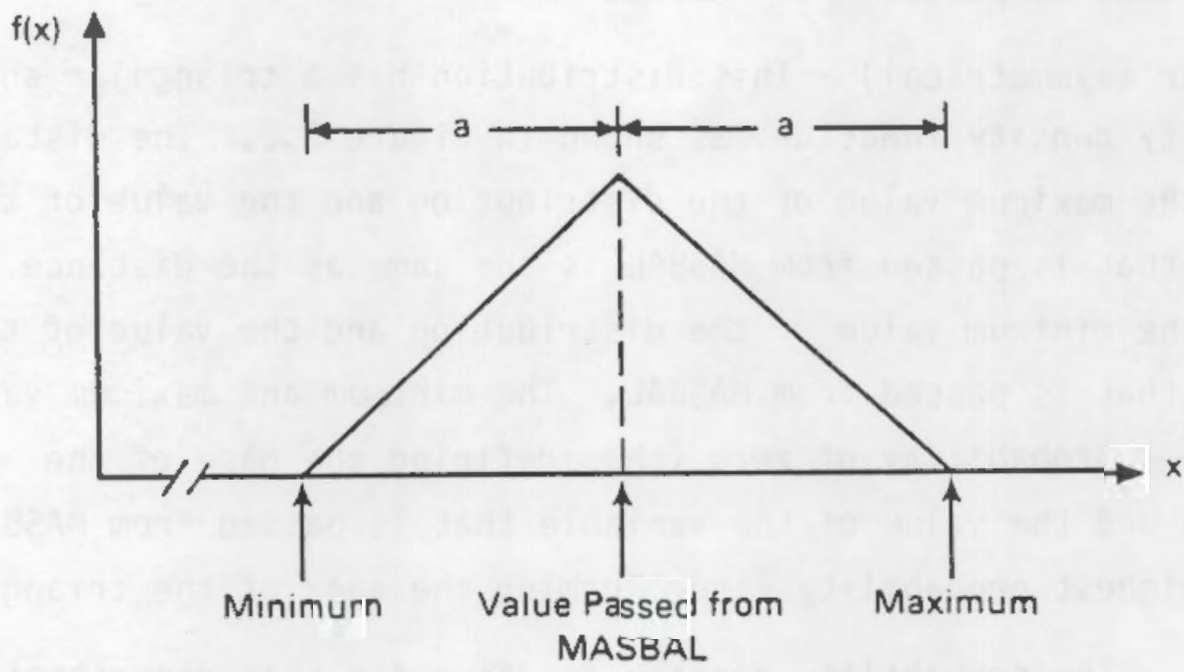

FIGURE 3.2. Probability Density Function for Symmetrical Triangular Distribution 
The mode (most likely value) of the distribution is the value of the variable that is passed from MASBAL. Since the lognormal distribution normally has zero as its lower bound, the user must specify an "offset" (as a percentage of the mode). This offset is subtracted from the mode, and the $x$-axis is transformed so that the of fset point is treated as zero. The scale on the transformed axis is adjusted so that the distance between the offset point and the mode is equivalent to $\exp \left(\mu-\sigma^{2}\right)$, which is the distance between zero and the mode when Equation (3.2) is used as the probability density function.

6. gamma - The probability density function for this distribution is

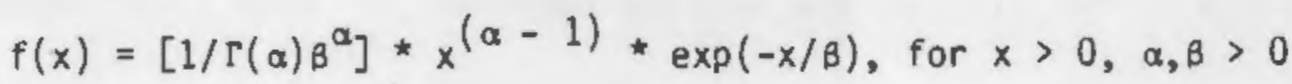

$$
\begin{aligned}
& f(x)=0 \text {, elsewhere }
\end{aligned}
$$

where $\alpha, \beta$ are parameters defining the shape of the distribution $\Gamma(\alpha)=$ gamma function of $\alpha$.

The mode (most likely value) of the distribution is the value of the variable that is passed from MASBAL. Because this distribution normally has zero as its lower bound, the user must specify an "offset" (as a percentage of the mode). This offset is subtracted from the mode, and the $x$-axis is transformed so that the offset point is treated as zero. The scale on the transformed axis is adjusted so that the distance between the offset point and the mode is equivalent to $(\alpha-1) B$, which is the distance between zero and the mode when Equation (3.3) is used as the probability density function.

7. beta - The probability density function for this distribution is

$$
\begin{aligned}
f(x)= & {[\Gamma(\alpha+\beta) / \Gamma(\alpha) \Gamma(\beta)] * x^{(\alpha-1) *(1-x)^{(\beta-1)},} } \\
& \text { for } 0<x<1 \\
f(x)= & 0, \text { elsewhere }
\end{aligned}
$$


where $\alpha, \beta$ are parameters defining the shape of the distribution.

The mode (most likely value) of the distribution is the value of the variable that is passed from MASBAL. Because this distribution normally has zero as its lower bound, the user must specify an "offset" (as a percentage of the mode). This offset is subtracted from the mode, and the $x$-axis is transformed so that the offset point is treated as zero. The scale on the transformed axis is adjusted so that the distance between the offset point and the mode is equivalent to $(\alpha-1) /(\alpha+\beta-2)$, which is the distance between zero and the mode when Equation (3.5) is used as the probability density function.

8. exponential - The probability density function for this distribution is

$$
\begin{array}{ll}
f(x)=(1 / \beta) * \exp (-x / \beta), & \text { for } x>0, \\
f(x)=0, & \text { els ewhere. }
\end{array}
$$

where $\beta$ is a parameter defining the shape of the distribution.

This distribution is actually a special case of the gamma distribution when $\alpha=1$. The mode of the distribution is the value of the variable that is passed from MASBAL. According to Equation (3.7), zero is the most likely value in the distribution, so the the $x$-axis is transformed such that the value of the variable passed from MASBAL is treated as zero. The user must specify an "offset" that defines an $x$-axis transformation such that the distance between the offset point and the value of the variable passed from MASBAL is equivalent to the distance between 0 and 1 on the non-transformed axis.

9. nonsymetrical uniform - This distribution has a rectangular probability density function, as shown in Figure 3.3. Unlike the symmetrical uniform distribution, the distance between the maximum value of the distribution and the value of the variable that is 


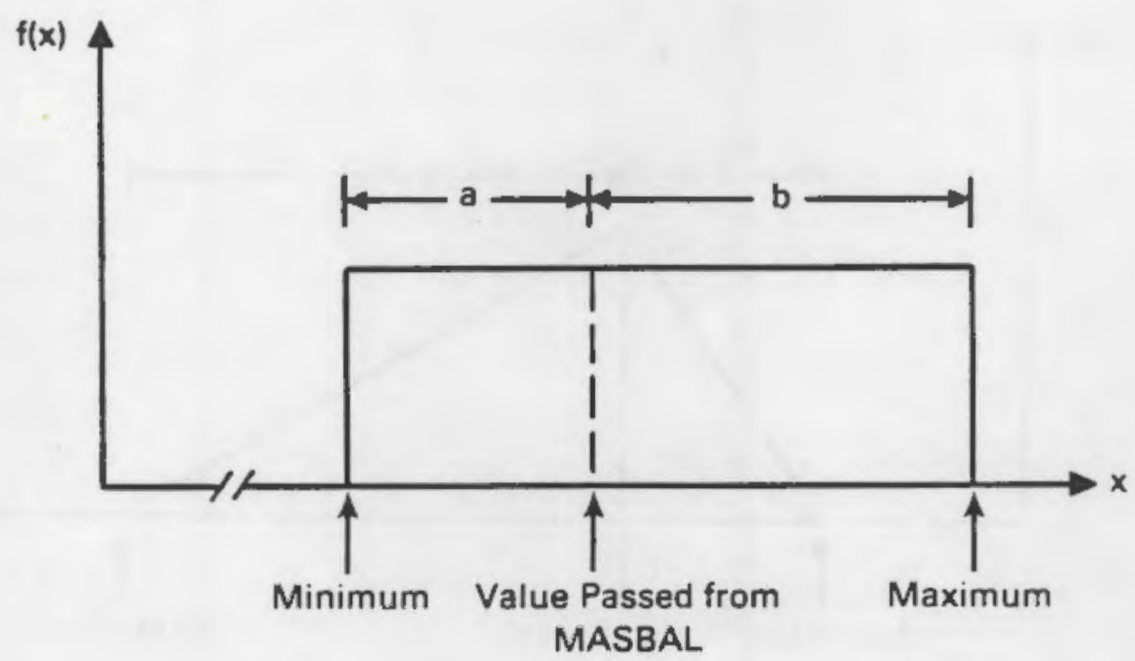

FIGURE 3.3. Probability Density Function for Nonsymmetrical Uniform Distribution

passed from MASBAL is not necessarily the same as the distance between the minimum value of the distribution and the value of the variable that is passed from MASBAL.

10. nonsymmetrical triangular - This distribution has a triangular probability density function, as shown in Figure 3.4. Unlike the symmetrical triangular distribution, the distance between the maximum value of the distribution and the value of the variable that is passed from MASBAL is not necessarily the same as the distance between the minimum value of the distribution and the value of the variable that is passed from MASBAL. The minimum and maximum value of the distribution and the value of the variable that is passed from MASBAL is not necessarily the same as the distance between the minimum value of the distribution and the value of the variable that is passed from MASBAL. The minimum and maximum values both have a probability of zero (thus defining the base of the triangle) and the value of the variable that is passed from MASBAL has the highest probability (thus forming the apex of the triangle). 
$f(x)$

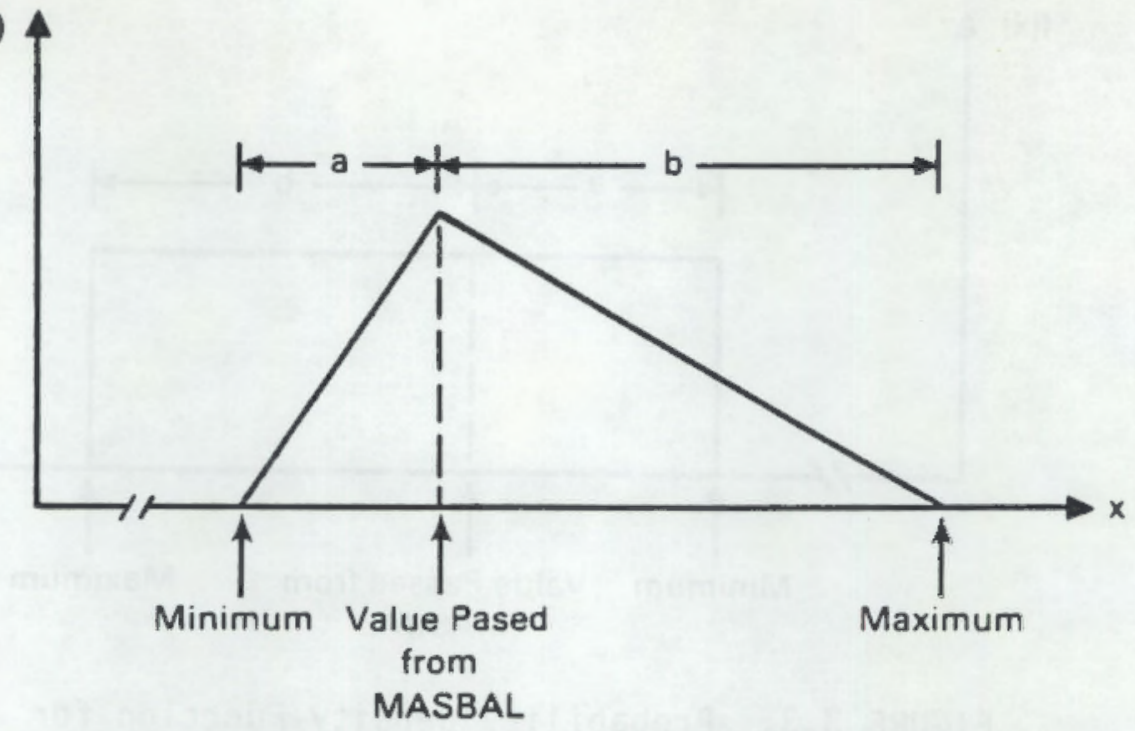

FIGURE 3.4. Probability Density Function for Nonsymmetrical Triangular Distribution

\subsubsection{User-Specified Inputs}

The user specifies the stastical distributions that describe each of the uncertainies in the process as well as all the parameters necessary to define these distributions. In MASBAL, the user must always specify one of the first four distributions listed in Section 3.11 .1 to describe errors in process measurements. This constraint exists because it is believed that all measurement errors are characterized by symmetrical distributions (the measured value comes from a distribution having a mean equal to the true value of the measured variable). This constraint does not apply to sources of inherent variability in the system, such as the batch-to-batch variability in the composition of the feed and the variability in the amount of water added to the slurry by the steam jet (both of which contribute to the overall variability in the feed composition).

Bias in process measurements is not strictly addressed in MASBAL because it is not a random error. If a measurement is known to have bias, the bias should be removed before the measurement is entered in one of the input files.

The inputs in STOCH.DAT are described in this section. The reader is referred to Appendix $A$ to see how the inputs are formatted in a typical STOCH.DAT file. 
- TIME DISTRIBUTION - The user must choose one of the first four distributions in Section 3.11.1 for simulating errors in time measurements. A distribution is specified by entering an integer from 1 to 4 . The user is limited to a choice of symmetrical distributions because it is believed that the error in measuring time will always be symmetrically distributed about the true time. If the user specifies an integer other than 1 to 4 , the code will give an error message.

- time StAndard DEVIATION - This specifies the "width" of the time distribution (in hours). If 1 is chosen as the distribution, the input is ignored. If 2 is chosen, the input is taken to be the standard deviation of a normal distribution that has a mean equal to the measured time. If 3 or 4 is chosen, the input is added and subtracted from the measured time to obtain the maximum and minimum of the distribution.

- FEed tANK VOLUME DISTRIBUtion - Discussion is analogous to TIME DISTRIBUTION except that this distribution is for simulating errors in measuring the level in the feed tank.

- feed tank volume Standard deviation - Discussion is analogous to TIME STANDARD DEVIATION except that the units are liters.

- FEED RATE DISTRIBUTION - Discussion is analogous to TIME DISTRIBUTION except that this distribution is for simulating errors in measuring the feed rate.

- feed rate standard deVIATION - Discussion is analogous to TIME STANDARD DEVIATION except that the units are liters per hour.

- gLASS POUR MASS DISTRIBUTION - Discussion is analogous to TIME DISTRIBUTION except that this distribution is for simulating errors in measuring the mass of glass pours.

- glass POUR MASS STANDARD DEVIATION - Discussion is analogous to TIME STANDARD DEVIATION except that the units are kilograms. 
- GLASS FORMER ADDITION DISTRIBUTION - Discussion is analogous to TIME DISTRIBUTION except that this distribution is for simulating errors in measuring the volume of slurry added to either the feed tank or the melter.

- GLASS FORMER ADDITION STANDARD DEVIATION - Discussion is analogous to TIME STANDARD DEVIATION except that the units are liters.

- MELTER glass VOLUME DistribUtion - Discussion is analogous to TIME DISTRIBUTION except that this distribution is for simulating errors in measuring the volume of glass in the melter.

- MELTER glass VOLUME STANDARD DEVIATION - Discussion is analogous to TIME STANDARD DEVIATION except that the units are liters.

- SLURRY SAMPLING ERROR - The inputs must be entered in tabular form. All alphanumeric constituent names that appear in the constituent list in DESIGN.DAT must be entered in the "Constituent" column. A distribution for each constituent must be entered in the "Dist." column, and a standard deviation for each constituent is entered in the "Std. Dev" column. The distributions are used to simulate sampling errors that occur when a slurry sample is taken (from either the makeup tank or the feed tank). The sampling errors result in sample-to-sample variation when replicate samples are taken. Each constituent must be assigned a distribution (from 1 to 4 ). If a constituent is left out, or if an integer other than 1 to 4 is specified for the distribution, the code will give an error message. All standard deviations should be specified as percentages of the measured values (relative percent error). If distribution 1 is specified for a constituent, the standard deviation of that constituent is ignored.

- SLURRY ANALYTICAL ERROR - Discussion is analogous to SLURRY SAMPLING ERROR except that the distributions are used to simulate errors in analyzing the slurry samples. 
- OFf-GAS SAMPLING ERROR - Discussion is analogous to SLURRY SAMPLING ERROR except that the distributions are used to simulate errors that occur when of f-gas samples are taken.

- off-gas anAlytical ERROR - Discussion is analogous to SLURRY SAMPLING ERROR except that the distributions are used to simalate errors in analyzing the off-gas samples.

- GLASS SAMPLING ERROR - Discussion is analogous to SLURRY SAMPLING ERROR except that the distributions are used to simulate errors that occur when glass samples are taken.

- glass analytical ERROR - Discussion is analogous to SLURry SAMPLing ERROR except that the distributions are used to simulate errors in analyzing the glass samples.

- ShIM PREPARATION ERROR - Discussion is analogous to SLURRY SAMPLING ERROR except that the distributions are used to simulate the uncertainty in knowing the composition of a slurry mixture based on a knowledge of how the slurry was prepared (i.e., knowing the amount of each ingredient that was added to the mixture).

- BATCH-TO-BATCH FEED VARIATION - The inputs must be entered in tabular form. All alphanumeric constituent names that appear in the constituent list in DESIGN.DAT must be entered in the "Constituent" column. A distribution for each constituent must be entered in the "Dist." column. The user may choose any of the ten distributions described in Section 3.11.1, except for the symmetrical uniform and symmetrical triangular distributions (these distributions can still be specified by selecting the nonsymetrical uniform or triangular distributions an setting the distance between the maxima and the mode equal to the distance between the minima and the mode). The distributions are specified by entering any integer from 1 to 10 (except 3 or 4). The distributions are used to simulate the variation in feed composition that occurs from batch to batch when MASBAL is run in MODE 3 (or when "future" batches occur in mode 2). Values for "A", 
"B", and " $C$ " should be entered for each constituent in the appropriate column. $A, B$, and $C$ are interpreted differently for different distributions. A "key" for interpretation of A, B, and C for each distribution is provided above the batch-to-batch feed variation table in STOCH.DAT (see printout in Appendix A). The key is described in greater detail here:

\begin{tabular}{|c|c|}
\hline Dist. & Parameters \\
\hline 1 & $A, B$, and $C$ are ignored (no parameters). \\
\hline 2 & $\begin{array}{l}\text { A - standard deviation specified as a percentage of the value } \\
\text { that is passed from MASBAL. } \\
B \text { and } C \text { are ignored. }\end{array}$ \\
\hline 5 & $\begin{array}{l}\text { A - mean for a log-normal distribution } \\
\text { B - standard deviation for a log-normal distribution } \\
C \text { - offset specified as a percentage of the value that is passed } \\
\text { from MASBAL - The offset is subtracted from the value passed } \\
\text { from MASBAL. The resulting value is then taken as the point } \\
\text { where the distribution first attains a probability greater } \\
\text { than zero. The value passed from MASBAL is used as the mode } \\
\text { of the distribution. }\end{array}$ \\
\hline 6 & $\begin{array}{l}\text { A - Value of alpha in the probability density function for a } \\
\text { gamma distribution. } \\
\text { B - Value of beta in the probability density function for a } \\
\text { gamma distribution. } \\
\text { C - Offset specified as a percentage of the value that is passed } \\
\text { from MASBAL. The offset is subtracted from the value passed } \\
\text { from MASBAL. The resulting value is then taken as the point } \\
\text { where the distribution first attains a probability greater } \\
\text { than zero. The value passed from MASBAL is used as the mode } \\
\text { of the distribution. }\end{array}$ \\
\hline 7 & $\begin{array}{l}\text { A - Value of alpha in the probability density function for a } \\
\text { beta distribution. } \\
\text { B - Value of beta in the probability density function for a beta } \\
\text { distribution. } \\
\text { C - Offset specified as a percentage of the value that is passed } \\
\text { from MASBAL. The offset is subtracted from the value passed } \\
\text { from MASBAL. The resulting value is then taken as the point } \\
\text { where the distribution first attains a probability greater } \\
\text { than zero. The value passed from MASBAL is used as the mode } \\
\text { of the distribution. }\end{array}$ \\
\hline
\end{tabular}


Dist.

8

9

10
Parameters

A - Value of beta in the probability density function for a exponential distribution.

$B$ - Dffset specified as a percentage of the value that is passed from MASBAL. The of fset defines an $x$-axis transformation such that the distance between the of fset point and the value of the variable passed from MASBAL is equivalent to the distance between 0 and 1 on the non-transformed axis (see Equation 3.7).

C - ignored.

9 A - Maximum value for the uniform distribution specified as a percentage of the value that is passed from MASBAL.

B - Minimum value for the uniform distribution specified as a percentage of the value passed from MASBAL.

C - ignored.

A - Maximum value for the triangular distribution specified as a percentage of the value that is passed from MASBAL.

$B$ - Minimum value for the triangular distribution specified as a percentage of the value passed from MASBAL.

C - ignored.

- steam jet VOLUME CORRECTION FACTOR DISTRIBUTION - A distribution must be specified under "0ist.", and a value for $A, B$, and $C$ must be specified under the appropriate letter. The distribution can be specified by entering any integer from 1 to 10 , except 3 or 4 . A, B, and $C$ are interpreted differently for different distributions (see BATCH-TO-BATCH FEED VARIATION). The specified distribution is used to simulate the uncertainty in the volume correction factor for the amount of water that is added to the feed during transfer from the makeup tank to the feed tank by steam jet. 
. 


\subsection{OUTPUT FILES}

The primary output generated by MASBAL is the composition of the glass exiting the melter as a function of time. When the production version of MASBAL is run, the glass composition data are essentially the only output that the code produces. When the debug version is run, however, several output files are generated in addition to those generated by the production version. These files are useful for determining the exact sequence of events that occurred in the simulation and for debugging the program. The files generated by both versions are discussed in the following sections. Examples of all output files are provided in Appendix $B$.

\subsection{OUTPUT FILES GENERATED BY PRODUCTION VERSION}

Dnly two sets of files are generated when the production version of MASBAL is run. The first set of files provides information on the glass composition (mass fraction) in the last region of the melter as a function of time. These files have the names COMP1.OUT through COMPx.OUT, where $x$ is a number between 1 and 20. A separate file is written for every five constituents that are specified in the model (a maximum of 20 files are created when 96 to 100 constituents are specified). Two examples of COMPx.OUT files are given in Appendix C (COMP1.OUT and COMP2.OUT). The time interval for writing the mass fractions to the files is specified by the user in the input file MODE.DAT.

The second set of output files generated by the production version of MASBAL provides information on the masses and average compositions of each glass pour. The file PORSUM.OUT gives the starting and stopping times and masses (in kilograms) of each pour. The files POURl.OUT through POURx.OUT (where $x$ is a number between 1 and 20) give the average mass fraction of each constituent in each of the pours. The pours are numbered for cross reference between the different files. A separate file named POURx.OUT is created for every five constituents specified in the model. Examples of PORSUM,OUT and POURx.OUT (POUR1.OUT and POUR2.OUT) are given in Appendix B. 


\subsection{OUTPUT FILES GENERATED BY DEBUG VERSION}

When the debug version of MASBAL is run, several files are generated in addition to those generated by the production version. These files are divided into two categories: 1) those that are generated before the simulation begins, and 2) those that are generated during the simulation. All the files that fall into the first category have the extension ".ECH". The data written to these files are "echoes" of input data that are read by the PRIME subroutine and by the various subroutines that PRIME calls. All the files that are generated during the simulation have the extension ".OUT". The following list provides a brief description of the contents of each of the output files generated by the debug version of MASBAL (excluding the files that are generated by the production version):

- BATRD.ECH - Contains echoes of initial data read from the input file BATCH.DAT by the subroutine BATRD. If MASBAL is run in modes 2, the values in BATRD.ECH will differ slightly from the values in BATCH.DAT because random measurement errors will be simulated. If MASBAL is run in mode 3 , this file is not generated.

- DSNRD.ECH - Contains echoes of all the data read from the input file DESIGN.DAT by the subroutine DSNRD.

- FEEDRD.ECH - Contains echoes of initial data read from the input file FEED.DAT by the subroutine FEEDRD. If MASBAL is run in modes 2, the values in FEEDRD.ECH will differ slightly from the values in FEED.DAT because random measurement errors will be simulated. If MASBAL is run in mode 3 , this file is not generated.

- FSHRD.ECH - Contains echoes of initial data read from the input file FSHIM.DAT by the subroutine FSHRD. If MASBAL is run in modes 2, the values in FSHRD.ECH will differ slightiy from the values in FSHIM.DAT because random measurement errors will be simulated. If MASBAL is run in mode 3 , this file is not generated. 
- INITRO.ECH - Contains echoes of all the data read from the input file INIT.DAT by the subroutine INITRO. If MASBAL is run in modes 2 or 3 , the values in INITRD.ECH will differ slightly from the values in

INIT.DAT because random measurement errors will be simulated.

- MODERO.ECH - Contains echoes of all the data read from the input file MOOE.DAT by the subroutine MODERD.

- MSHRO.ECH - Contains echoes of initial data read from the input file MSHIM.DAT by the subroutine MSHRD. If MASBAL is run in modes 2 , the values in MSHRO.ECH will differ slightly from the values in MSHIM.DAT because random measurement errors will be simulated. If MASBAL is run in mode 3 , this file is not generated.

- OFFRO.ECH - Contains echoes of initial data read from the input file OFFGAS,DAT by the subroutine OFFRD. If MASBAL is run in modes 2 or 3 , the values in OFFRD.ECH will differ slightly from the values in OFFGAS.DAT because random measurement errors will be simulated. If MASBAL is run in mode 3 , this file is not generated.

- POURRO.ECH - Contains echoes of initial data read from the input file POUR.OAT by the subroutine POURRD. If MASBAL is run in modes 2 or 3 , the values in POURRD.ECH will differ slightly from the values in POUR.DAT because random measurement errors will be simulated. If MASBAL is run in mode 3 , this file is not generated.

- PRIME.ECH - If MASBAL is run in mode 3 , this file contains the time at which the first glass pour is scheduled to start. If MASBAL is run in modes 1 or 2 , this file is empty.

- STOCRD.ECH - Contains echoes of all the data read from the input file STOCH.DAT by the subroutine STOCRD. If MASBAL is run in mode 1 , this file is not generated.

- BATCH.OUT - Contains the starting and stopping times of transfers of slurry from the makeup tank to the feed tank, and the simulated concentrations of each constituent in the feed tank after each transfer. BATCH.OUT also contains echoes of data read from the input file BATCH.OAT during the simulation. If MASBAL is run in mode 2 , the 
simulated times and concentrations will differ slightly from the values in BATCH.DAT because random measurement errors will be simulated. If MASBAL is run in mode 3 , the times and concentrations will not be read from BATCH.DAT, but they will be generated internally by the program. In this case, BATCH.OUT will contain echoes of the internally generated times and concentrations. The concentrations written to the file will correspond to concentrations in the makeup tank, which differ from concentrations in the feed tank because water is added to the slurry during the transfer from the makeup tank to the feed tank (as a result of the steam jet).

- CHGREg.OUT - Contains the times at which the subroutine CHGREG is called and the name of the subroutine that made the call. CHGREG is called each time the melter feed rate or feed composition changes, as these changes will cause the masses of the various regions in the melter to change (assuming that the melter is not modeled as a single ideally-mixed region).

- FDRATE.OUT - Contains the times at which the melter feed rate changes and the new feed rate after each change. FDRATE.OUT also contains echoes of data read from the input file FEED.DAT during the simulation.

- OFFGAS.OUT - Contains the times at which the offgas system is sampled and the volatilization rates of each constituent, which are calculated from the offgas data. OFFGAS.OUT also contains echoes of data read from the input file OFFGAS.DAT during the simulation. When MASBAL is run in mode 3 , this file is empty.

- PORHIS.OUT - Contains the times at which glass pours are started and stopped and the masses of the pours (in chronological order). Information specifying whether a glass pour was 1) scheduled from POUR.DAT, 2) scheduled as a "future pour" from within MASBAL, or 3) interrupted as a result of a low glass level in the melter is also contained in PORHIS.OUT. 
- REGMAS.OUT - Contains the mass of each region in the melter as a function of time. The interval for writing the masses to the file is the same as the interval for writing mass fractions in the last region of the melter to the COMPx.OUT files (see Section 4.1). This interval is specified by the user in MODE.DAT.

- SHIMS.OUT - Contains the times at which glass formers are added to either the feed tank or the melter and the compositions of the slurries that are added. If glass formers are added to the feed tank, the composition in the feed tank immediately after the addition is written to the file. SHIMS.OUT also contains echoes of data read from the input files FSHIM.DAT and MSHIM.DAT during the simulation. When MASBAL is run in mode 3 , SHIMS.OUT is empty. 


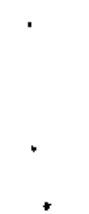

"

•

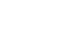




\subsection{EXECUTION OF MASBAL}

To execute MASBAL, the SIMAN simulation language must be installed on the host computer system, and the following files must be present in the default di rectory:

- DMASBAL ,EXE

- PMASBAL .EXE

- MASBAL.P

- The 11 input files described in Chapter 3.D.

If MASBAL is installed on a Digital Equipment Corporation VAX/VMS computer system, the VAX/VMS command files supplied with the MASBAL software package can be used to run the program. If another computer system is used, a specific set of instructions will have to be developed to properly execute the program.

MASBAL can be run in either interactive mode or batch mode. The advantage of running the program in batch mode is that once the job is submitted, the user can issue other commands or $\log$ out while the job is executing. If MASBAL is run in the interactive mode, the user will have to wait until the run completes before the terminal can be used for other commands. An advantage to running in the interactive mode is that the user will know immediately if an execution error or an error due to improper setup of the input files occurs.

Assuming that MASBAL is installed on a VAX computer, the following commands can be issued to execute the program:

- DMASBAL - to run the debug version in interactive mode

- PMASBAL - to run the production version in interactive mode

- omasbat - to run the debug version in batch mode

- PMASBAT - to run the production version in batch mode.

The time required to complete a run is dependent on several factors, the most important of which are the length of the simulation and the rumber of constituents in the simulation. The run time is almost directly proportiona? to the length of the simulation (doubling the simulation length will double the run time), but it is less than directly proportional to the number of constituents (doubling the number of constituents will increase the run time but not by 
a factor of two . The exact time required for a run will depend on the computer system used and the number of other active processes on the system.

Regardless of whether MASBAL is run in the batch or interactive mode, the code does not prompt the user for information. All information must be present in the MASBAL input files prior to the start of the run. If the information in the input files is erroneous or inconsistent, the run will either terminate with error status or complete with results that are obviously incorrect. 


\subsection{IEST CASES}

During the development of MASBAL, several test cases were run to test various features of the program. Some of these test cases provide excellent demonstrations of the capabilities of MASBAL.

\subsection{BORON TRACER STUDIES}

In one series of test cases, a step change in the concentration of boron in the feed to the melter was simulated. The step change occurred after 10 hours of operation of the melter (when a new batch of feed was transferred from the makeup tank to the feed tank). The concentration of boron in the feed tank prior to the transfer was $35 \mathrm{~g}$ oxide/L, corresponding to a mass fraction of $\mathrm{B}_{2} \mathrm{O}_{3}$ in the glass of 0.1 . The concentration of boron in the feed tank after the transfer was $70 \mathrm{~g}$ oxide/L, corresponding to a mass fraction of $\mathrm{B}_{2} \mathrm{O}_{3}$ in the glass of 0.2 (the concentration of silicon in the feed tank simultaneously dropped from $175 \mathrm{~g}$ oxide/L to $140 \mathrm{~g}$ oxide $/ \mathrm{L}$ in order to maintain constant oxide loading in the feed).

Seven cases were run in which the mixing characteristics of the melter were modeled differently. The seven variations of modeling the melter were:

1. one ideally-mixed tank

2. two ideally-mixed regions in series, with each region representing $50 \%$ of the melter volume

3. three ideally-mixed regions in series, with each region representing $33.3 \%$ of the melter volume

4. four ideally-mixed regions in series, with each region representing $25 \%$ of the melter volume

5. five ideally-mixed regions in series, with each region representing $20 \%$ of the melter volume

6. a plug flow region and an ideally-mixed region in series - The plug flow region represented $20 \%$ of the melter volume 
7. a plug flow region and two ideally-mixed regions in series - The plug flow region represented $20 \%$ of the melter volume, and each of the ideally-mixed regions represented $40 \%$ of the melter volume.

The results of the seven runs are shown graphically in Figures 6.1 and 6.2. The curves show how the composition of $\mathrm{B}_{2} \mathrm{O}_{3}$ in the last region of the melter varied with time as a function of how the melter was modeled. These curves are in excellent agreement with results calculated analytically. The shapes of the curves could be altered somewhat by changing the relative volume percentages of the various regions in the melter.

These test run results imply that the parameters in MASBAL could be adjusted to fit the behavior observed in actual melter tracer studies. In this way, MASBAL could be "calibrated" to simulate a specific melter system, such as the West Valley CTS.

\subsection{STARTUP FROM AN IDLING CONDITION}

A series of test cases was run in which a plant startup was simulated. In all of these cases, the melter was modeled as having more than one ideallymixed region at steady state, but the initial conditions dictated that the melter be a single ideally-mixed region at the start of the simulation. This situation corresponds to a melter that is initially idling, as it is believed that idling melters are ideally-mixed. The purpose of the runs was to test the algorithms that describe the change in mass of the various regions in the melter as a function of feed rate (see Section 2.4.3).

The output from one of the test cases is shown in Figure 6.3. In this case, the melter was modeled as having two ideally-mixed regions of equal volume at steady state. The value of $\beta$ in Equation (2.7) was specified as 2.0. The curves in Figure 6.3 are in excellent agreement with the predictions of Equation (2.8), which is the analytical solution of Equation $(2.7)$. The zig-zag appearance of the curve for the second region is a result of simulating batch glass pours. This pouring strategy causes the mass of the region to fluctuate. 


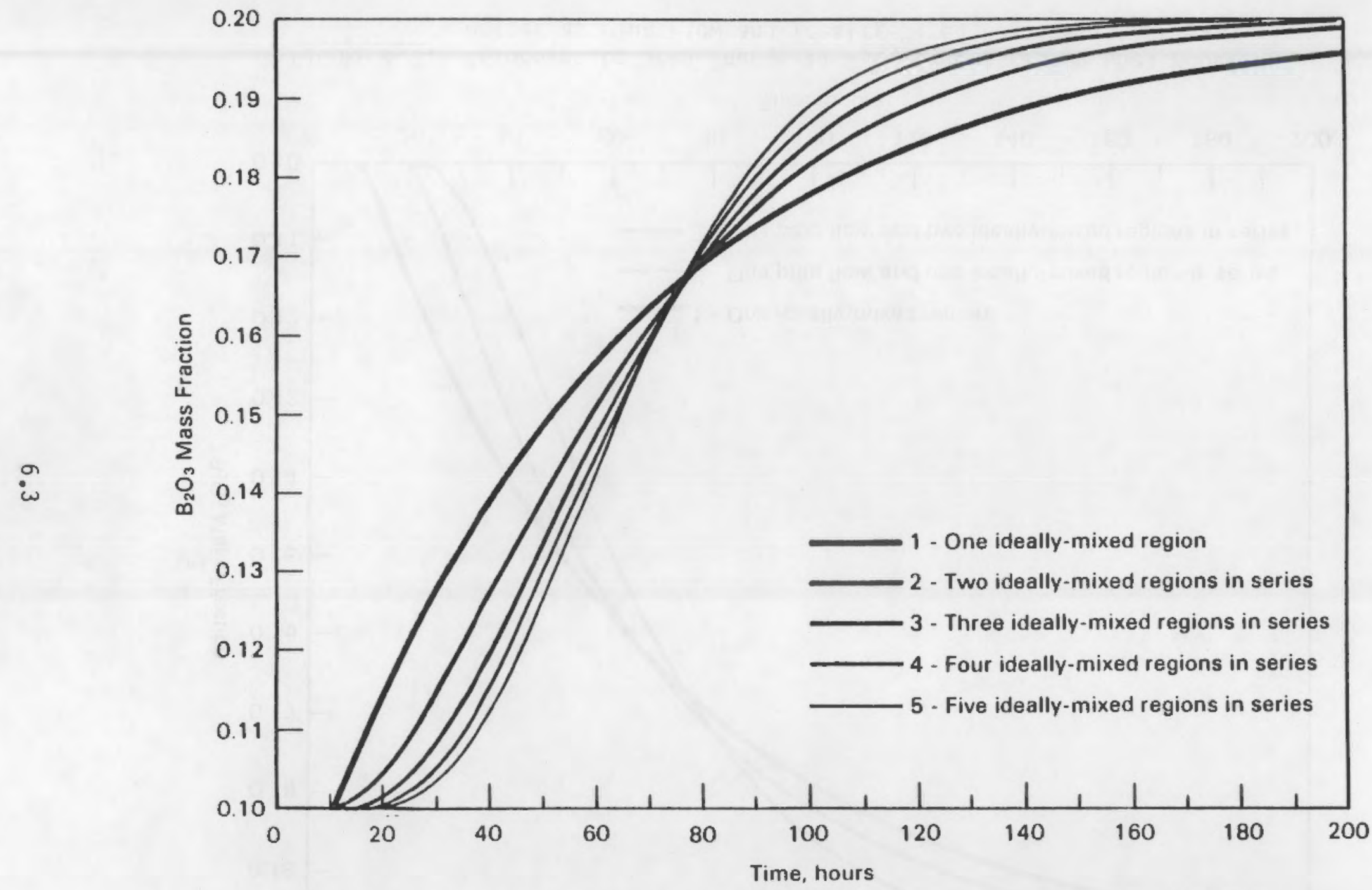

FIGURE 6.1. Responses to Step Change in $\mathrm{B}_{2} \mathrm{O}_{3}$ Concentration when Modeling Melter as Ideally-Mixed Regions in Series 


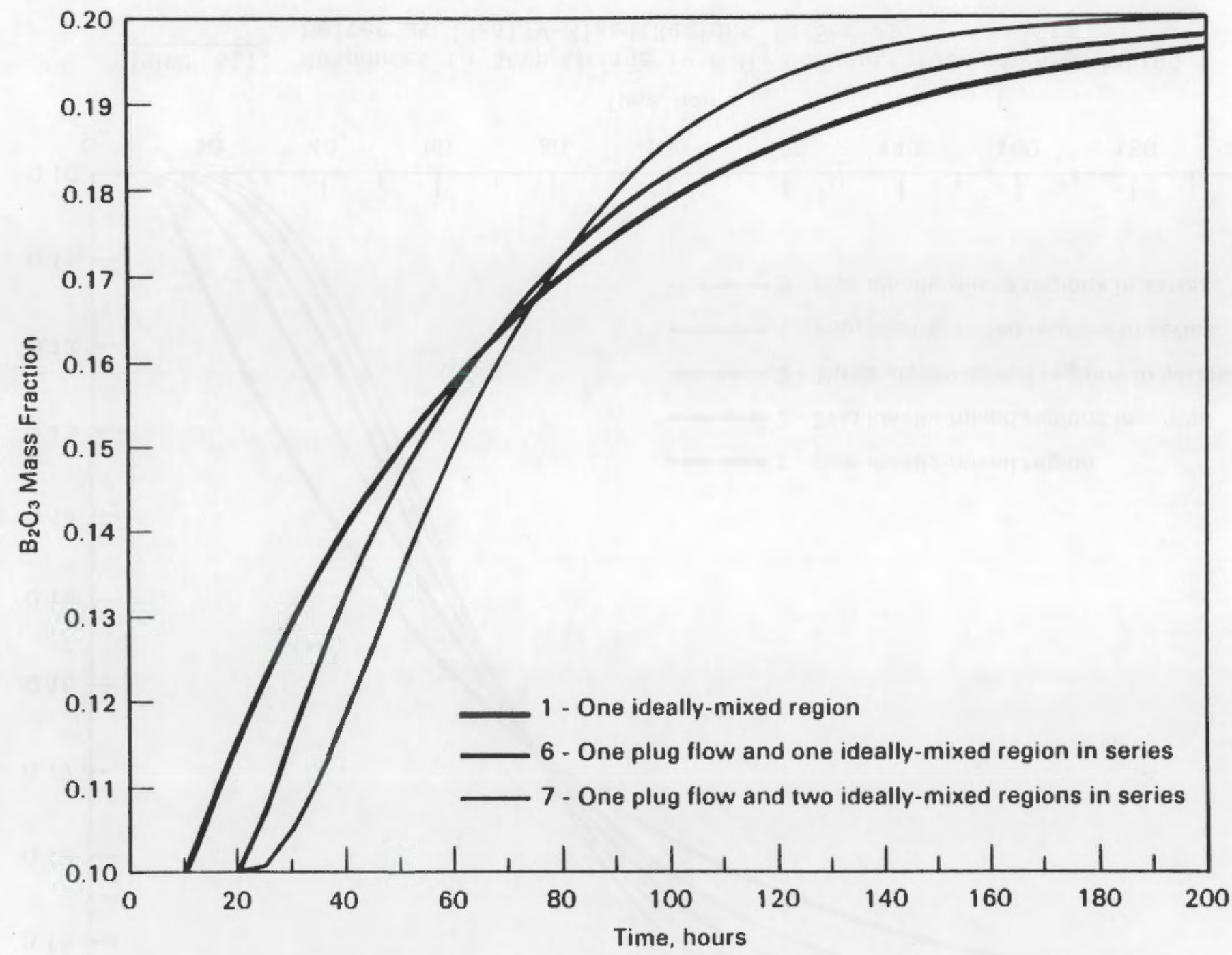

FIGURE 6.2. Responses to Step Change in $\mathrm{B}_{2} \mathrm{O}_{3}$ Concentration when Modeling Melter as Plug Flow and Ideally-Mixed Regions in Series 


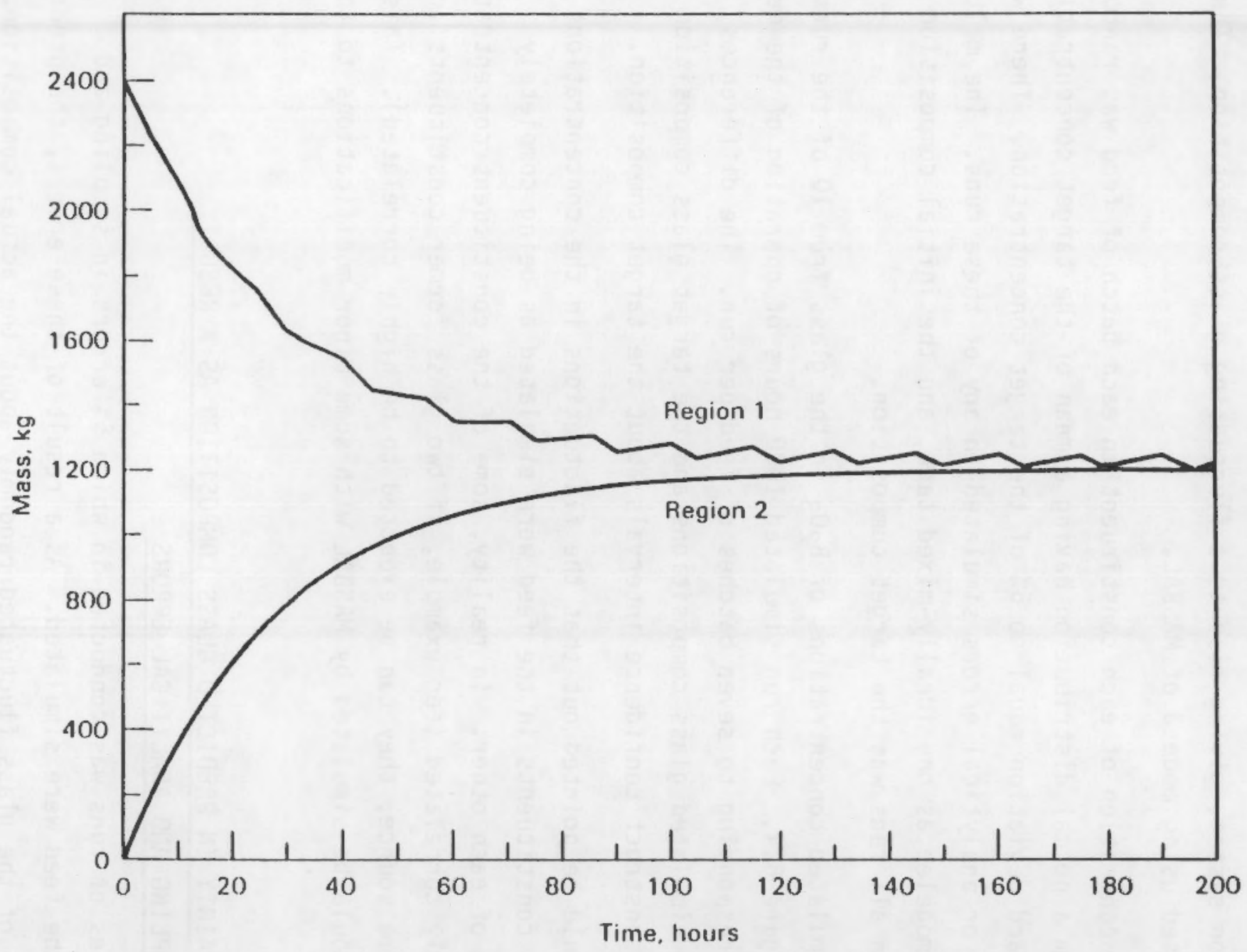

FIGURE 6.3. Change in Mass of Melter Regions when Starting from an Idling Condition (Two Ideally-Mixed Regions in Series) 


\subsection{VARIABILITY IN GLASS COMPOSITION AS A FUNCTION OF VARIABILITY IN FEED COMPOSITION}

A series of runs was conducted in which a $5 \%$ variability in the feed composition was simulated. This variability was propagated through the simulated vitrification system, giving rise to a fluctuating glass composition. The runs were conducted using mode 3 of MASBAL.

The concentration of each constituent in each batch of feed was randomly sampled from a normal distribution having a mean of the target concentration and a standard deviation equal to $5 \%$ of the target concentration. There were no sampling or analytical errors simulated in any of these runs. The melter was always modeled as one ideally-mixed tank, and the initial composition of the glass in all runs was the target composition.

The simulated concentrations of $\mathrm{B}_{2} \mathrm{O}_{3}$ in the glass from 10 of the runs are shown in Figure 6.4. Each run simulated 1000 hours of operation of the melter system, corresponding to seven batches of feed per run. The differences between the simulated glass compositions and the target glass composition could be used to construct confidence intervals about the target composition.

It should be pointed out that the fluctuations in the concentrations of each of the constituents in the feed were simulated as being completely independent of each other. In reality, some of the constituent concentrations may be highly correlated (for example, if two glass former constituents come from the same source, they can be expected to be highly correlated). This situation could be simulated by MASBAL with some minor modifications to the program.

\subsection{UNCERTAINTY IN PREDICTED GLASS COMPOSITION AS A RESULT OF SAMPLING AND ANALYTICAL ERRORS}

A series of runs was conducted in which $5 \%$ errors in sampling and analyzing the feed were simulated. As a result of these errors, the predicted composition of the glass fluctuated randomly about the actual composition. The runs were conducted using mode 3 of MASBAL. 


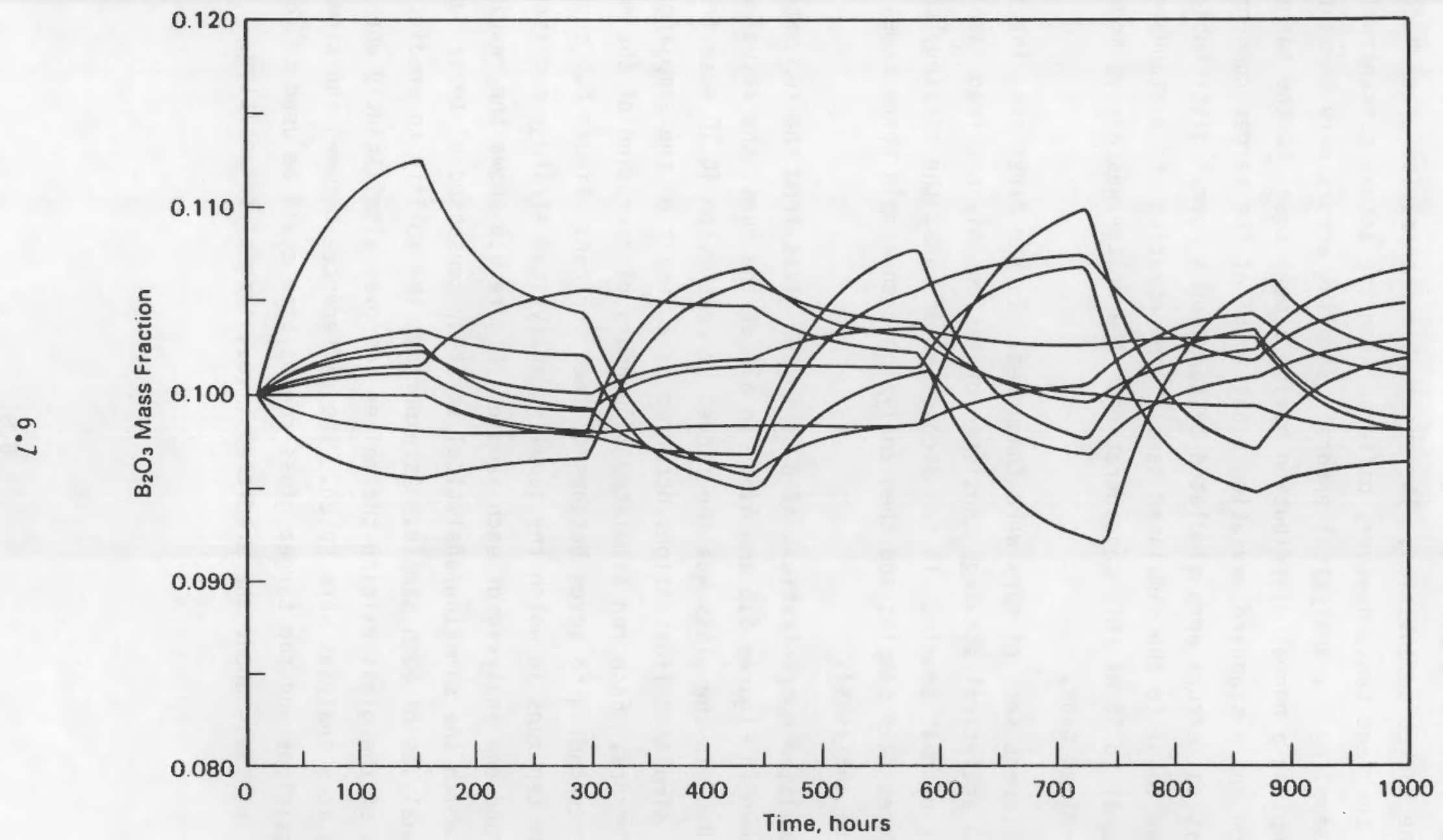

FIGURE 6.4. Variability in Glass Composition as a Result of a 5\% Batch-to-Batch Variability in Feed Composition 
The actual composition of each batch of feed was simulated as the target composition. Therefore, the actual composition of the glass in all runs should have been the target composition. The apparent concentration of each constituent in the feed tank, however, differed from the actual concentration because of sampling and analytical errors. Sampling errors were simulated by randomly sampling a normal distribution having a mean equal to the target concentration and a standard deviation equal to $5 \%$ of the target concentration. Analytical errors were simulated by sampling a normal distribution having a mean equal to the simulated sample concentration and a standard deviation equal to $5 \%$ of this concentration. The melter was always modeled as one ideally-mixed tank.

Two different sets of runs were conducted. In the first set, the feed sampling and analytical strategy consisted of taking only one feed sample and one analysis of that sample. In the second set of runs, the strategy consisted of taking three feed samples and then analyzing each sample three times (for a total of nine analyses).

The simulated concentrations of $\mathrm{B}_{2} \mathrm{O}_{3}$ in the glass from the two sets of runs are shown in Figures 6.5 and 6.6. In all of the runs, the actual concentration of $\mathrm{B}_{2} \mathrm{O}_{3}$ in the glass was the target concentration $(0.10$ mass fraction). The simulated fluctuations occurred as a result of the sampling and analytical errors. Each run simulated 1000 hours of operation of the melter system, corresponding to seven batches of feed per run. Figure 6.5 shows the results from ten runs in which the sampling/analytical strategy consisted of one sample and one analysis of each sample. Figure 6.6 shows the results from 10 runs in which the sampling/analytical strategy consisted of three samples and three analyses of each sample. As expected, the ability to predict the composition of the glass exiting the melter improved significantly when more samples and more analyses were taken. The differences between the simulated glass compositions and the target glass composition could be used to construct confidence intervals about the predicted (i.e., target) composition. 


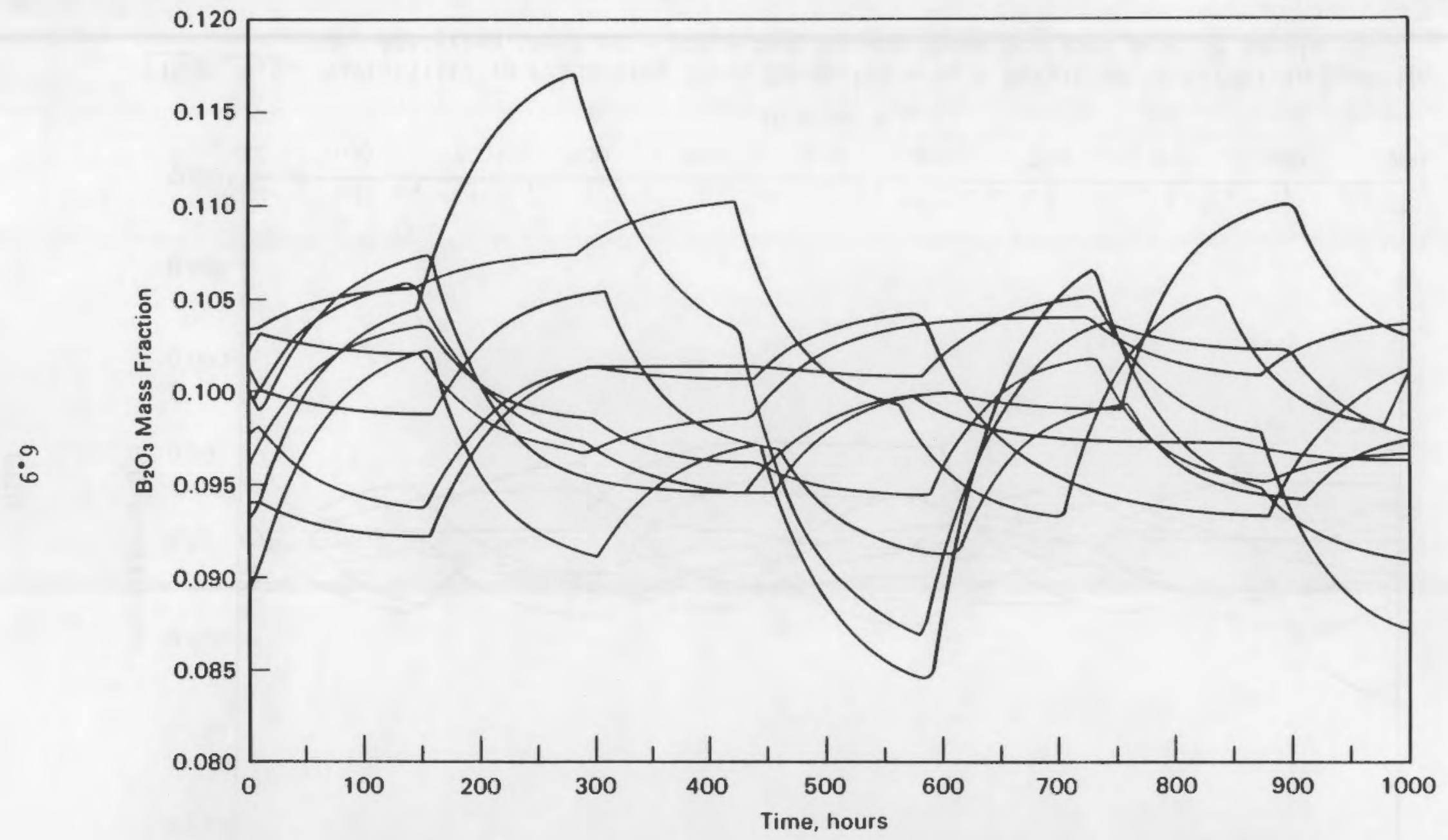

FIGURE 6.5. Variability in Predicted Glass Composition as a Result of 5\% Errors in Sampling and Analyzing the Feed - One Sample and One Analysis of Each Sample 


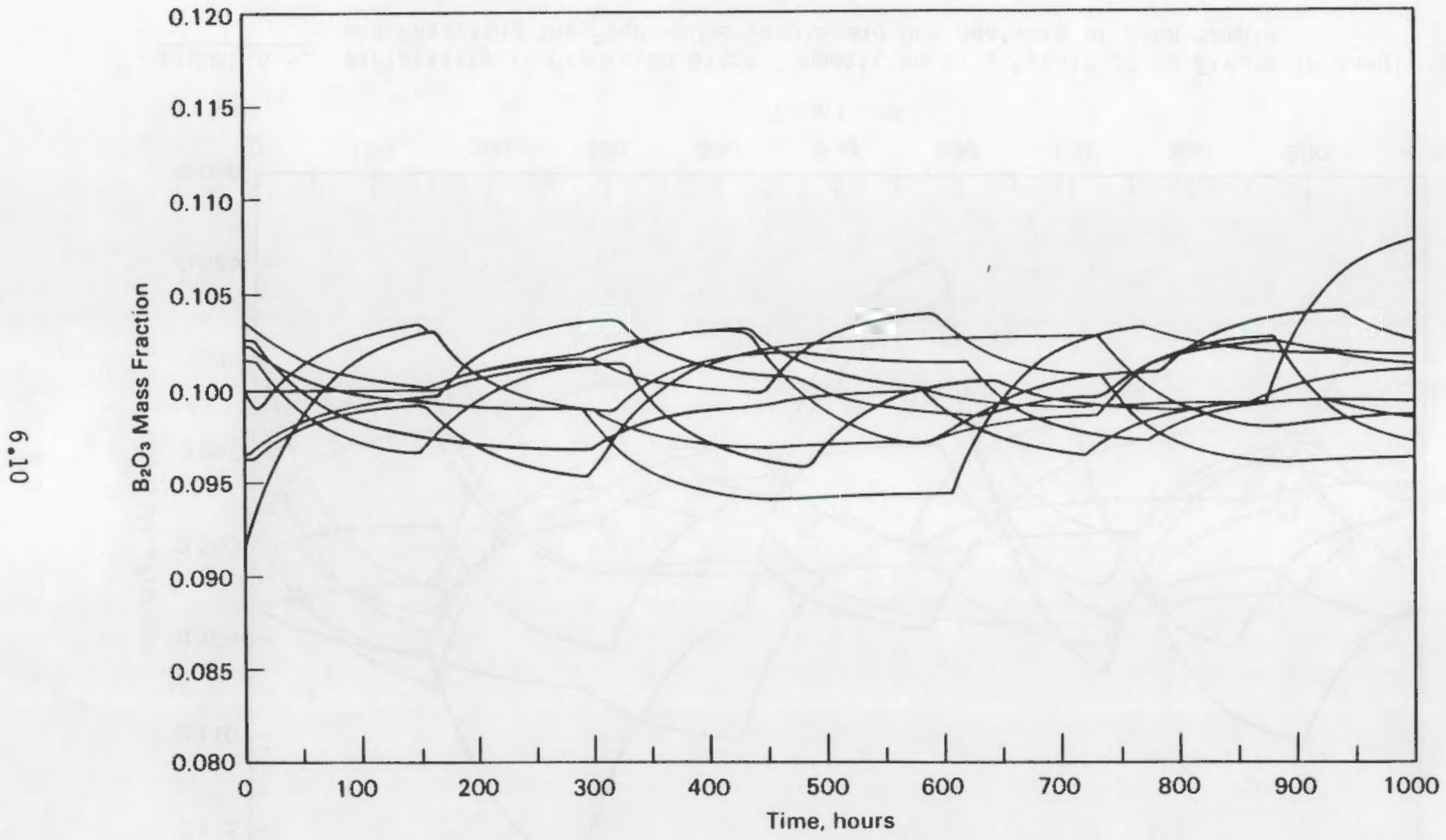

FIGURE 6.6. Variability in Predicting Glass Composition as a Result of 5\% Errors in Sampling and Analyzing the Feed - Three Samples and Three Analyses of Each Sample 


\subsection{ACKNOWLEDGMENTS}

The author would like to thank Brian Day for his help in programing MASBAL. Duane Faletti, Bill Kuhn, Joe Westsik, George Mellinger, and John Carrell all provided programatic guidance and helpful suggestions at various times during the development of MASBAL. Ven Arakali, the principle contact at West Valley Nuclear Services, provided design input and much needed information on the West Valley vitrification system. Steve Slate provided a peer review of the report. Editorial support was provided by Ted Ceckiewicz. PNL word processing and graphics staff also assisted in preparation of the document. This report was prepared for the West Valley Support Task of the Department of Energy's Nuclear Waste Treatment Program at Pacific Northwest Laboratory. 


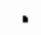

, 


\subsection{REFERENCES}

Choi, S. C. 1978. Introductory Applied Statistics in Science. Prentice-Hall, Inc., Englewood Cliffs, New Jersey.

Pegden, C. D. 1985. Introduction to SIMAN. Systens Modeling Corporation, State College, Pennsylvania.

Peterson, M. E., D. McCarthy, and K. D. Muhlstein. 1986. Design of a Mixing System for Simulated High-Level Nuclear Waste Melter Feed Slurries. PNL-5745, Pacific Northwest Laboratory, Richland, Washington.

Tsokos, C. P. 1972. Probability Distributions: An Introduction to Probability Theory with Applications. Duxbury Press, Belmont, California. 


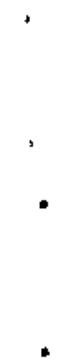

" 
APPENDIX A

EXAMPLES DF INPUT FILES 


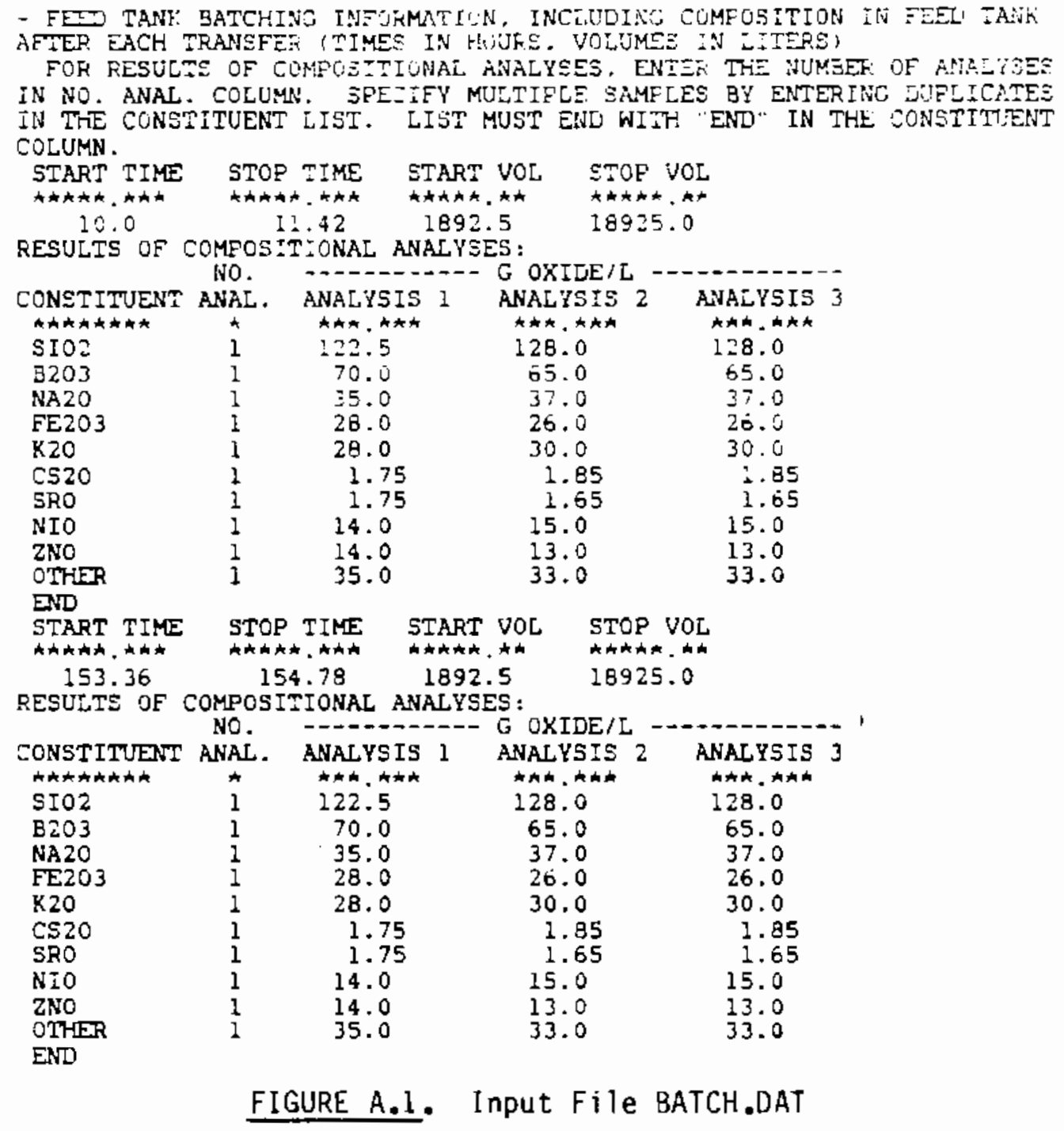




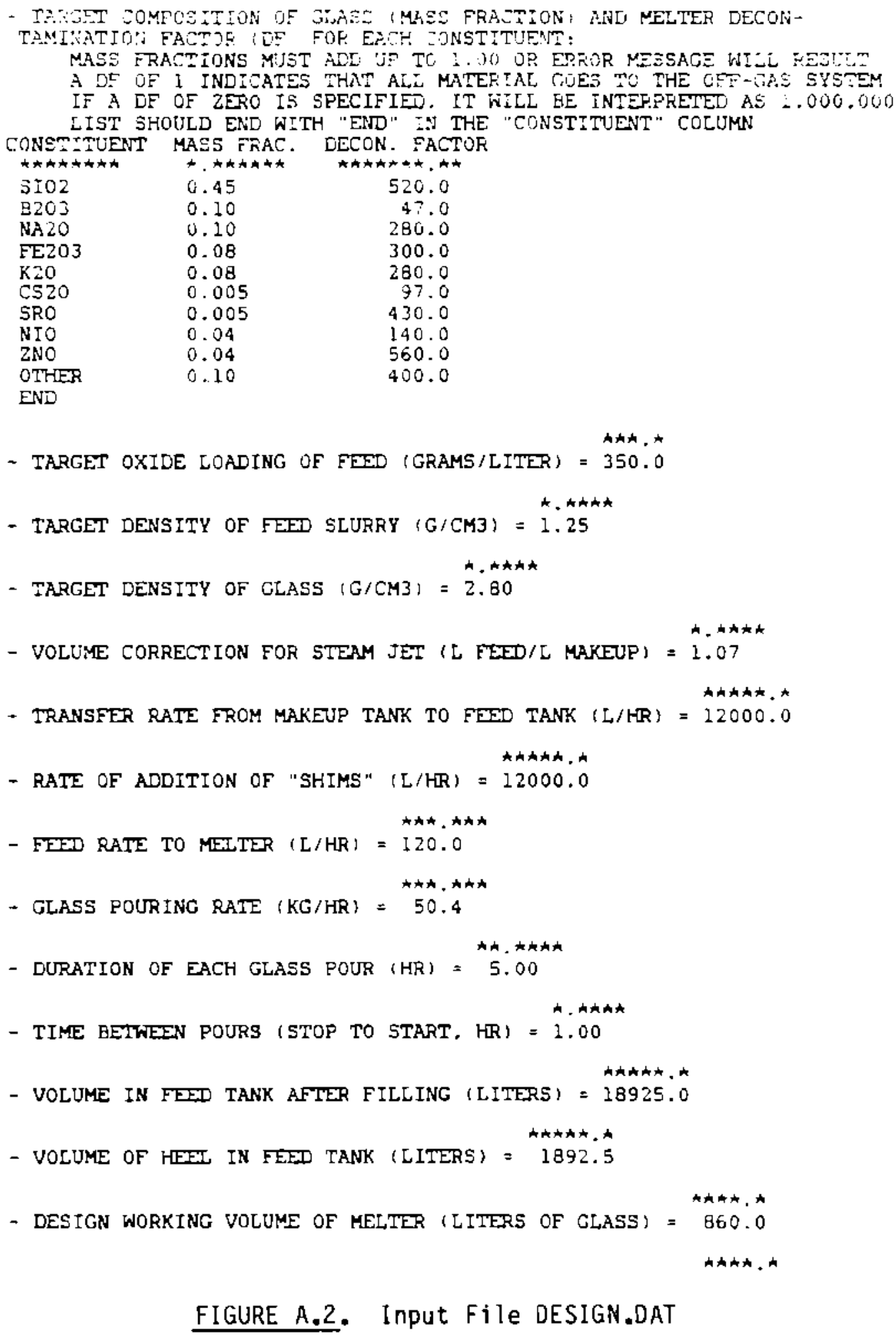




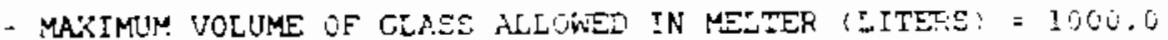

- MINIMUM VOLUME OF GLASS ALLOWED IN MELTER (LITERE: = 700.9)

- PARAMETER FOR ADJUSTMENT OF TIME CONSTANT $=\frac{\hbar}{2 .} \cdot{ }^{\star}$

FIGURE A.2. (contd)

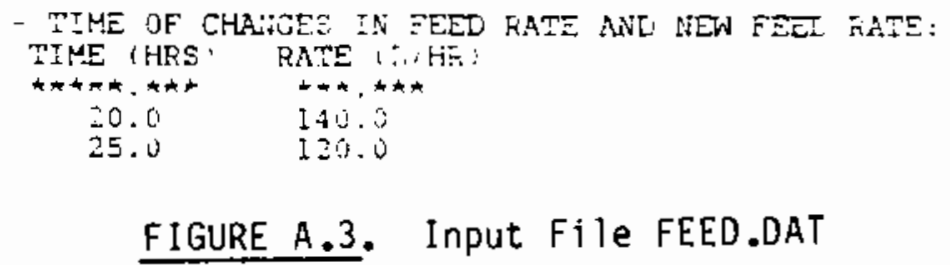

FIGURE A.3. InPut File FEED.DAT

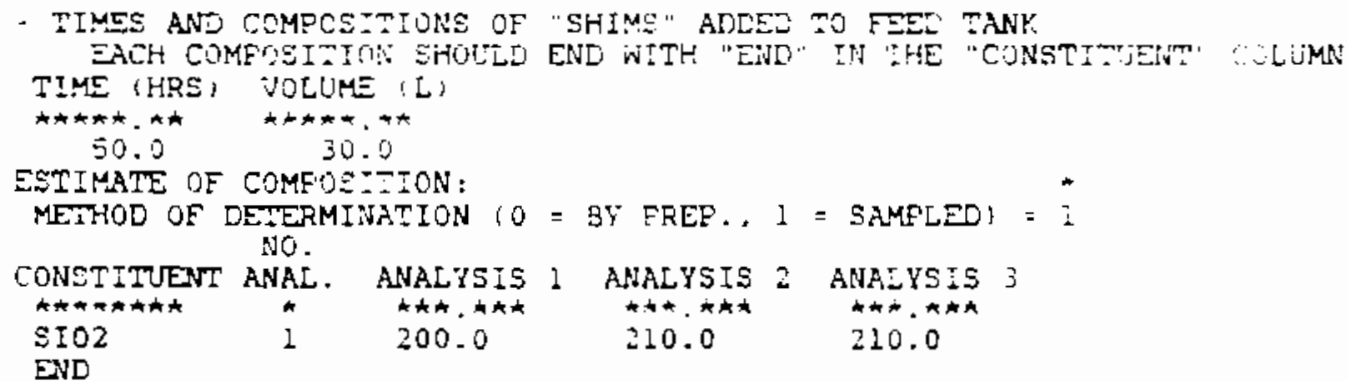

FIGURE A.4. Input File FSHIM.DAT 


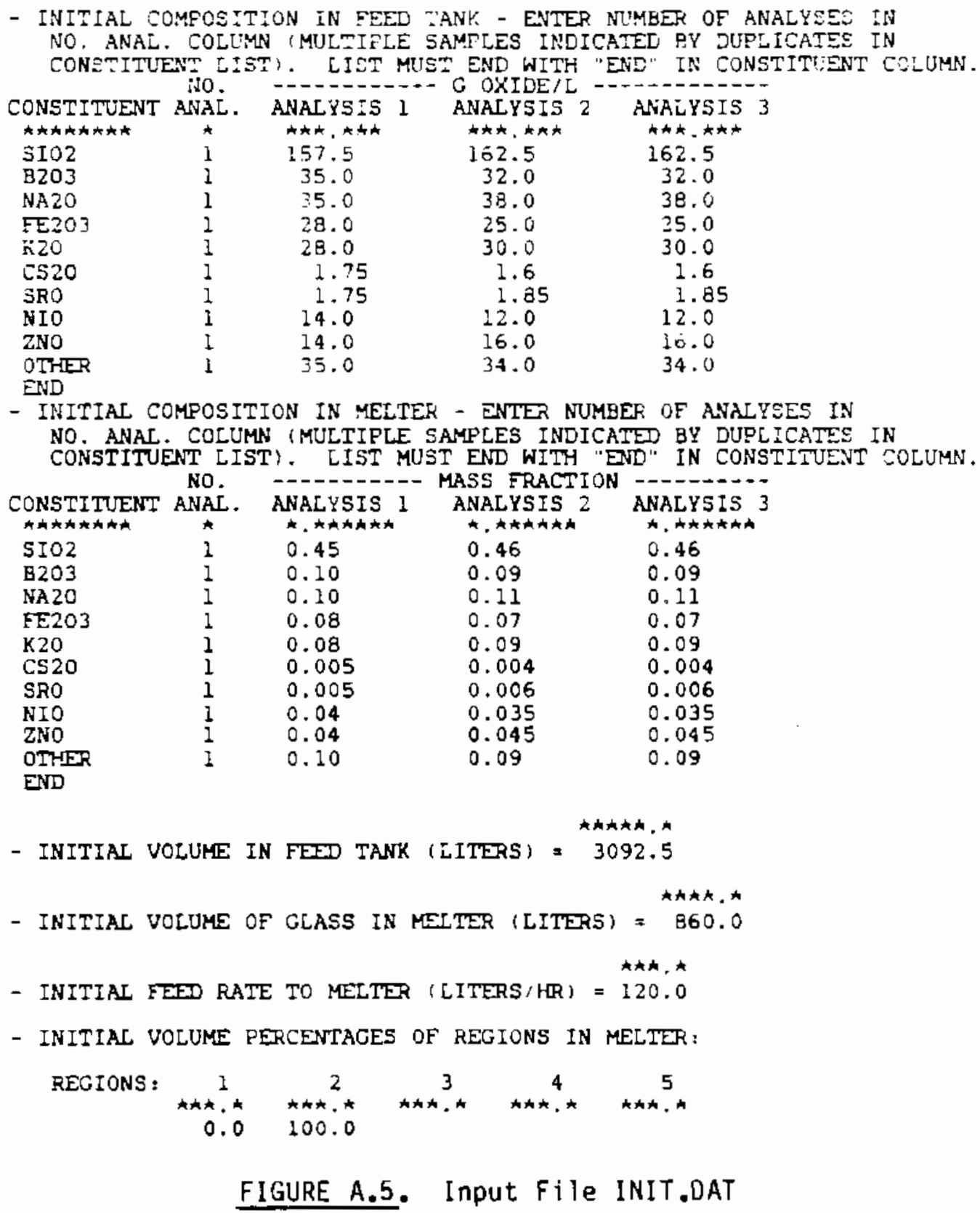


- MODE OF GPERATION:

3 = DETEHMNISTIC . JEING TROCESS DATA

2 = STOCHAITIC USINC FROCESS DATA

3 = STOCHASTIC USING RANDOMLY GENERATED DATA

MODE $=\stackrel{\star}{2}$

- LENGTH OF SIMULATION (HOURS) $=200 . \hat{0}$

- NUMBER OF REFEAT SIMULATIONS (DEFAULTS TO 1 IF MODE $=$ i) $=\begin{gathered}\star \star \star \\ 1\end{gathered}$

- TIME INTERVAL FOR RECORDING COMPOSITION IN MELTER (HRS) $=5.0$

- IF MODE 1 OR 2 IS CHOSEN. COMPOSITION OF FUTURE BATCHES OF FED:

1 = TARGET COMPOSITION

2 = SAME COMPOSITION AS LAST BATCH OF FEED

COMPOSITION $=\stackrel{i}{i}$

- IF 2 IS CHOSEN IN PRECEDING INPUT, HOW MANY BATCHES OF FEED SHOULD HAVE THIS COMPOSITION?

NUMBER OF BATCHES $=10$

- NUMBER OF SAMPLES OF FEED PER BATCH (CHOOSE 1 TO 5$)=1$

- NUMBER OF ANALYSES PER SAMPLE OF FEED (CHOOSE I TO 3 ) $=$ *

- OPTION FOR MODELING MIXING BEHAVIOR OF MELTER:

$I=I$ IDEALLY-MIXED REGION

$2=1$ PLUG FLOW FOLLOWED BY I OR 2 IDEALLY-MIYFD REGIONS IN SERIES

$3=2$ TO 5 IDEALLY-MIXED REGIONS IN SERIES

OPTION $=3$

- NUMBER OF IDEALLY-MIXED REGIONS IN MEITER:

IF OPTION I IS CHOSEN. INPUT IS IGNORED

IF OPTION 2 IS CHOSEN, MUST SPECIFY 1 OR 2

IF OPTION 3 IS CHOSEN, MUST SPECIFY 2 TO 5

NUMBER $\approx 2$

- VOLUME PERCENTAGES OF REGIONS IN MELTER:

IF OPTION I IS CHOSEN, INPUT IS IGNORED (100\% IS ASSUMED)

IF OPTION 2 IS CHOSEN, REGION 1 IS THE PLUG FLOW REGION

PERCENTAGES MUST ADD UP TO 100 OR ELSE ERROR MESSAGE WILL RESULT IDEALLY-MIXED REGIONS SHOULD BE ORDERED FROM SMALLEST TO LARGEST

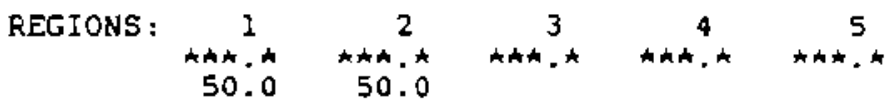

FIGURE A.7. Input File MODE.DAT 


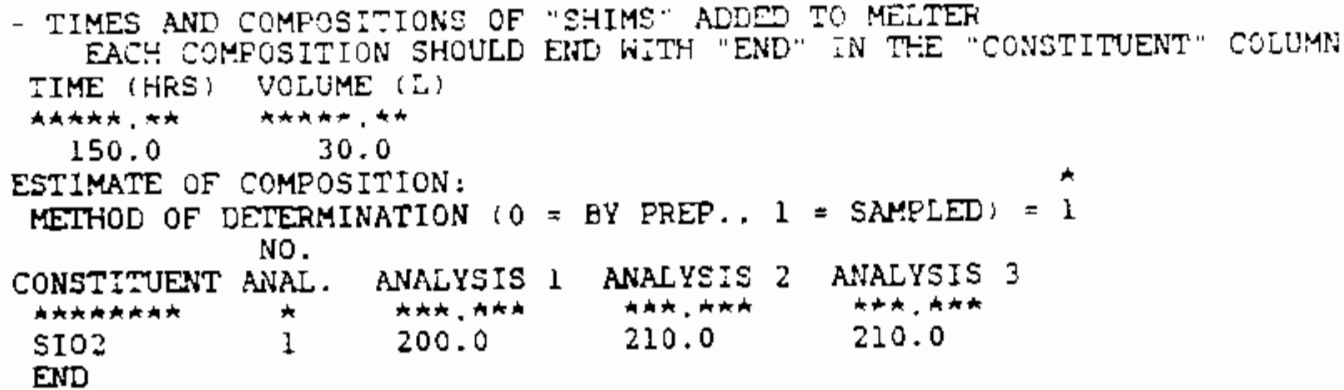

FIGURE A.8. Input file MSHIM.DAT

- TIMES AND ANAEYSES OF ÜF-GAE SAMPLES

FOR RESULTS OF COMFOSITYONAL AMIALYSES, ENTER TUE NUMEER OF ANALYSES IN NO. ANAL. COLUMN. SPESIFY MULTIPLE SAMFIES E IN THE CONSTITUENT LIST. CIST MUST END WITH "END" IN THE CONSTITUEN" COLUMN.

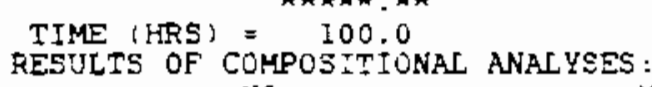

OTHER

END

$\begin{array}{ccc}\text { ANALYSIS 1 } & \text { MASS (GMS) } \\ \text { ANALIS 2 } & \text { ANALYSIS } 3 \\ 0.0 & 10.0 & 10.0 \\ 0.0 & 10.0 & 10.0 \\ 0.0 & 10.0 & 10.0 \\ 0.0 & 10.0 & 10.0 \\ 0.0 & 10.0 & 10.0 \\ 0.0 & 10.0 & 10.0 \\ 0.0 & 10.0 & 10.0 \\ 0.0 & 10.0 & 10.0 \\ 0.0 & 10.0 & 10.0 \\ 0.0 & 10.0 & 10.0\end{array}$

FIGURE A.9. Input file OFFGAS.DAT 


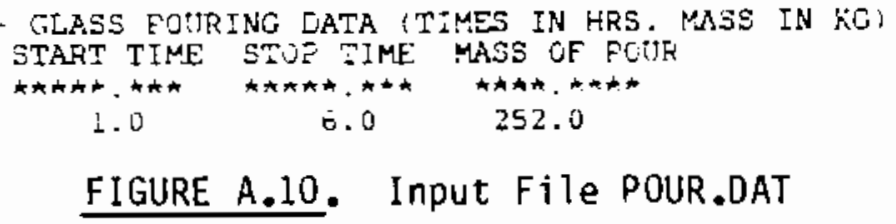

FIGURE A.10. Input File POUR.DAT 
- WHEN SPECIFYING A DISTRIBUTION, USE THE FCLLOWING LESEND: 1. CONETANT (NO DISTRIBUTION)

2. NORMAL

3. UNIFORM (SYMMETRICAL)

4. THIANGULAR (SYMEETKICAL)

5. LOG-NORMAL

6. GAMMA

7. BETA

8. EXPONENTIAL

9. GENERAL UNIFORM

10. GENERAL TRIANGJLAR

TIME DISTRIBUTION (CHOOSE 1 TO 4$)=2$

TIME STANDARD DEVIATION (HOURS) $=0.001$

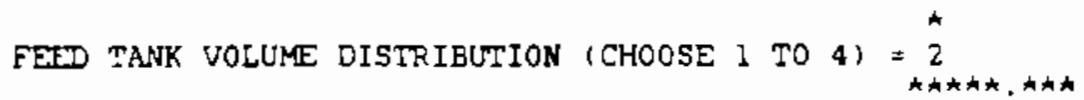

FEED TANK VOLUME STANDARD DEVIATION (LITERS) $=100.0$

FEED RATE DISTRIBUTION (CHOOSE I TO 4 ) $=2$

FEED RATE STANDARD DEVIATION (LITERS/HR)

GLASS POUR MASS DISTRIBUTION (CHOOSE I TO 4 ) $=2^{\star}$

GLASS POUR MASS STANDARD DEVIATION $(\mathrm{KG})=0.01$

GLASS FORMER ADDITION DISTRIBUTION (CHOOSE 1 TO 4 ) $=$ *

GLASS FORMFR ADDITION STANDARD DEVIATION (LITERS) $={ }^{\star \star \star *}, 5^{\star \star \star}$

MELTER GLASS VOLUME DISTRIBUTION (CHOOSE I TO 4 ) $==_{\star \star \star}^{2}$

MELTER GLASS VOLUME STANDARD DEVIATION (LITERS) $=10.0$

SLURRY SAMPLING ERROR (CHOOSE I TO 4 FOR DISTRIBUTION)

CONSTITUENT DIST. STD. DEV (q)

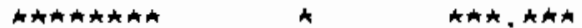

$5502 \quad 2.0$

$8203 \quad 2.0$

NA2O 34.0

$\begin{array}{lll}\mathrm{FE} 203 & 4 & 5.0\end{array}$

$\begin{array}{lll}\mathrm{K} 2 \mathrm{O} & 2 & 1.0\end{array}$

$\begin{array}{lll}\mathrm{CS} 20 & 2 & 3.0\end{array}$

SRO

NIO

ZNO

OTHER

2.223

10.0

END

SLURRY ANALYTICAL ERROR (CHOOSE I TO 4 FOR DISTRIBUTION) CONSTITUENT DIST. STD. DEV (क)

FIGURE A.II. Input File STOCH.DAT 


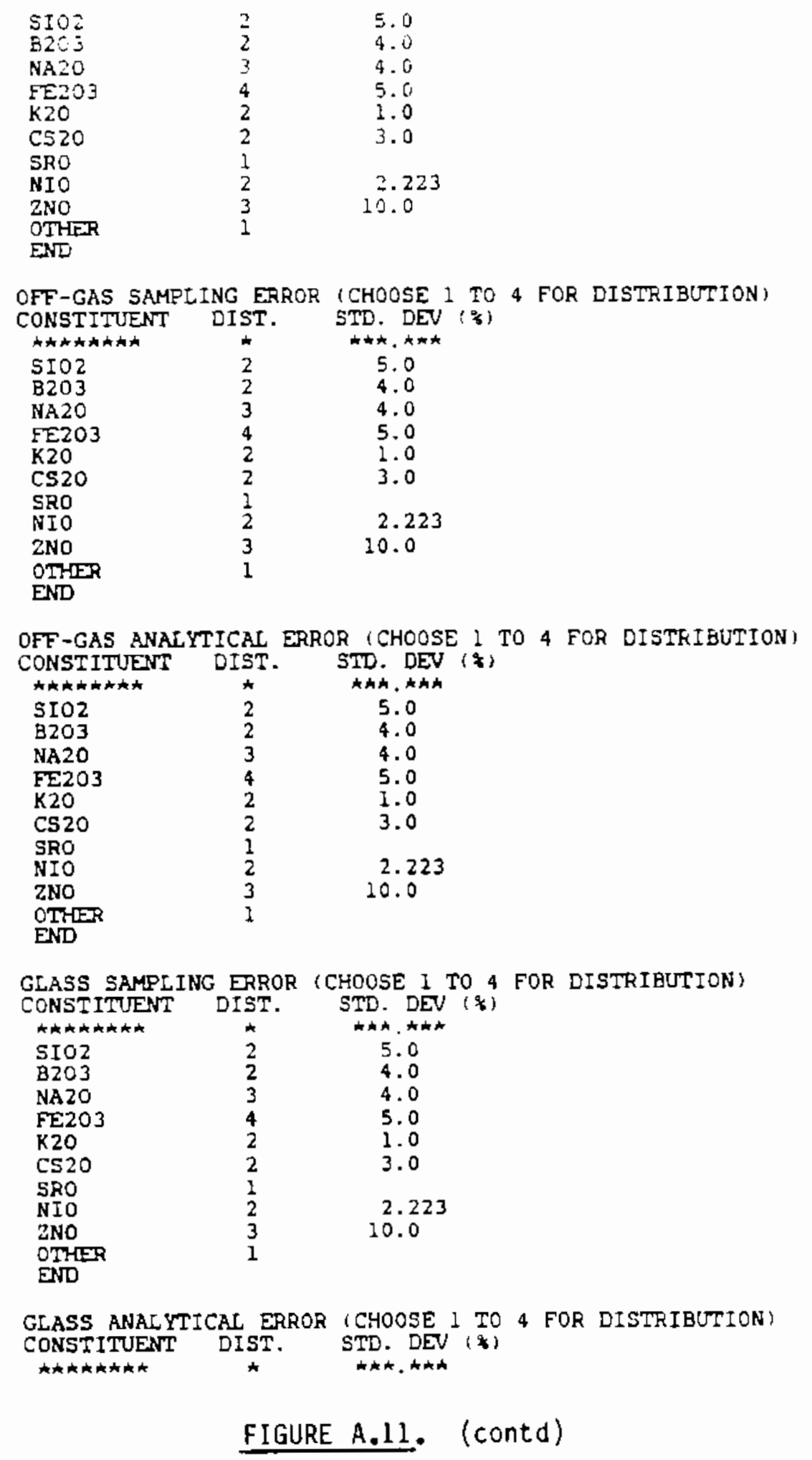




\begin{tabular}{|c|c|c|}
\hline $\begin{array}{l}\text { SIO2 } \\
\text { B2O3 } \\
\text { NA2O } \\
\text { FE203 } \\
\text { K20 } \\
\text { CS20 } \\
\text { SRO } \\
\text { NIO } \\
\text { ZNO } \\
\text { OTHER } \\
\text { END }\end{array}$ & $\begin{array}{l}2 \\
2 \\
3 \\
4 \\
2 \\
2 \\
1 \\
2 \\
3 \\
1\end{array}$ & $\begin{array}{l}5.0 \\
4.0 \\
4.0 \\
5.0 \\
1.0 \\
3.0 \\
2.223 \\
10.0\end{array}$ \\
\hline $\begin{array}{l}\text { SHIM PREPARATION } \\
\text { CONSTITUENT DI } \\
5102 \\
\text { E203 } \\
\text { NA20 } \\
\text { FE203 } \\
\text { K20 } \\
\text { CS20 } \\
\text { SRO } \\
\text { NIO } \\
\text { 2NO } \\
\text { OTHER } \\
\text { END }\end{array}$ & $\begin{array}{l}\text { ERROR } \\
\text { IST. } \\
2 \\
2 \\
3 \\
4 \\
2 \\
2 \\
1 \\
2 \\
3 \\
1\end{array}$ & $\begin{array}{l}\text { (CHOOSE I TO } 4 \text { FOR DISTRIBUTION) } \\
\text { STD. DEV (\$) } \\
5.0 \\
4.0 \\
4.0 \\
5.0 \\
1.0 \\
3.0 \\
2.223 \\
10.0\end{array}$ \\
\hline
\end{tabular}

- FOR THE EOLLOWING DISTRIBUTIONS, A, B, AND C MUST BE SPECIFIED AS FOLLOWS:

$$
\text { DIST. }
$$<smiles>C[Te]</smiles>

1
2
5
6
7
8
9
10

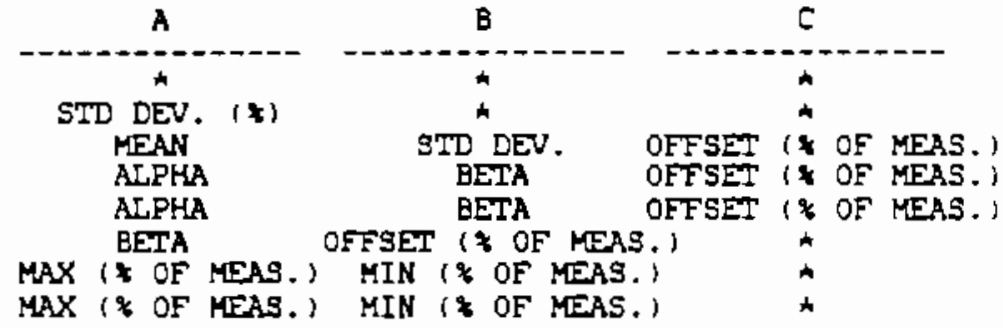

BATCH-TO-BATCH FEED VARIATION $T$ UEE ANY OISTRIEUTION EXCEPT 3 OR 4 ) CONSTITUENT

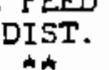

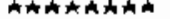

$\mathrm{SIO} 2$

B203

NA2O

FE203

$\mathrm{K} 20$

C520

SRO

NIO

ZNO

OTHER

END

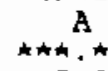

5.0

4.0

2.0

2.0

2.0

0.5

5.0

10.0

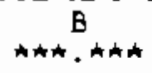

0.5

3.0

5.0

10.0

10.0

STEAM JET VOLUME CORRECTION FACTOR DISTRIBUTION (USE ANY DISTRIBUTION EXCEPT 3 OR 4)

$$
\text { DIST. }
$$

10
A

15.0

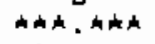

10.0

FIGURE A.11. (contd) 


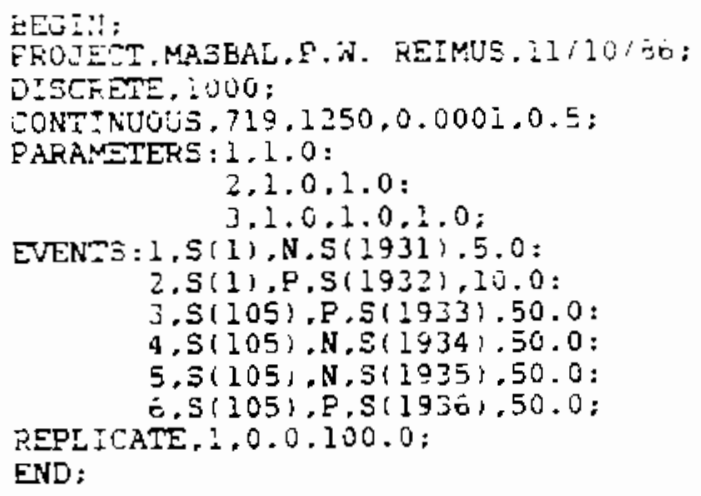

FIGURE A.12. SIMAN Experiment File MASBAL .EXP 
APPENDIX B

EXAMPLES OF OUTPUT FILES 


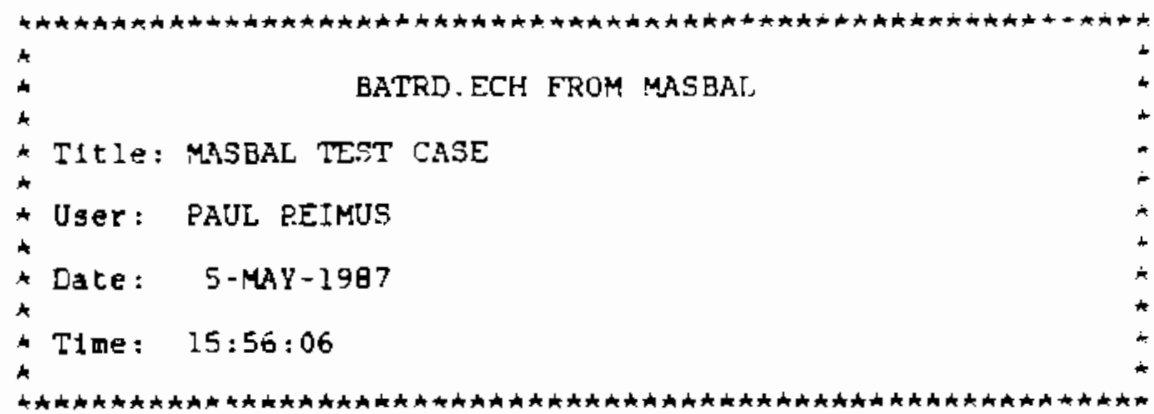

START TIME OF BATCH TO FEED TANK (HR) $=10.001$

STOP TIME OF BATCH 20 FEFD TANK ( $\mathrm{HR}$ ) $=11.420$

VOLUML IN EEED TANK PRIOR TO BATCH (L) $=1819.642$

VOLUME IN FEED TANK AFTER BATCH $(L)=18947.949$

FIGURE B.1. Output File BATRD.ECH 


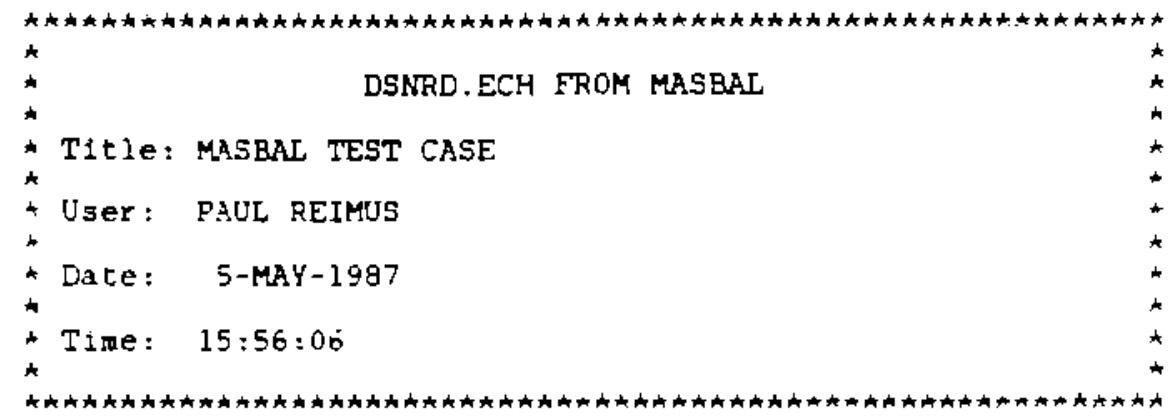

TARGET GLASS COMPOSITION AND DECON. FACTORS

CONSTITUENT MASS FRAC. DECON. FACTOR

$\begin{array}{llr}\text { SIO2 } & 0.450000 & 520.00 \\ \text { B203 } & 0.100000 & 47.00 \\ \text { NA20 } & 0.100000 & 280.00 \\ \text { FE203 } & 0.090000 & 300.00 \\ \text { K2O } & 0.090000 & 280.00 \\ \text { CS20 } & 0.005000 & 97.00 \\ \text { SRO } & 0.005000 & 430.00 \\ \text { NIO } & 0.040000 & 140.00 \\ \text { ZNO } & 0.040000 & 560.00 \\ \text { OTHER } & 0.100000 & 400.00\end{array}$

TARGET OXIDE LOADING OF FEED $(\mathrm{G} / \mathrm{L})=350.00$

TARGET FEED DENSITY (G/CMI) $=1.2500$

TARGET GLASS DENSITY $(\mathrm{G} / \mathrm{CM} 3)=2.8000$

VOLUME CORRECTION FOR STEAK JET (L FEED/L MAKEUP) $=1.0700$

TRANSFER RATE FROM MAKEUP TANK TO FEED TANK $(\mathrm{L} / \mathrm{HR})=12000.00$

RATE OF ADDITION OF "SHIMS" (L/HR) $=12000.00$

DESIGN FEED RATE TO HELTER $(L / H R)=120.000$

DESIGN GLASS POURING RATE (KC/HR) $=50.400$

DURATION OF EACH GLASS POUR $(H R)=5.0000$

TIME BETWEEN POURS (STOP TO START, HR) $=1.0000$

VOLUME IN FEED TANK AFTER FILLINC $\langle\mathrm{L}\rangle=I B 925.00$

VOLUME OF HEFT IN FEFD TANK (L) $=1892.50$

DESIGN WORKING VOLUNE OF MELTER (L) $=860.00$

MAXIMUS VOLUME OF CLASS IN MELTER $(\mathrm{L})=1000.00$

MINIMUM VOLUME OF GLASS IN MELTTER (C) $=700.00$

PARAMEIER FOR ADJUSTMENT OF TIME CONSTANT $=2.0$

FIGURE B.2. Output File DSNRO.ECH 


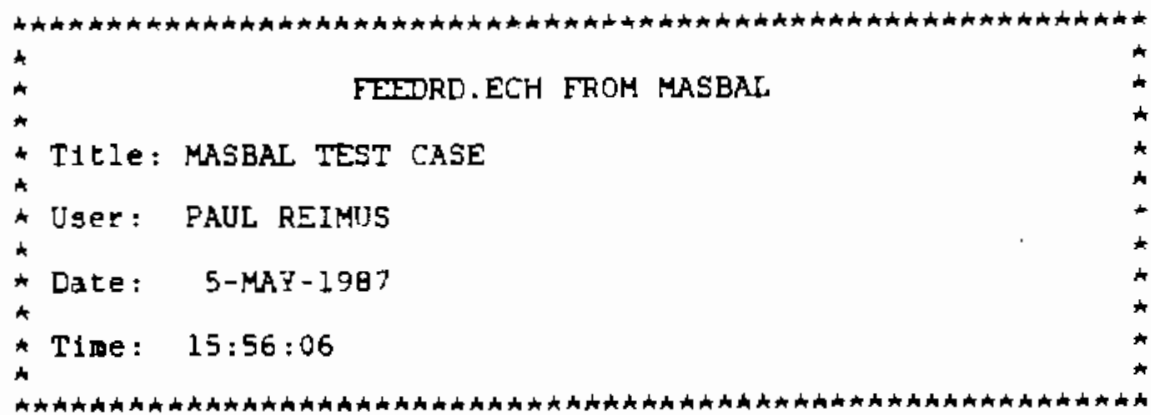

TIME OF INITIAL EEED RATE CHANGE (HR) $=20.001$

RATE AFTER CHANGE $([/ \mathrm{HR})=134.443$

FIGURE B.3. Output File FEEDRD.ECH

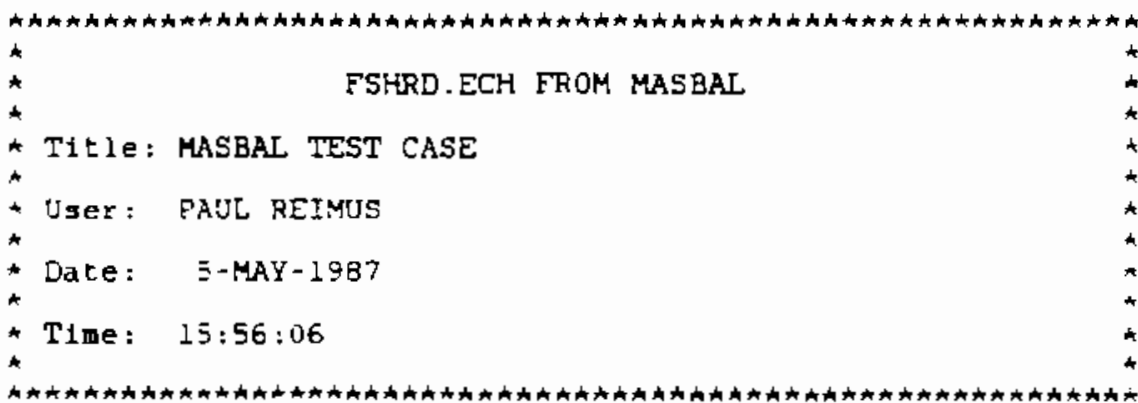

TIME OF FIRST FEED SHIM = 50.001

VOLUME OF FIRST FEED SHIM $=27.803$

FIGURE B.4. Output File FSHRD.ECH 


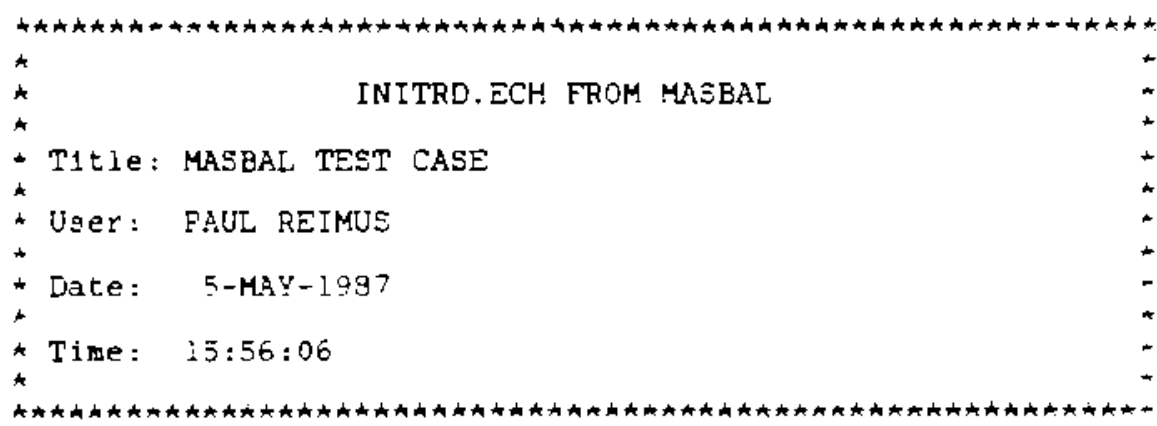

INITIAL FEED COMPOSITION DATA

$\begin{array}{llrrr}\text { CONSTITUENT } & \text { N } & \text { ANALYSIS } 1 & \text { ANALYSTS } & \text { ANALYSIS } 3 \\ & & & & \\ \text { SI02 } & 1 & 157.500 & 162.500 & 162.500 \\ \text { B203 } & 1 & 35.000 & 32.000 & 32.000 \\ \text { NA20 } & 1 & 35.000 & 38.000 & 38.000 \\ \text { FE203 } & 1 & 28.000 & 25.000 & 25.000 \\ \text { K20 } & 1 & 28.000 & 30.000 & 30.000 \\ \text { C520 } & 1 & 1.750 & 1.600 & 1.600 \\ \text { SR0 } & 1 & 1.750 & 1.850 & 1.850 \\ \text { NI0 } & 1 & 14.000 & 12.000 & 12.000 \\ \text { ZNO } & 1 & 14.000 & 16.000 & 16.000 \\ \text { OTHER } & 1 & 35.000 & 34.000 & 34.000 \\ \text { END } & 0 & 0.000 & 0.000 & 0.000\end{array}$

INITIAL GLASS COMPOSITION DATA

$\begin{array}{llrrr}\text { CONSTITUENT } & \text { N } & \text { ANALYSIS 1 } & \text { ANALYSIS 2 } & \text { ANALYSIS } 3 \\ \text { SI02 } & I & 0.450000 & 0.460000 & 0.460000 \\ \text { B203 } & 1 & 0.100000 & 0.090000 & 0.090000 \\ \text { NA20 } & 1 & 0.100000 & 0.110000 & 0.110000 \\ \text { EE203 } & 1 & 0.080000 & 0.070000 & 0.070000 \\ \text { K20 } & 1 & 0.080000 & 0.090000 & 0.090000 \\ \text { CS20 } & 1 & 0.005000 & 0.004000 & 0.004000 \\ \text { SRO } & 1 & 0.005000 & 0.006000 & 0.006000 \\ \text { NI0 } & 1 & 0.040000 & 0.035000 & 0.035000 \\ \text { ZNO } & 1 & 0.040000 & 0.045000 & 0.045000 \\ \text { OTHER } & 1 & 0.100000 & 0.090000 & 0.090000 \\ \text { END } & 0 & 0.000000 & 0.000000 & 0.000000\end{array}$

CALCULATED CONCENTRATIONS IN FEED TANK AND MELTER

$\begin{array}{lrrrrrr}\text { CONSTITUENT } & G \text { OX/L EFET } & \text { WT. FRAC. } & \text { NSF } & \text { NAF } & \text { NSG } & \text { NAG } \\ \text { SI02 } & 144.580 & 0.443343 & 1 & 1 & 1 & 1 \\ \text { B203 } & 34.198 & 0.107373 & 1 & 1 & 1 & 1 \\ \text { NA20 } & 34.681 & 0.096811 & 1 & 1 & 1 & 1 \\ \text { FE203 } & 27.770 & 0.078492 & 1 & 1 & 1 & 1 \\ \text { K20 } & 27.373 & 0.081999 & 1 & 1 & 1 & 1 \\ \text { C520 } & 1.662 & 0.005090 & 1 & 1 & 1 & 1 \\ \text { SRO } & 1.750 & 0.005204 & 1 & 1 & 1 & 1 \\ \text { NIO } & 14.075 & 0.039669 & 1 & 1 & 1 & 1 \\ \text { ZNO } & 15.163 & 0.037935 & 1 & 1 & 1 & 1 \\ \text { OTHER } & 35.000 & 0.104085 & 1 & 1 & 1 & 1\end{array}$

FIGURE B.5. Output File INITRD.ECH 
INITIAL VOLUME IN FESD TANK $(L)=\frac{3112.19}{\text { INITIAL VOLUME IN MELTER (L) }=848.77}$

INITIAL FEED RATE = 113.24

$=113.24$ IN METTEP $=0.0 .0$

INITIAL VOLUME \& OF RECIONS IN MELTER $=$

HIGH LEVEL IN FEED TANK (L) $=19028.723$

HIGH LEVE, IN METTES (GMS) = 2752984.250

FESTAFT FEED LEVE: IY MEITER (GMS) = 2622984.250

LOW LEVEL IN NETTEF: (GMS ${ }^{\prime}=1959675.000$

RESTART POUR LEVE: IN MELTER (GMS) = 2099675.000

FIGURE B.5. (contd)

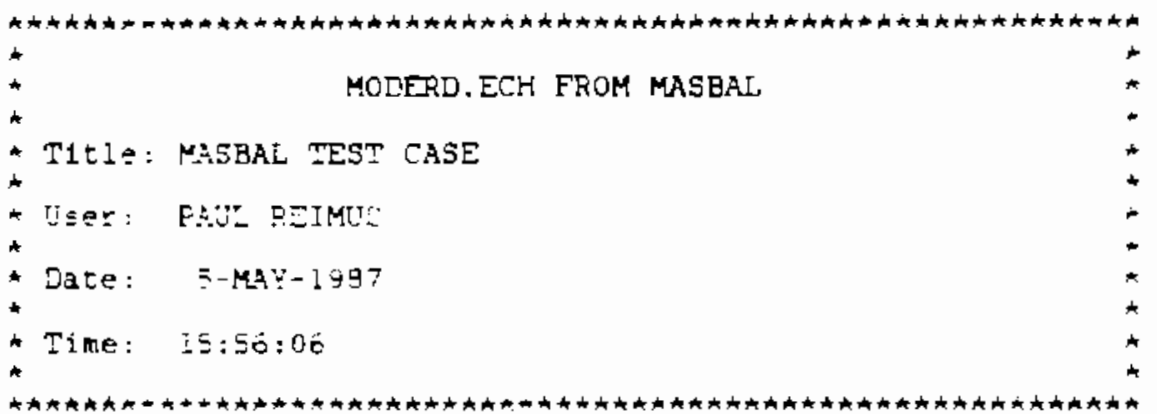

MODE $=2$

IENGTH OF SIMULA.TION $=200.0$

NUMEER OF REPEAT SIMULATIONS =

TIME INTERVAL FC? REOORDING COMPOS̈ITION $=5.0$

DPTION FOR FUTUPE BATCHES $=1$

IF MODE $=3$. OETION SET $=1$ IN PRIME

NUMBER OF BATCMES $=10$

NUMBER OF SAMPLES PER BATCH $=1$

NUMBER OF ANALYSES PER SAMPLE $=1$

OPTION FOR MODELING MELTER $=3$

-- THE FOLLOWING WILL BE IGNORED IF OPTION = 1 --

NUMBER OF IDEALL $i$-MIXED REGIONS $=z$

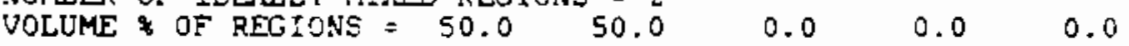

\section{FIGURE B.6. Output File MODERD.ECH}




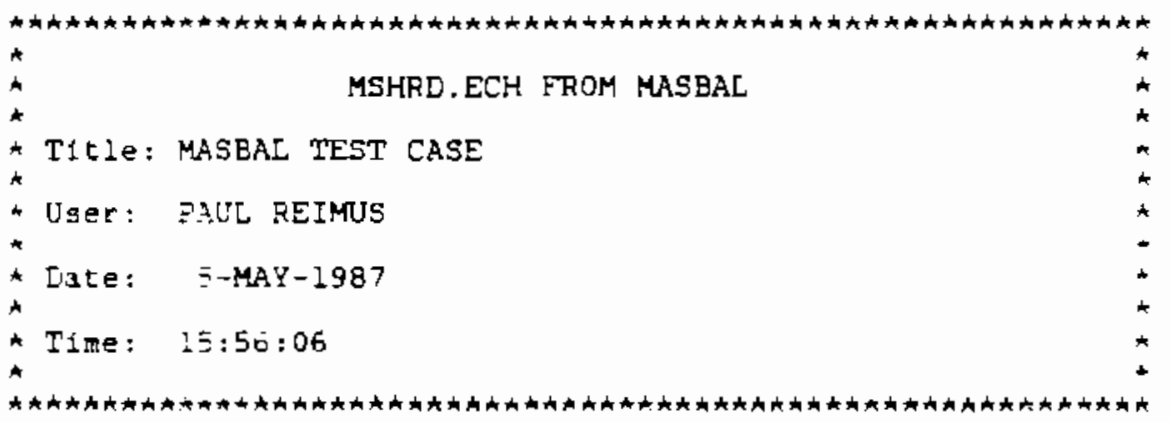

IIME OF TIRST MERTE SHIM $=149.999$

VOLUME OF FIRST MEITEE SHIM $=28.672$

FIGURE B.7. Output File MSHRD.ECH

B. 6 


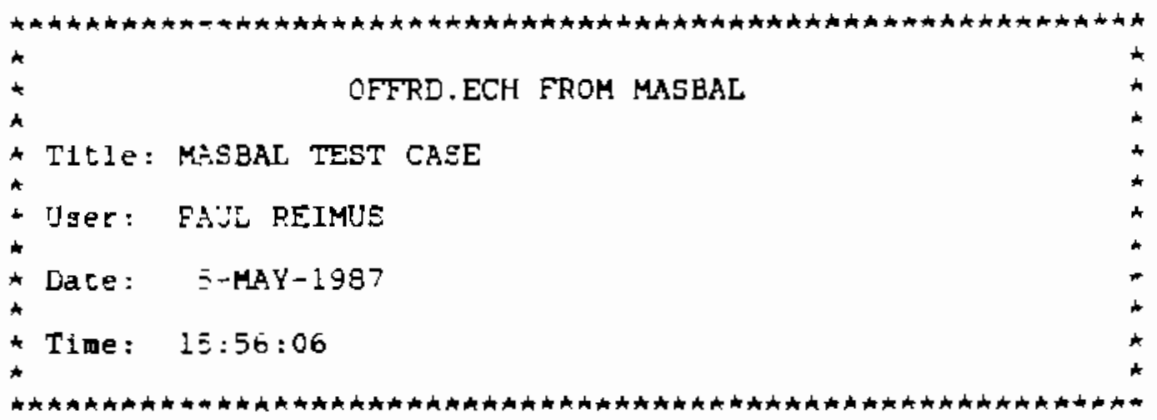

INITIAL DATA FROM OFF-GAS SYSTEM

$\begin{array}{llrrr}\text { CONSTITUENT } & N & \text { ANALYSIS I } & \text { ANALYSIS } 2 & \text { ANALYSIS I } \\ & & & & \\ \text { SIO2 } & 1 & 0.0000 & 10.0000 & 10.0000 \\ \text { B203 } & 1 & 0.0000 & 10.0000 & 10.0000 \\ \text { NA20 } & 1 & 0.0000 & 10.0000 & 10.0000 \\ \text { FE203 } & 1 & 0.0000 & 10.0000 & 10.0000 \\ \text { K20 } & 1 & 0.0000 & 10.0000 & 10.0000 \\ \text { CS20 } & 1 & 0.0000 & 10.0000 & 10.0000 \\ \text { SR0 } & 1 & 0.0000 & 10.0000 & 10.0000 \\ \text { NIO } & 1 & 0.0000 & 10.0000 & 10.0000 \\ \text { ZNO } & 1 & 0.0000 & 10.0000 & 10.0000 \\ \text { OTHER } & 1 & 0.0000 & 10.0000 & 10.0000 \\ \text { END } & 0 & 0.0000 & 0.0000 & 0.0000\end{array}$

TIME WEN OFF-GAS SAMPLE WAS TAKEN (HR) $x 100.001$

CALCULATED VOLATILIZATION RATES

$\begin{array}{lccc}\text { CONSTITUENT } & \text { VOLAT RATE } & \text { NSAMO } & \text { NANLO } \\ \text { SI02 } & 0.0000 & 1 & 1 \\ \text { B203 } & 0.0000 & 1 & 1 \\ \text { NA20 } & 0.0000 & 1 & 1 \\ \text { FE203 } & 0.0000 & 1 & 1 \\ \text { K20 } & 0.0000 & 1 & 1 \\ \text { CS20 } & 0.0000 & 1 & 1 \\ \text { SRO } & 0.0000 & 1 & 1 \\ \text { NI0 } & 0.0000 & 1 & 1 \\ \text { 2NO } & 0.0000 & 1 & 1 \\ \text { OTHER } & 0.0000 & 1 & 1\end{array}$

FIGURE B.8. Output File OFFRD.ECH 


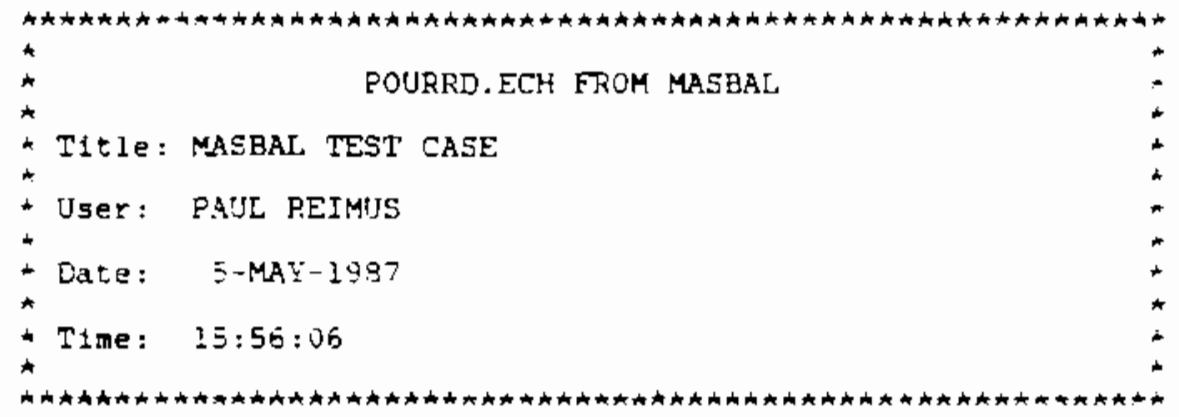

IIME OF STARTING, INITIAT POUR $\mathrm{HR} ;=1.001$ IIME OF STOPPING INITIAL POUR $(\mathrm{HR})=5.000$

MASS OF INITIAL POUK $(K G)=252.003$

FIGURE B.9. Output File POURRD.ECH

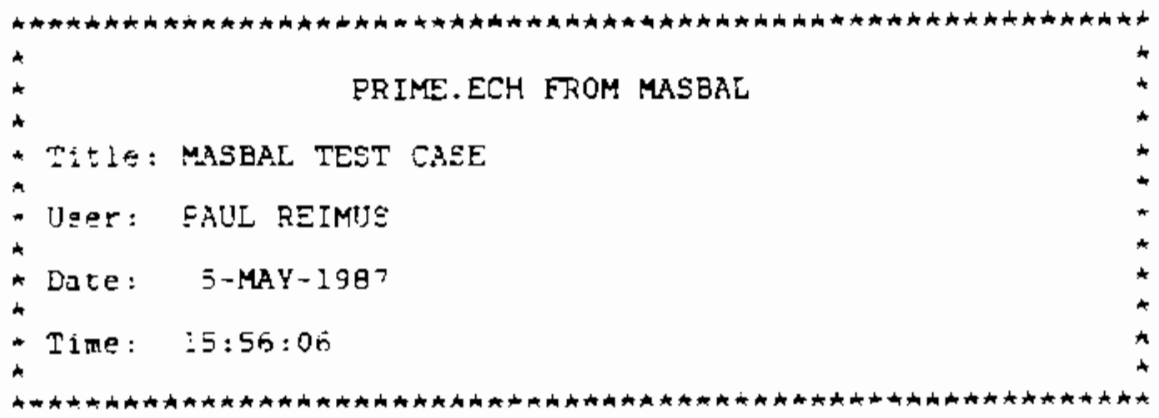

ECHO FROM PAIME.FOF - ONLY FOP MODE :

FIGURE B.10. Output File PRIME.ECH

B.8 


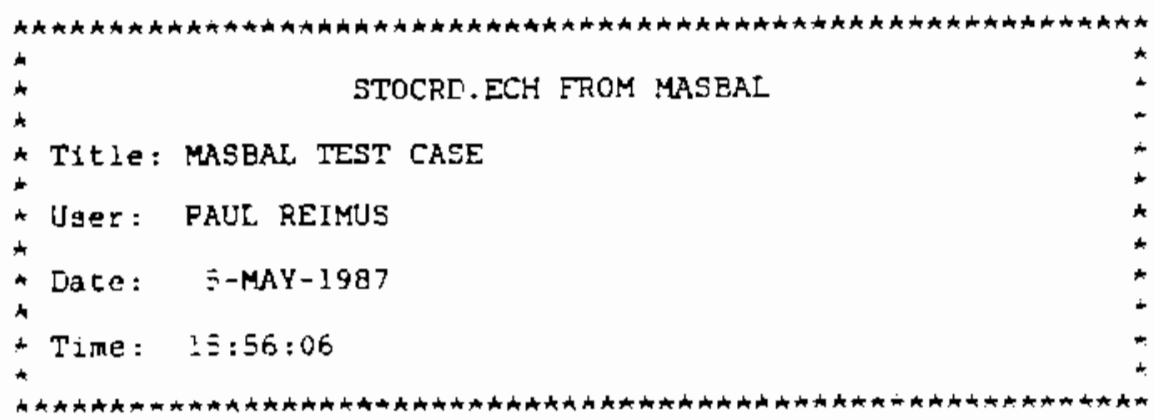

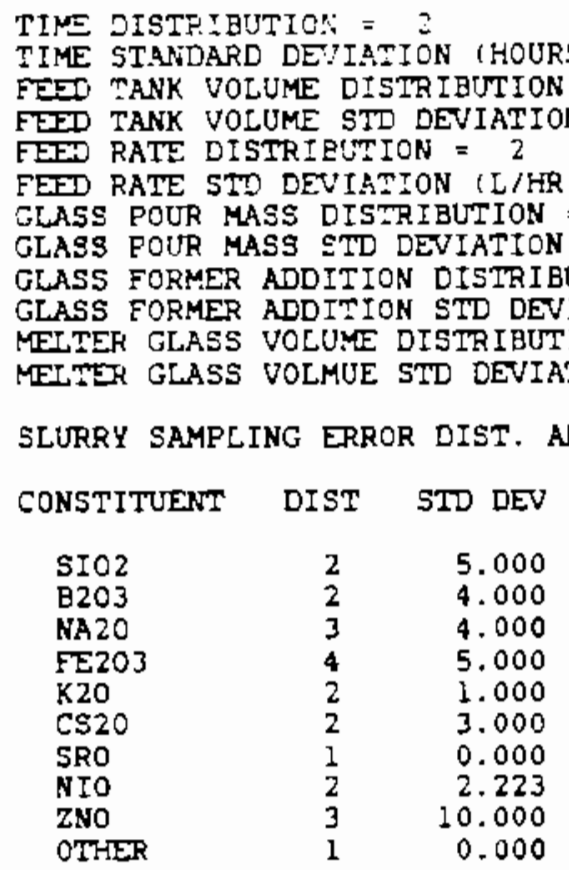

SLURRY ANALYTICAL ERROR DIST. AND STD. DEV.

$\begin{array}{lrr}\text { CONSTITUENT } & \text { DIST } & \text { STD DEV } \\ \text { SIO2 } & 2 & 5.000 \\ \text { B203 } & 2 & 4.000 \\ \text { NA20 } & 3 & 4.000 \\ \text { FE203 } & 4 & 5.000 \\ \text { K20 } & 2 & 1.000 \\ \text { CS20 } & 2 & 3.000 \\ \text { SRO } & 1 & 0.000 \\ \text { NIO } & 2 & 2.223 \\ \text { ZNO } & 3 & 10.000 \\ \text { OTHER } & 1 & 0.000\end{array}$

OFF GAS SAMPLING ERROR DIST. AND STD. DEV. CONSTITUENT DIST STD DEV

FIGURE B.11. Output File STOCRD.ECH 


$\begin{array}{llr}\mathrm{SIO2} & 2 & 5.000 \\ \mathrm{~B} 203 & 2 & 4.000 \\ \mathrm{NA} 20 & 3 & 4.000 \\ \mathrm{FE} 203 & 4 & 5.000 \\ \mathrm{~K} 20 & 2 & 1.000 \\ \mathrm{C} S 20 & 2 & 3.000 \\ \mathrm{~S} 20 & \vdots & 0.000 \\ \text { NIO } & \vdots & 2.223 \\ \text { ZNO } & 3 & 10.000 \\ \text { OTHER } & 3 & 0.000\end{array}$

JFF GAS ANALYTICAL ERROR DIST. AND STD. DEJ.

$\begin{array}{lrr}\text { CONSTITUENT } & \text { DIST } & \text { STD DEV } \\ \text { SIO2 } & 2 & 5.000 \\ \text { B203 } & 2 & 4.000 \\ \text { NA20 } & 3 & 4.000 \\ \text { FE203 } & 4 & 5.000 \\ \text { K20 } & 2 & 1.000 \\ \text { C520 } & 2 & 3.000 \\ \text { SRO } & 1 & 0.000 \\ \text { NIO } & 2 & 2.223 \\ \text { ZNO } & 3 & 10.000 \\ \text { OTHER } & 1 & 0.000\end{array}$

GLASS SAMPLING ERROR DIST. AND STD. DEV.

$\begin{array}{lrr}\text { CONSTITUENT } & \text { DIST } & \text { STD DEV } \\ \text { SI02 } & 2 & 5.000 \\ \text { B203 } & 2 & 4.000 \\ \text { NA20 } & 3 & 4.000 \\ \text { FE203 } & 4 & 5.000 \\ \text { K20 } & 2 & 1.000 \\ \text { C520 } & 2 & 3.000 \\ \text { SRO } & 1 & 0.000 \\ \text { NIO } & 2 & 2.223 \\ \text { ZNO } & 3 & 10.000 \\ \text { OTHER } & 1 & 0.000\end{array}$

GLASS ANALYTICAL ERROR DIST. AND STD. DEV.

$\begin{array}{lrr}\text { CONSTITUENT } & \text { DIST } & \text { STD DEV } \\ \text { SI02 } & 2 & 5.000 \\ \text { B203 } & 2 & 4.000 \\ \text { NA20 } & 3 & 4.000 \\ \text { FE203 } & 4 & 5.000 \\ \text { K20 } & 2 & 1.000 \\ \text { CS20 } & 2 & 3.000 \\ \text { SRO } & 1 & 0.000 \\ \text { N1O } & 2 & 2.223 \\ \text { ZNO } & 3 & 10.000 \\ \text { OTHER } & 1 & 0.000\end{array}$

SHIM PREPARATION ERROR DIST, AND STD. DEV.

CONSTITUENT DIST STD DEV

FIGURE B.11. (contd) 


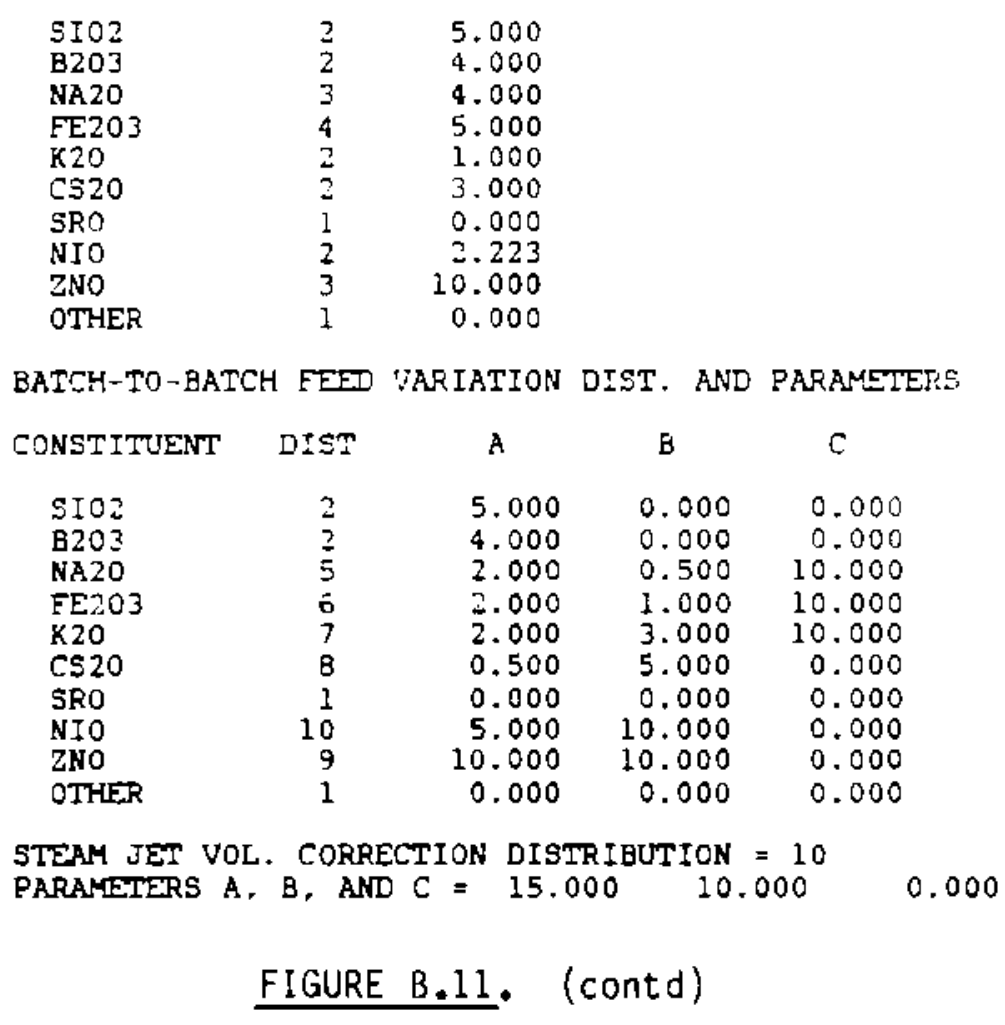



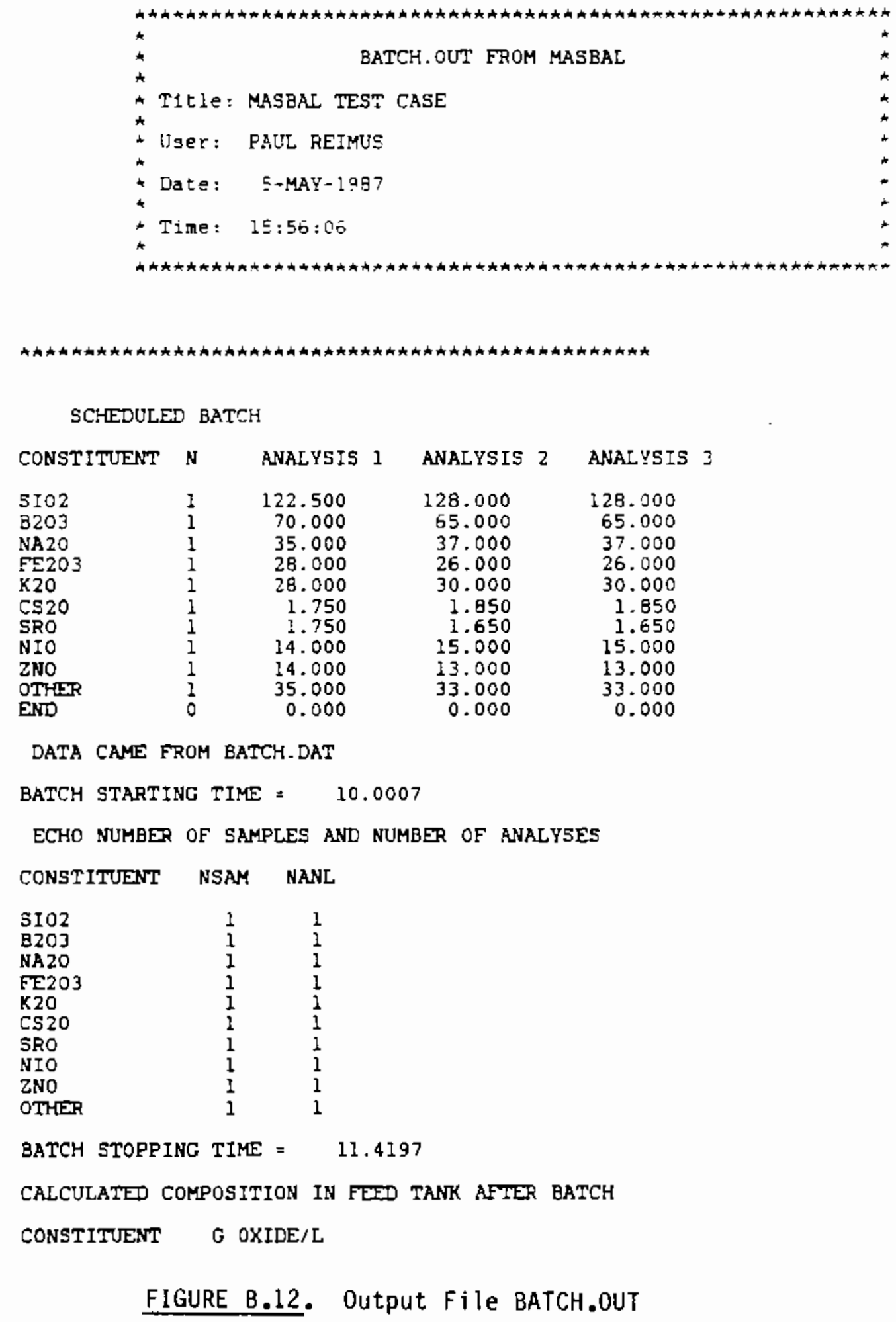


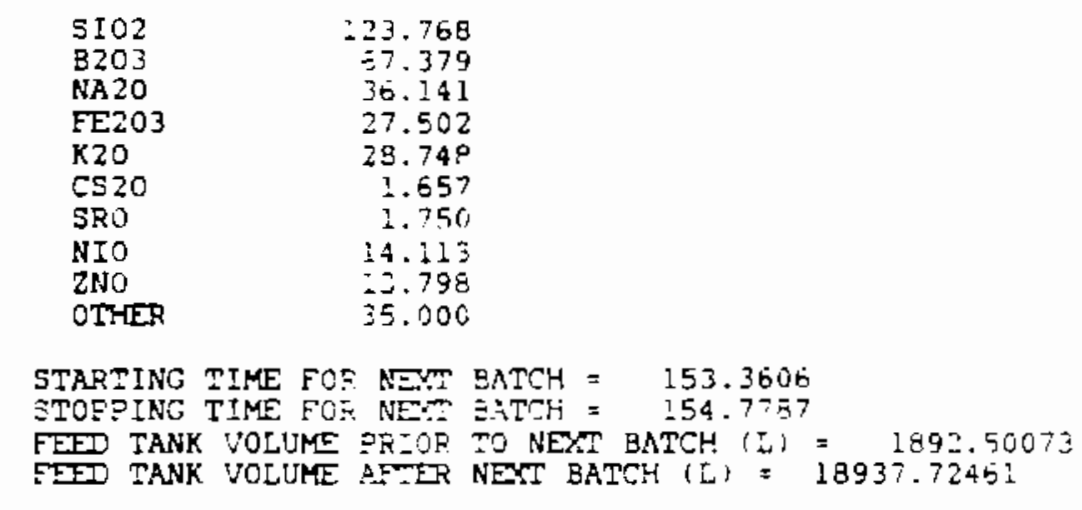

\begin{tabular}{|c|c|c|c|c|}
\hline \multicolumn{5}{|c|}{ SCHEDULED BATCH } \\
\hline CONSTITUENT & N & ANALYSIS 1 & ANALYSIS 2 & ANALYSIS \\
\hline $\begin{array}{l}\text { SIO2 } \\
\text { B203 } \\
\text { NA20 } \\
\text { FE203 } \\
\text { K2O } \\
\text { CS2O } \\
\text { SRO } \\
\text { NIO } \\
\text { ZNO } \\
\text { OTHER } \\
\text { END }\end{array}$ & $\begin{array}{l}1 \\
1 \\
1 \\
1 \\
1 \\
1 \\
1 \\
1 \\
1 \\
1 \\
0\end{array}$ & $\begin{array}{r}122.500 \\
70.000 \\
35.000 \\
28.000 \\
28.000 \\
1.750 \\
1.750 \\
14.000 \\
14.000 \\
35.000 \\
0.000\end{array}$ & $\begin{array}{r}128.000 \\
65.000 \\
37.000 \\
26.000 \\
30.000 \\
1.050 \\
1.650 \\
15.000 \\
13.000 \\
33.000 \\
0.000\end{array}$ & $\begin{array}{r}128.000 \\
65.000 \\
37.000 \\
26.000 \\
30.000 \\
1.050 \\
1.650 \\
15.000 \\
13.000 \\
33.000 \\
0.000\end{array}$ \\
\hline
\end{tabular}

DATA CAME FROH BATCH.DAT

BATCH STARTING TIME $=153.3606$

ECHO NUMBER OF SAMPLES AND NUMBER OF ANALYSES

CONSTITUENT RSAM NANL

$\begin{array}{lll}\text { S102 } & 1 & 1 \\ \text { H203 } & 1 & 1 \\ \text { NA20 } & 1 & 1 \\ \text { FE203 } & 1 & 1 \\ \text { K20 } & 1 & 1 \\ \text { CS20 } & 1 & 1 \\ \text { SRO } & 1 & 1 \\ \text { NIO } & 1 & 1 \\ \text { ZNO } & 1 & 1 \\ \text { OTHER } & 1 & 1\end{array}$

BATCH STOPPING TIME $=154.7787$

CALCULATED COMPOSITION IN FEED TANK AFTER BATCH

FIGURE B.12. (contd) 


\begin{tabular}{|c|c|}
\hline CONSTITUENT & $\mathrm{G} \quad \mathrm{OX}: \mathrm{DE} / \mathrm{L}$ \\
\hline $\begin{array}{l}\mathrm{SIO} 2 \\
\text { B203 } \\
\text { NA2O } \\
\text { FE203 } \\
\text { K2O } \\
\text { C520 } \\
\text { ERO } \\
\text { NIO } \\
\text { 2NO } \\
\text { OTHEO }\end{array}$ & $\begin{array}{r}128.627 \\
71.472 \\
32.996 \\
27.761 \\
2 E .466 \\
: .780 \\
\vdots .750 \\
1.518 \\
14.184 \\
3 E .000\end{array}$ \\
\hline
\end{tabular}

FIGURE B.12. (contd) 


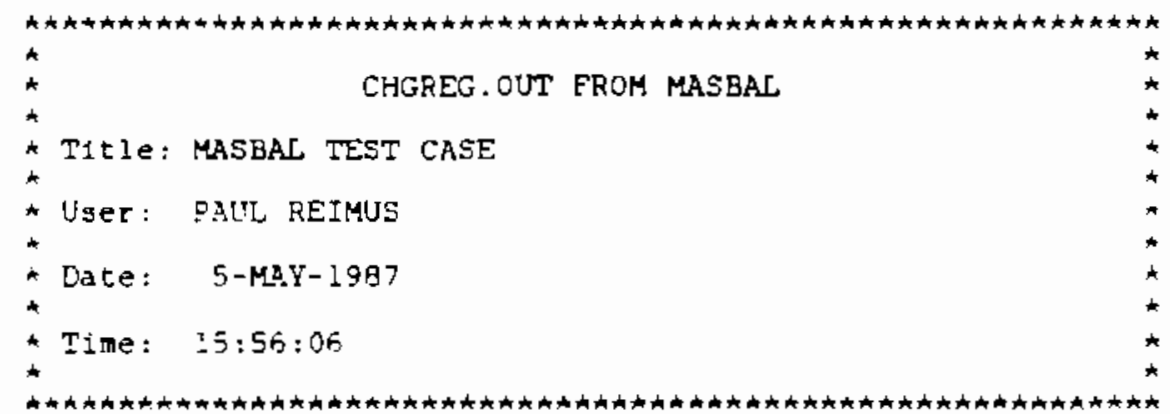

HISTORY OF CALLS TO SUEROUTINE CHGREG

TIME SUBROUTINE MAKING CALL

10.0110

10.0207

10.0221

10.0132

10.0221

10.0378

10.0457

10.0002

10.0850

10.0536

10.0850

10.1160

10.1314

10.1993

10.2088

10.1469

10.2088

10.2508

10.2718

10.3640

10.3769

10.2928

10.3769

10.4503

10.5576

10.5726

10.4747

10.5726

10.7684

10.7847

10.7847

11.0059

11. 0243

11.0243

20.0005

24.9993

149.9990

150.0014

153.4856

153.5481

153.8221

153.8606

153.6106

153.8606

154.3221

154.3606

154.1106

F드이

FEETEE

FEEDEQ

FEEDEQ

FEEDEQ

FEFDEQ

FEEDEQ

FEEDEQ

FESTEQ

FEEDEQ

FEEDEO

FEDEEQ

FEEDEQ

FEEDEO

FEEDEQ

FEEDEQ

FEEDEO

FEIDEO

FEEDEQ

FECTOEO

FEYDEO

FEEDEO

FEEDEQ

FEEDEQ

FEEDEO

FEEDEQ

FEEDEO

FEEDEO

FEEDEO

FEEDEO

FEFDEO

FEDEO

FEFDEO

FEFDEQ

CHFEED

CHFEED

MSHIY

MSTOP

FEDDEQ

FEEDEQ

FEEDEQ

FEFDEQ

FEEDEQ

STEDEO

FEFDEQ

FEDDEO

FEEDEO

FESER

FIGURE B.13. Output File CHGREG.OUT 


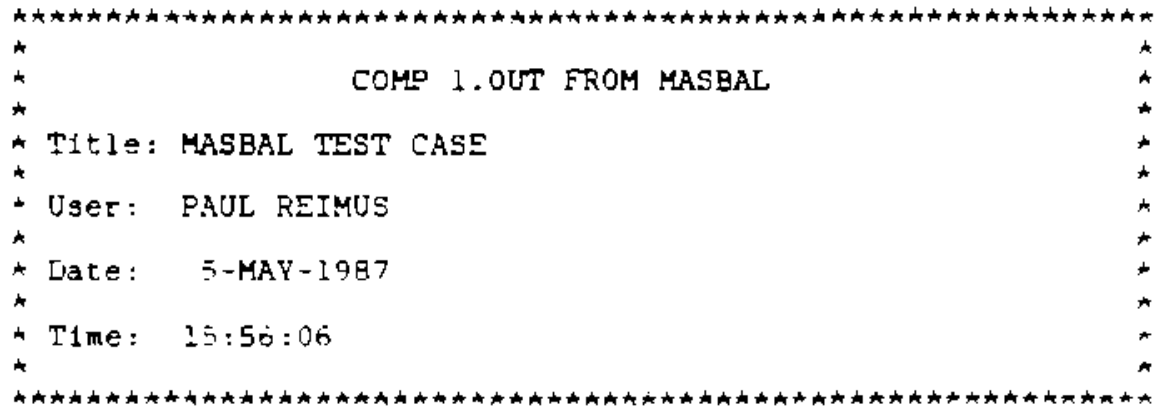

COMFOSITION IN LAST MELTEE REGION (MAES FPACTION)

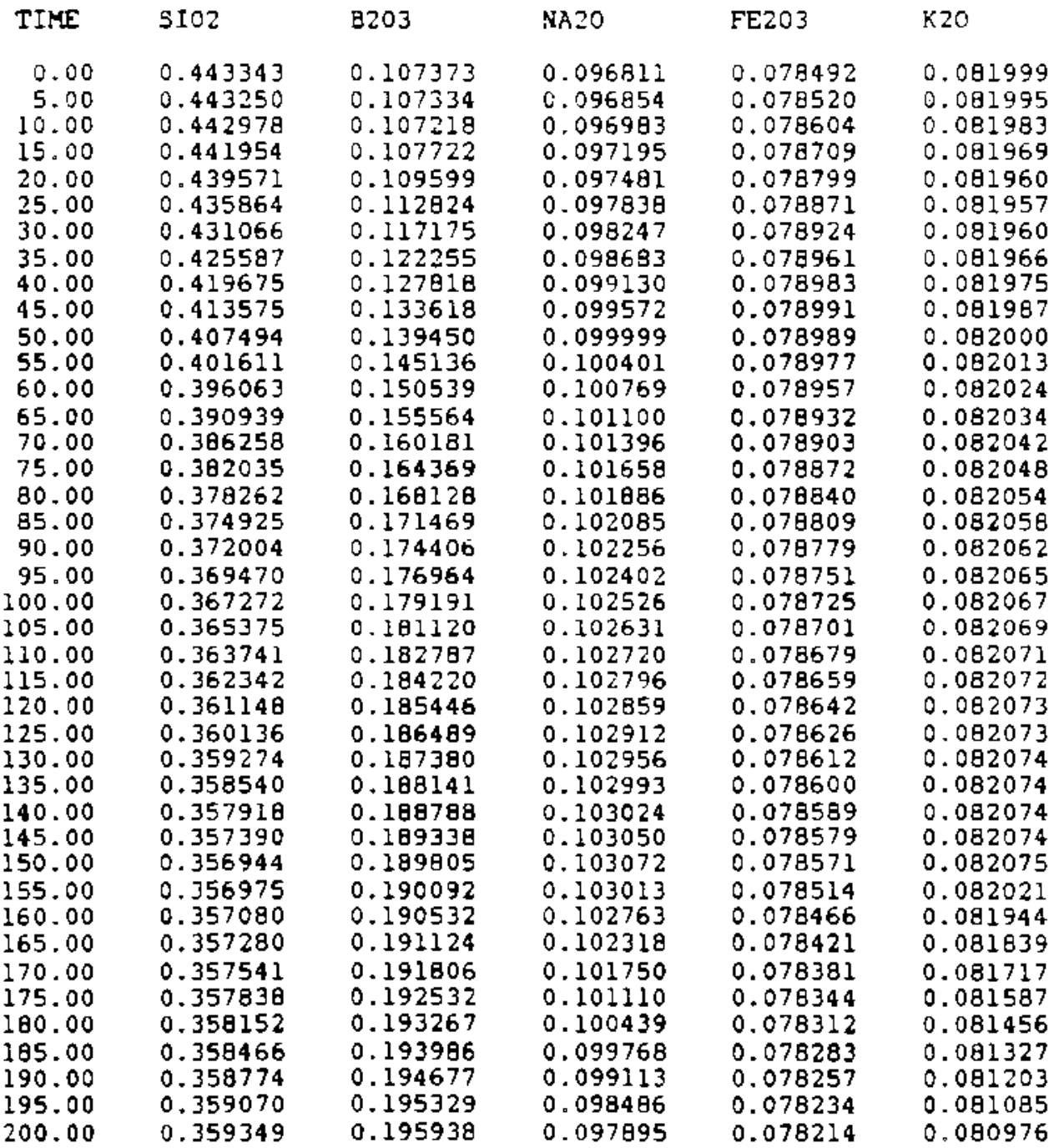

FIGURE B.14. Output File COMP 1.0UT 


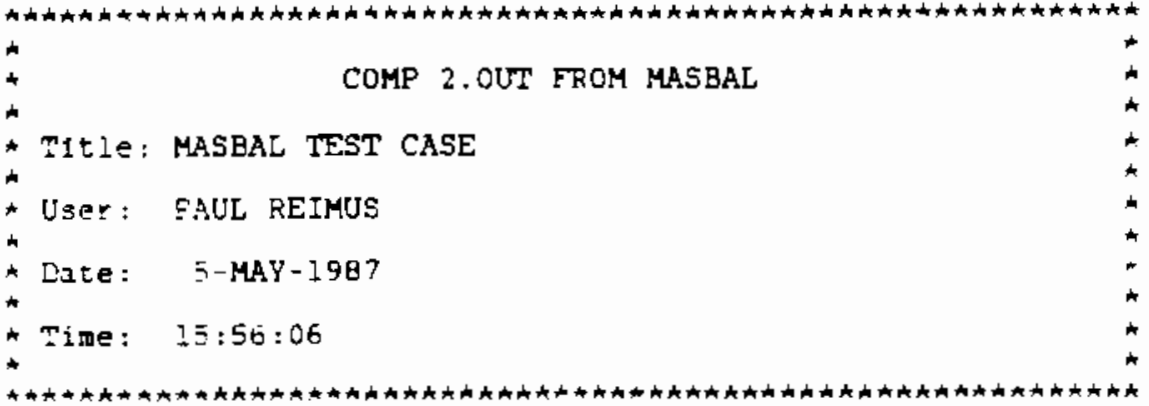

COMPOSITION IN LAST MELTER REGION (MASS FRACTION)

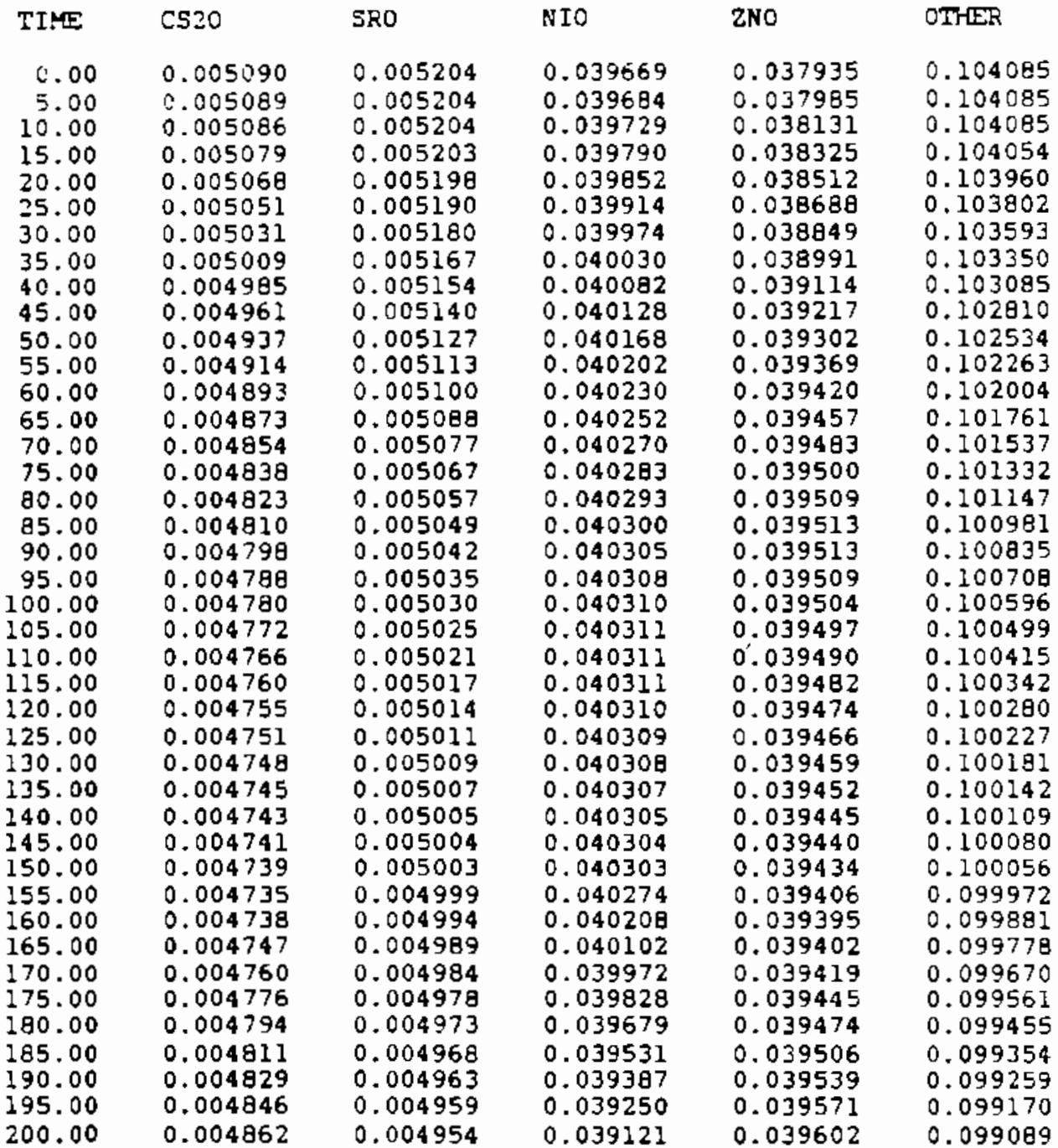

FIGURE B.15. Output File COMP 2.0UT 


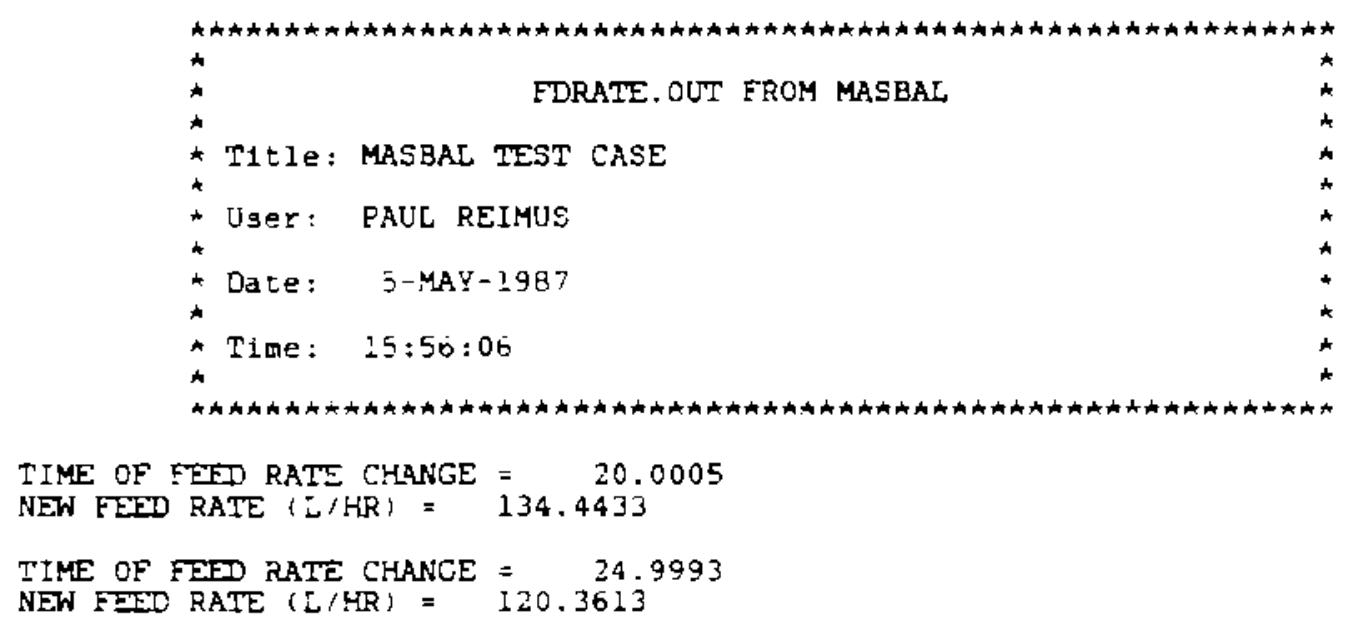

FIGURE B.16. Output File FDRATE.OUT 


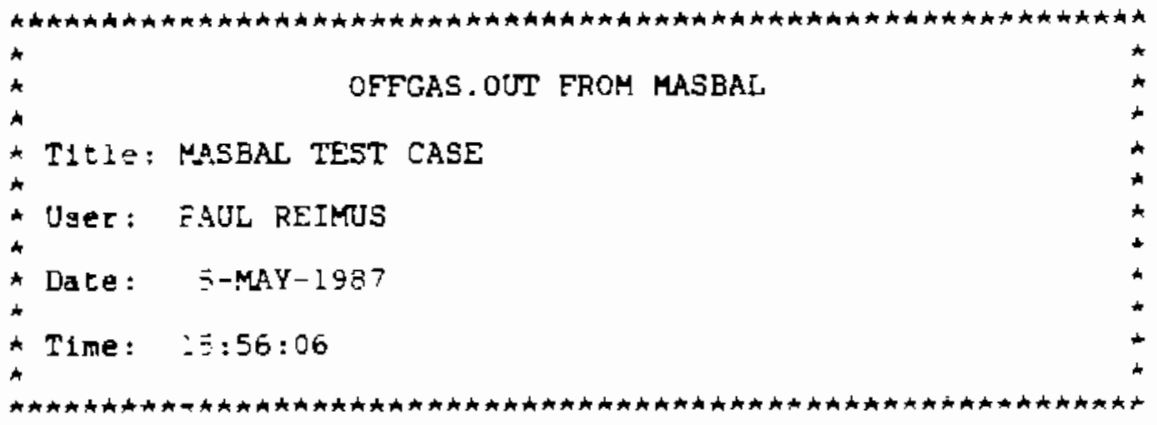

\begin{tabular}{|c|c|c|c|c|}
\hline NEW & $E T$ OF & OFF-GAS DATA & & \\
\hline CONSTITUENT & $\mathbf{N}$ & ANACYSIS I & ANACYSIS 2 & ANALYSIS 3 \\
\hline $\begin{array}{l}\text { SIO2 } \\
\text { B2O3 } \\
\text { NA2O } \\
\text { FE203 } \\
\text { K20 } \\
\text { CS20 } \\
\text { SRO } \\
\text { NIO } \\
\text { ZNO } \\
\text { OTHER } \\
\text { SND }\end{array}$ & $\begin{array}{l}1 \\
1 \\
1 \\
1 \\
1 \\
1 \\
1 \\
1 \\
1 \\
1 \\
0\end{array}$ & $\begin{array}{l}0.0000 \\
0.0000 \\
0.0000 \\
0.0000 \\
0.0000 \\
0.0000 \\
0.0000 \\
0.0000 \\
0.0000 \\
0.0000 \\
0.0000\end{array}$ & $\begin{array}{r}10.0000 \\
10.0000 \\
10.0000 \\
10.0000 \\
10.0000 \\
10.0000 \\
10.0000 \\
10.0000 \\
10.0000 \\
10.0000 \\
0.0000\end{array}$ & $\begin{array}{r}10.0000 \\
10.0000 \\
10.0000 \\
10.0000 \\
10.0000 \\
10.0000 \\
10.0000 \\
10.0000 \\
10.0000 \\
10.0000 \\
0.0000\end{array}$ \\
\hline
\end{tabular}

TIME UNTIL THE NEXT OFF-GAS SAMPLING $=200.0002$

CALCULATED VOLATILIZATION RATES UNTIL NEXT SAMPLE CONSTITUENT VOLAT. RATE

$\begin{array}{ll}\text { SIO2 } & 0.0000 \\ \text { B2O3 } & 0.0000 \\ \text { NA2O } & 0.0000 \\ \text { FE203 } & 0.0000 \\ \text { K2O } & 0.0000 \\ \text { CS20 } & 0.0000 \\ \text { SRO } & 0.0000 \\ \text { NIO } & 0.0000 \\ \text { ZNO } & 0.0000 \\ \text { OTHER } & 0.0000\end{array}$

FIGURE 8.17 . Output File OFFGAS.OUT 


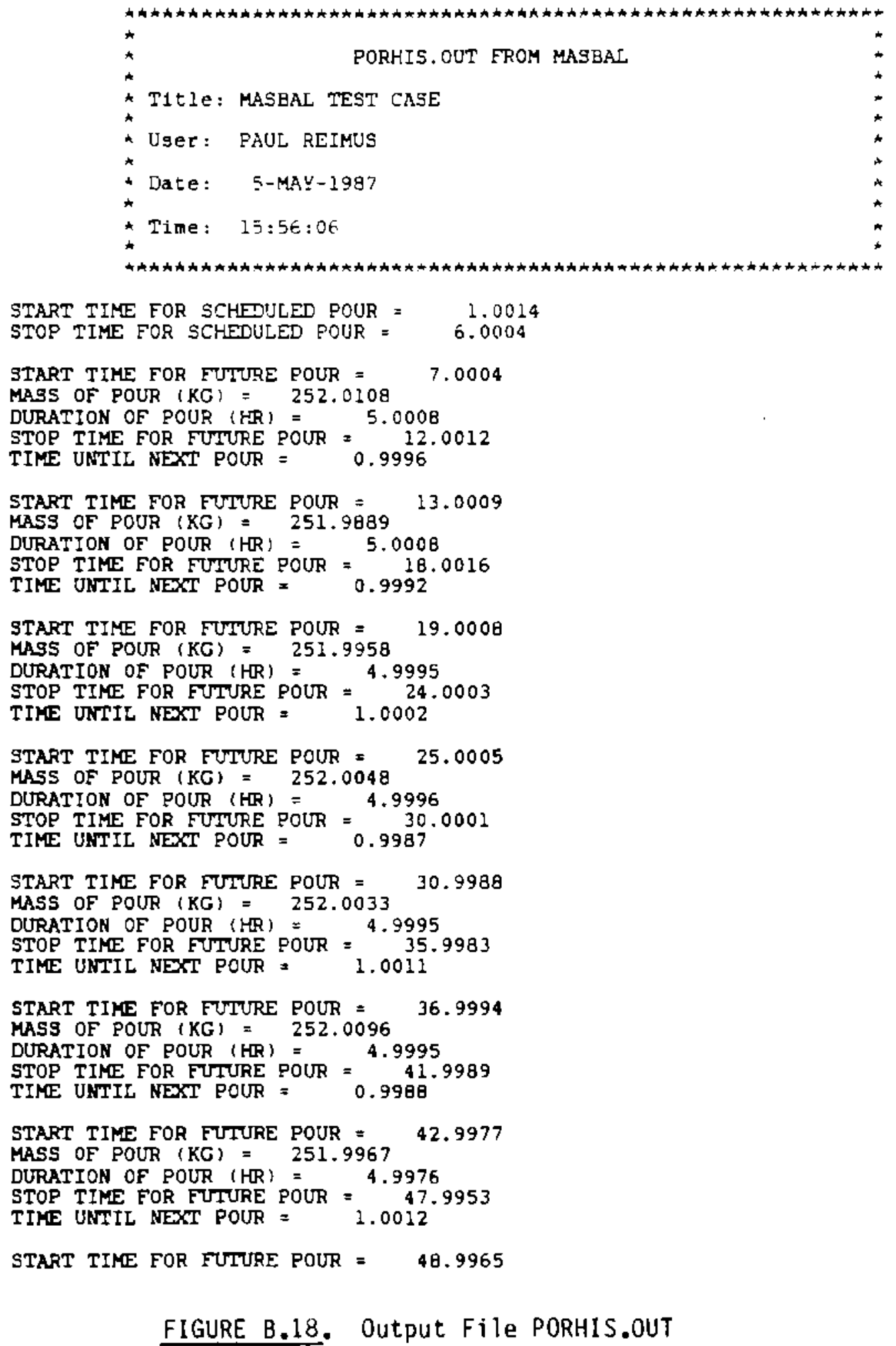

FIGURE B.18. Output File PORHIS.OUT 


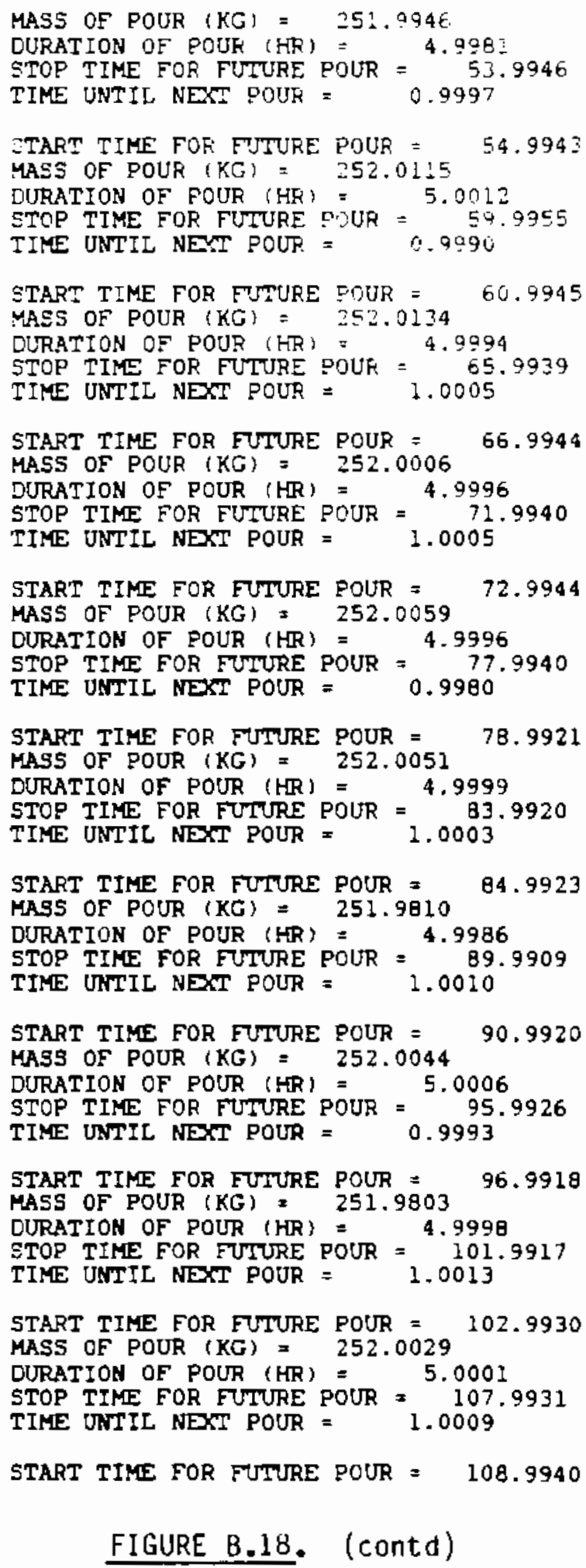




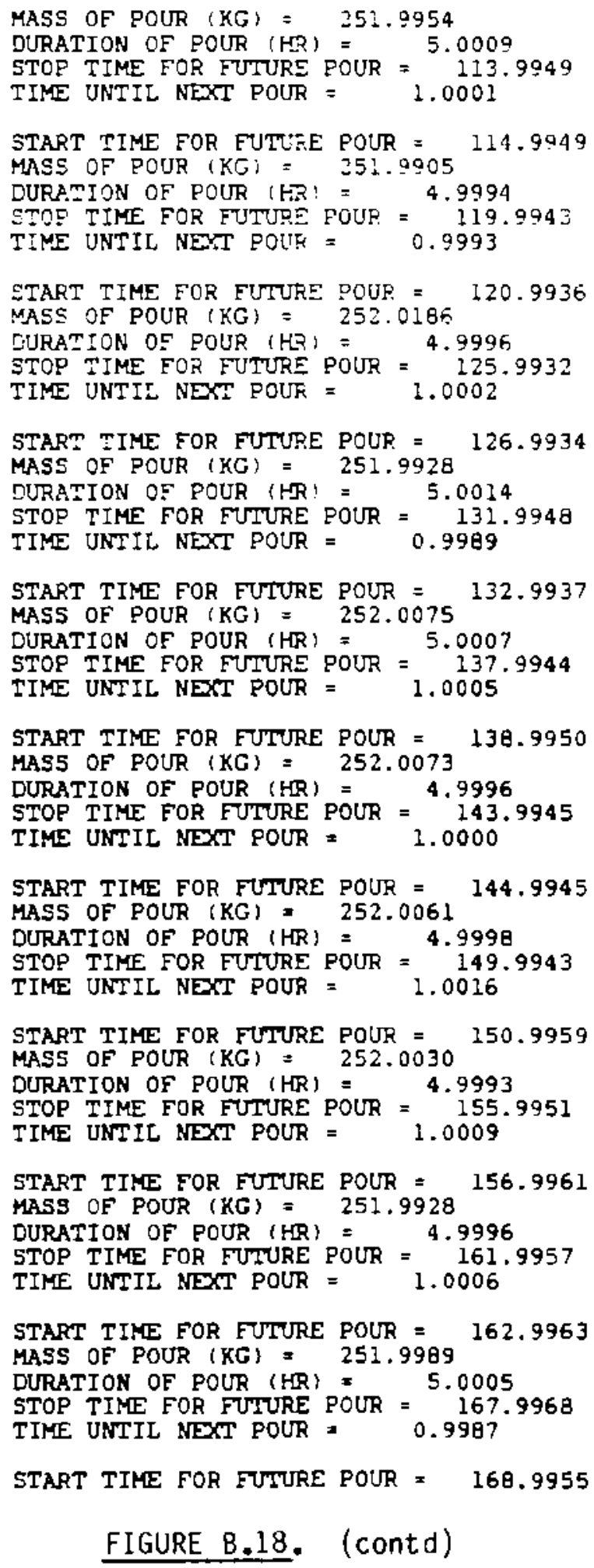




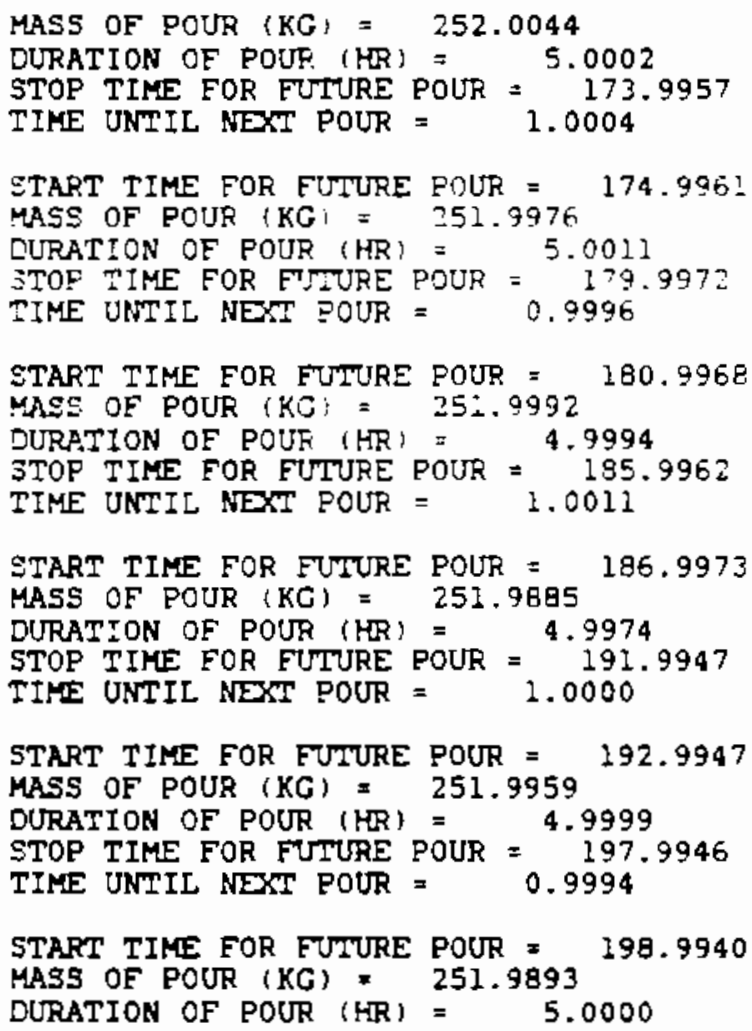

FIGURE B.18. (contd) 


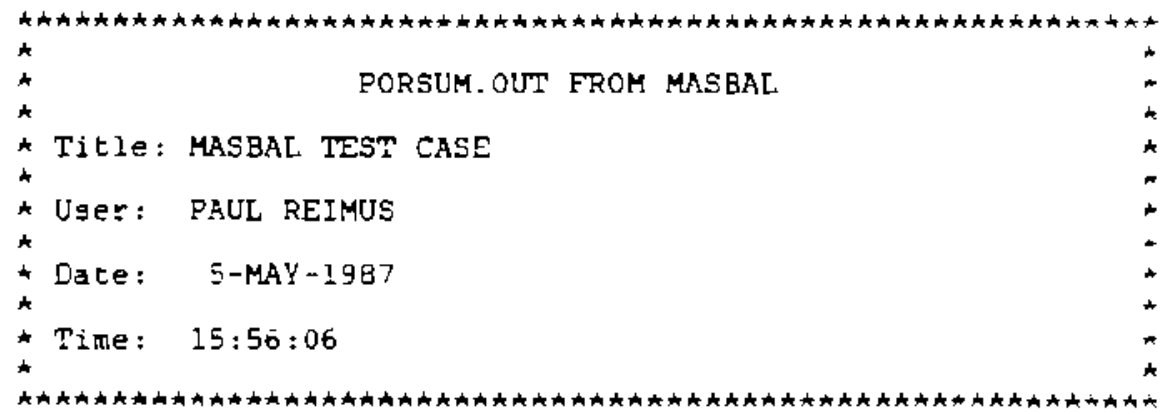

CANISTER POURING SUMMARY - TIMES AND MASSES OF POURS

TIMES ARE HOURS SINCE START OF SIMULATION

\begin{tabular}{|c|c|c|c|}
\hline NUMBER & START TIME & STOP TIME & MASS (KG) \\
\hline 1 & 1.0014 & 6.0004 & 252.00288 \\
\hline 2 & 7.0004 & 12.0012 & 252.01086 \\
\hline 3 & 13.0009 & 18.0016 & 251.98094 \\
\hline 4 & 19.0000 & 24.0003 & 251.99567 \\
\hline 5 & 25.0005 & 30.0001 & 252.00479 \\
\hline 6 & 30.9988 & 35.9903 & 252.00331 \\
\hline 7 & 36.9994 & 41.9909 & 252.00935 \\
\hline$\theta$ & 42.9977 & 47.9953 & 251.99678 \\
\hline 9 & 48.9965 & 53.9946 & 251.99486 \\
\hline 10 & 54.9943 & 59.9955 & 252.01167 \\
\hline 11 & 60.9945 & 65.9939 & 252.01314 \\
\hline 12 & 66.9944 & 71.9940 & 252.00110 \\
\hline 13 & 72.9944 & 77.9940 & 252.00560 \\
\hline 14 & 78.9921 & 83.9920 & 252.00526 \\
\hline 15 & 04.9923 & 89.9909 & 251.98132 \\
\hline 16 & 90.9920 & 95.9926 & 252.00400 \\
\hline 17 & $96.991 \theta$ & 101.9917 & 251.98010 \\
\hline 18 & 102.9930 & 107.9931 & 252.00270 \\
\hline 19 & 108.9940 & 113.9949 & 251.99545 \\
\hline 20 & 114.9949 & 119.9943 & 251.99037 \\
\hline 21 & 120.9936 & 125.9932 & 252.01865 \\
\hline 22 & 126.9934 & $131.994 \mathrm{~g}$ & 251.99257 \\
\hline 23 & 132.9937 & 137.9944 & 252.00746 \\
\hline 24 & 138.9950 & 143.9945 & 252.00748 \\
\hline 2 & .9945 & 149.9943 & 252.00635 \\
\hline 26 & 9959 & 155.9951 & 252.00337 \\
\hline 27 & 156.9961 & 161.9957 & 251.99321 \\
\hline $2 \theta$ & 162.9963 & 167.9968 & 251.99811 \\
\hline 4 & 168.9955 & 173.9957 & 252.00433 \\
\hline 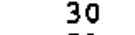 & 174.9961 & 179.9972 & 251.99838 \\
\hline 3 & 180.9968 & 185.9962 & 251.99843 \\
\hline 3 & .9973 & 191.9947 & 251.9888 \\
\hline 37 & . 9947 & 197.9946 & 251.9961 \\
\hline
\end{tabular}

FIGURE B.19. Output File PORSUM.OUT 


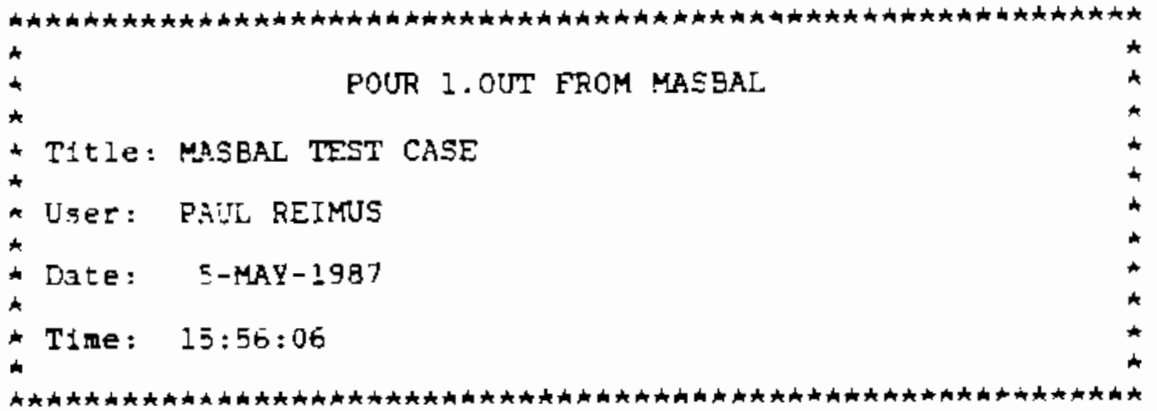

COMPOSITION OF BATCH GLASS POURS (MASE FPACTION)

\begin{tabular}{|c|c|c|c|c|c|}
\hline NUMBER & SI0Z & $\mathrm{B} 203$ & NA2O & FE203 & $\mathrm{k} 20$ \\
\hline $\begin{array}{l}1 \\
2 \\
3 \\
4 \\
5 \\
6 \\
7 \\
6 \\
9 \\
10 \\
11 \\
12 \\
13 \\
14 \\
15 \\
16 \\
17 \\
19 \\
19 \\
20 \\
21 \\
22 \\
23 \\
24 \\
25 \\
26 \\
27 \\
26 \\
29 \\
30 \\
31 \\
32 \\
33\end{array}$ & $\begin{array}{l}0.443290 \\
0.442995 \\
0.441716 \\
0.439546 \\
0.433546 \\
0.427275 \\
0.420267 \\
0.412964 \\
0.405721 \\
0.398826 \\
0.392463 \\
0.386727 \\
0.391656 \\
0.377242 \\
0.373446 \\
0.370216 \\
0.367492 \\
0.365211 \\
0.363310 \\
0.361734 \\
0.360432 \\
0.359359 \\
0.356478 \\
0.357755 \\
0.357162 \\
0.356969 \\
0.357068 \\
0.357306 \\
0.357626 \\
0.357993 \\
0.358371 \\
0.358744 \\
0.359098\end{array}$ & $\begin{array}{l}0.107350 \\
0.107242 \\
0.107908 \\
0.110478 \\
0.114916 \\
0.120685 \\
0.127260 \\
0.134204 \\
0.141160 \\
0.147843 \\
0.154068 \\
0.159718 \\
0.164746 \\
0.169149 \\
0.172955 \\
0.176210 \\
0.179967 \\
0.181297 \\
0.183228 \\
0.194844 \\
0.186184 \\
0.187292 \\
0.188206 \\
0.188958 \\
0.189576 \\
0.190004 \\
0.190487 \\
0.191193 \\
0.192021 \\
0.192897 \\
0.193770 \\
0.194607 \\
0.195390\end{array}$ & $\begin{array}{l}0.096836 \\
0.096970 \\
0.097224 \\
0.097583 \\
0.098039 \\
0.098551 \\
0.099095 \\
0.099615 \\
0.100121 \\
0.100566 \\
0.101002 \\
0.101367 \\
0.101681 \\
0.101947 \\
0.102177 \\
0.102359 \\
0.102513 \\
0.102640 \\
0.102744 \\
0.102828 \\
0.102896 \\
0.102952 \\
0.102996 \\
0.103032 \\
0.103061 \\
0.103032 \\
0.102789 \\
0.102261 \\
0.101562 \\
0.100778 \\
0.099971 \\
0.099179 \\
0.090426\end{array}$ & $\begin{array}{l}0.078508 \\
0.078595 \\
0.078716 \\
0.078822 \\
0.078899 \\
0.078951 \\
0.078981 \\
0.078991 \\
0.078986 \\
0.078968 \\
0.078940 \\
0.078906 \\
0.078869 \\
0.078631 \\
0.078794 \\
0.078760 \\
0.078728 \\
0.078699 \\
0.078673 \\
0.078650 \\
0.078631 \\
0.078613 \\
0.078598 \\
0.078566 \\
0.078575 \\
0.078530 \\
0.078471 \\
0.078417 \\
0.078370 \\
0.078328 \\
0.078291 \\
0.078260 \\
0.078232\end{array}$ & $\begin{array}{l}0.081997 \\
0.081984 \\
0.081968 \\
0.081959 \\
0.081958 \\
0.081964 \\
0.081974 \\
0.081988 \\
0.082004 \\
0.082019 \\
0.082031 \\
0.082041 \\
0.082049 \\
0.082055 \\
0.082060 \\
0.082064 \\
0.082067 \\
0.082069 \\
0.082071 \\
0.082072 \\
0.082073 \\
0.082074 \\
0.082074 \\
0.082074 \\
0.082074 \\
0.082037 \\
0.081952 \\
0.081827 \\
0.081679 \\
0.081522 \\
0.081365 \\
0.001215 \\
0.081074\end{array}$ \\
\hline
\end{tabular}

FIGURE B.20. Output File POUR 1.OUT 


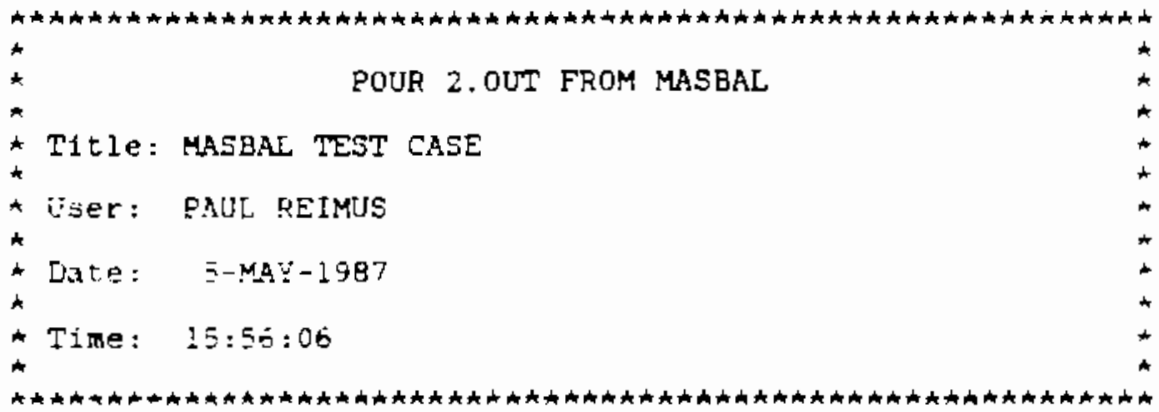

COMPOSITION OF BATCH GLASS FOURS (MASS FRACTION)

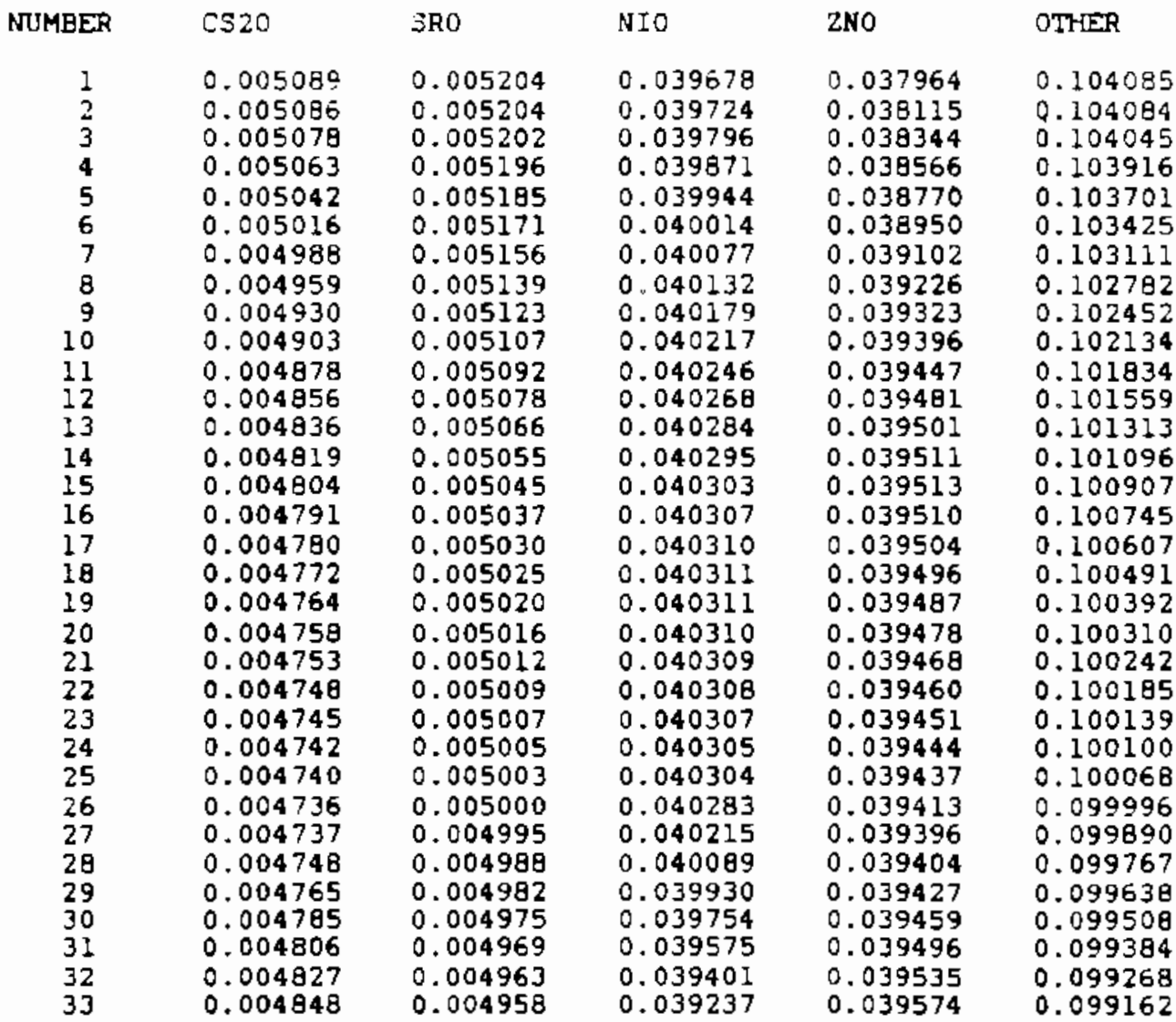

FIGURE B.21. Output file POUR 2.0UT 


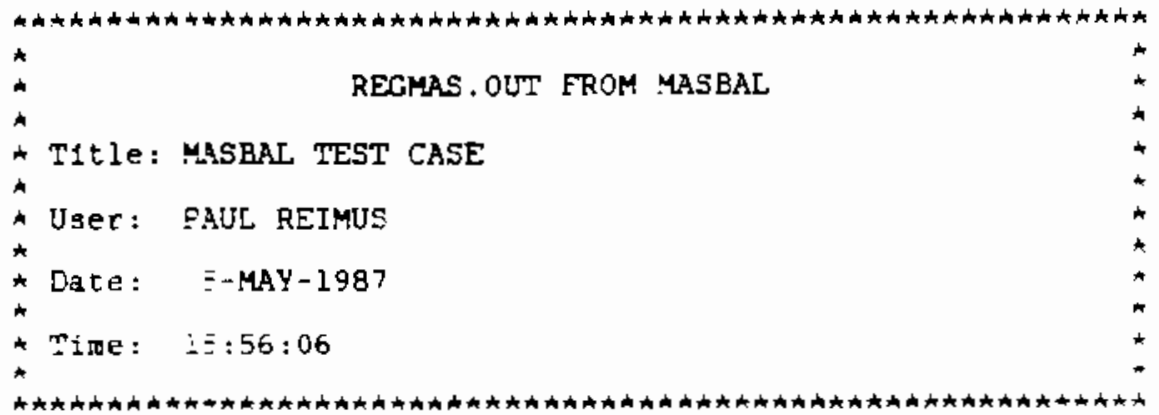

MASS CE ALL REGIONS IN MELTER (GMS)

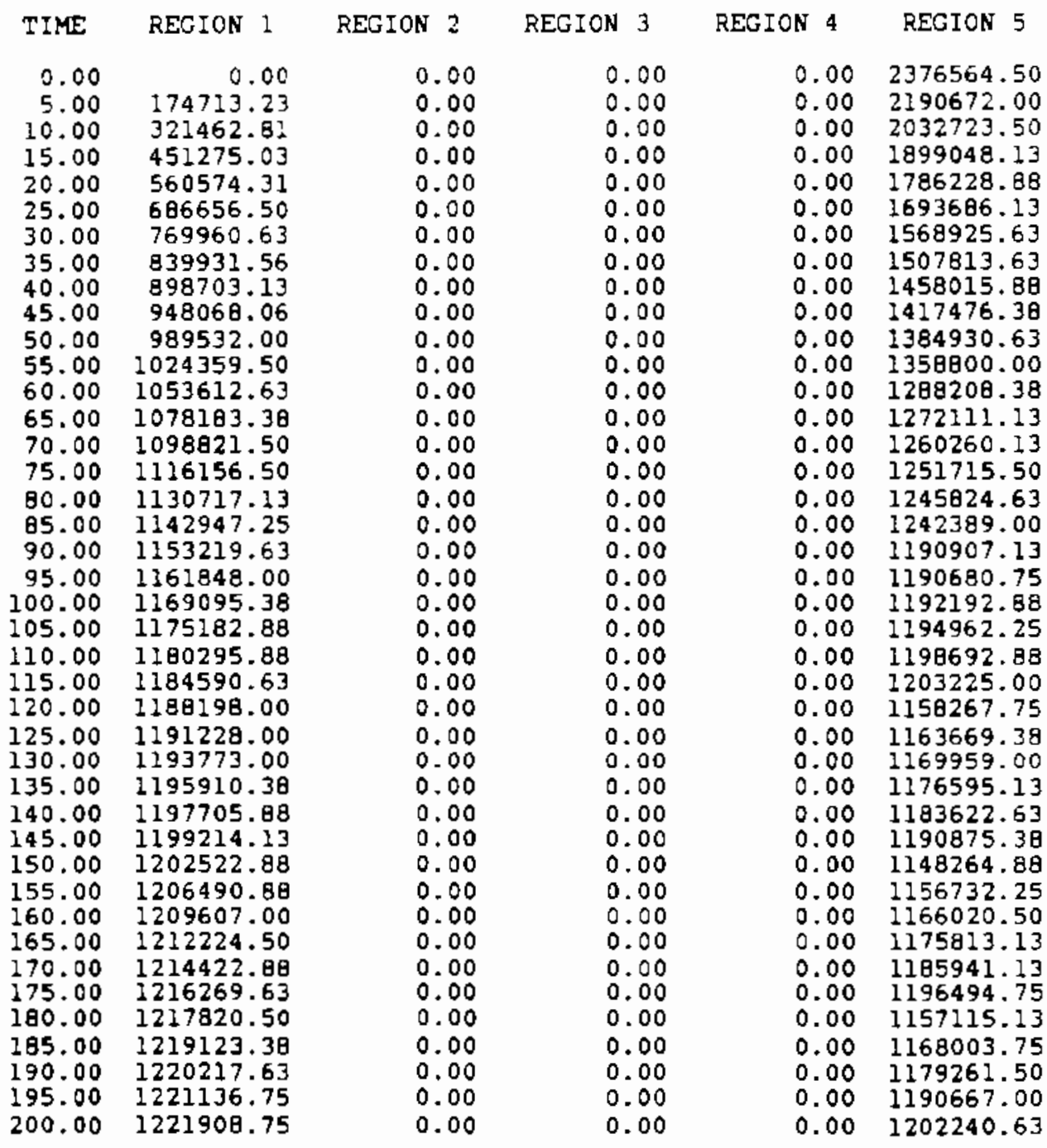

\section{FIGURE B.22. Output file REGMAS.OUT}




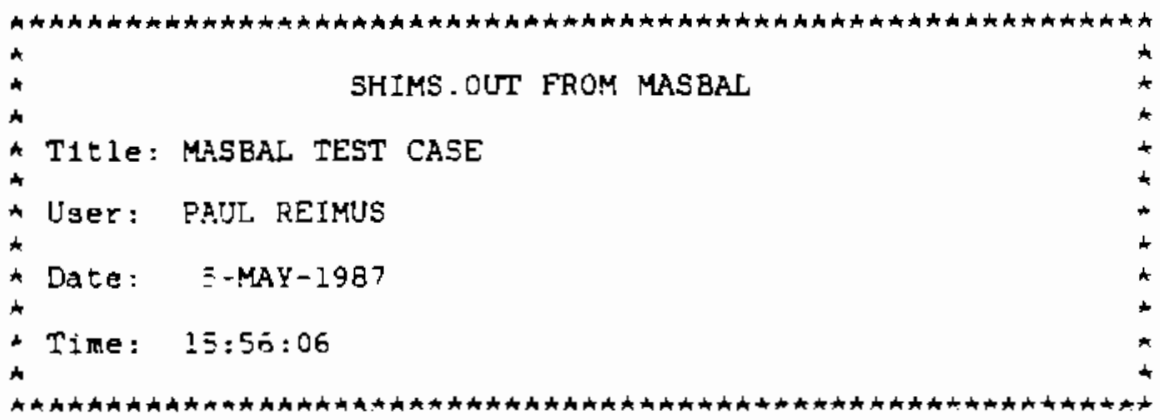

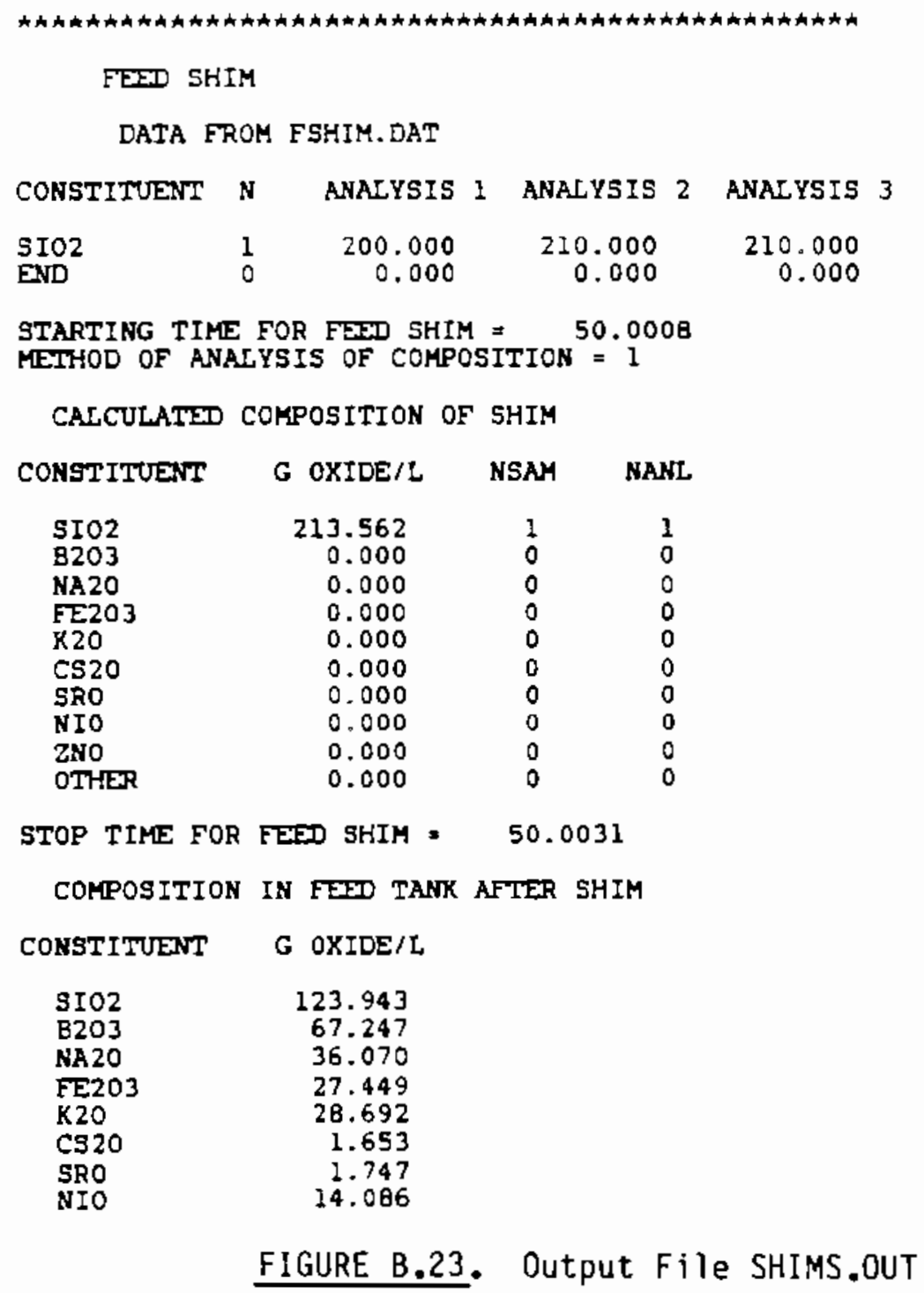




$\begin{array}{ll}\text { 2NO } & 13.771 \\ \text { OTHER } & 34.932\end{array}$

\begin{tabular}{|c|c|c|c|c|}
\hline \multicolumn{5}{|c|}{ MELTER SHIM } \\
\hline \multicolumn{5}{|c|}{ DATA FROM MSHIM.DAT } \\
\hline CONSTITUENT & ANALVSIS I & \multicolumn{2}{|c|}{ ANALYSIE 2} & ANALYSIS 3 \\
\hline $\begin{array}{l}\text { EIO2 } \\
\text { END }\end{array}$ & $\begin{array}{r}200.000 \\
0.000\end{array}$ & \multicolumn{2}{|c|}{$\begin{array}{r}210.000 \\
0.000\end{array}$} & $\begin{array}{r}210.000 \\
0.000\end{array}$ \\
\hline \multicolumn{4}{|c|}{$\begin{array}{l}\text { STAPTING TIME FOR MELTER SHIM = } \\
\text { METHOD OF ANALYSIS OF COMPOSITION }=1\end{array}$} & \\
\hline \multicolumn{4}{|c|}{ CALCULATED COMPOSITION OF SHIM } & \\
\hline CONSTITUENT & G OXIDE $/ \mathrm{L}$ & JSAMY & NANLM & \\
\hline $\begin{array}{l}\text { SIO2 } \\
\text { B203 } \\
\text { NA20 } \\
\text { FE203 } \\
\text { K2O } \\
\text { CS20 } \\
\text { SRO } \\
\text { NIO } \\
\text { ZNO } \\
\text { OTHER }\end{array}$ & $\begin{array}{r}171.575 \\
0.000 \\
0.000 \\
0.000 \\
0.000 \\
0.000 \\
0.000 \\
0.000 \\
0.000 \\
0.000\end{array}$ & $\begin{array}{l}1 \\
0 \\
0 \\
0 \\
0 \\
0 \\
0 \\
0 \\
0 \\
0\end{array}$ & $\begin{array}{l}1 \\
0 \\
0 \\
0 \\
0 \\
0 \\
0 \\
0 \\
0 \\
0\end{array}$ & \\
\hline STOP TIME FOR & MEITER SHIM = & 150 & 0014 & \\
\hline & FIGURE $B .23$ & & ntd) & \\
\hline
\end{tabular}




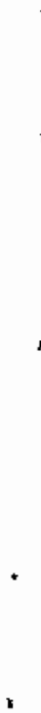

$r$

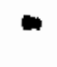




\section{DISTRIBUTION}

No. of

Copies

OFFSITE

30 DOE Technical Information Center

6 DOE Office of Civilian Radioactive Waste Management Forrestal Building Washington, DC 20585

ATTN: L. H. Barrett, RW-33

C. R. Cooley, RW-40

J. R. Hilley, RW-30

S. H. Kale, RW-20, RW-32

D. E. Shelor

R. Stein, RW-23

4 DOE Office of Defense Waste \& Transportation Management GTN

Washington, DC 20545

ATTN: T. C. Chee, DP -123

G. H. Daly, DP-123

J. E. Lytle, DP-12

K. Chacey, OP-123

4 DOE Office of Remedial Action \& GTN Waste Technology

Washington, DC 20545

ATTN: J. A. Coleman, NE-24

T. W. Mc intosh, NE-24

W. R. Voigt, NE-20

H. F. Walter, NE-24

A. T. Clark

Division of Fuel Material Safety

Nuclear Regulatory Commission

Washington, OC 20555
No. of

Copies

V. Stello

Office of the Executive

Director for Operations

Mail Station 6209

Nuclear Regulatory Commission

Washington, DC 20555

G. L. Sjoblom

Environmental Protection Agency

Office of Radiation Programs

401 M Street, S.W.

Washington, DC 20460

J. M. McGough

DOE Albuquerque Operations Office

P.0. Box 5400

Albuquerque, NM 87185

P. G. Hagan

Joint Integration Office

Bldg. 3, 2nd Floor

2201 San Pedro N.E.

Albuquerque, NM 87110

E. Maestas

DOE West Valley Operations Office

P.0. Box 191

West Valley, NY 14171

3 DOE Idaho Operations Dffice

550 Second Street

Idaho Falls, ID 83401

ATTN: J. P. Hamric

S. T. Hinschberger

J. L. Lyle

F. T. Fong

DOE San Francisco Operations

1333 Broadway

Oak land, CA 94612 
No. of

Copies

M. R. Jugan

OOE Oak Ridge Operations Office

P.0. Box E

Oak Ridge, TN 37830

W. J. Brumley

DOE Savannah River Operations Office

P.0. Box A

Aiken, SC 29801

M. J. Steindler

Argonne National Laboratory

9700 South Cass Avenue

Argonne, IL 60439

C. S. Abrams

Argonne National Laboratory

P.0. Box 2528

Idaho Falls, ID 83401

3 Battelle Memorial Institute

Project Management Division

$505 \mathrm{King}$ Avenue

Columbus, $\mathrm{OH} 43201$

ATTN: W. A. Carbiener

W. S. Madia

Technical Library

L. D. Ramspott

Lawrence Livermore National

Laboratory

University of California

P.0. Box 808

Livermore, CA 94550

D. T. Oakley, MS 619

Los Alamos Scientific Laboratory

P.0. Box 1663

Los Alamos, NM 87544

4 Oak Ridge National Laboratory

P.0. Box Y

Oak Ridge, TN 37830

ATTN: J. 0. Blomeke

W. D. Burch

R. T. Jubin

L. J. Mezga
No. of

Copies

2 Sandia Laboratories

P.0. Box 5800

Albuquerque, NM 87185

ATTN: R. W. Lynch

Technical Library

J. R. Berreth

Westinghouse Idaho Nuclear

Co., Inc.

P.0. Box 4000

Idaho Falls, ID 83401

6 E. I. du Pont de Nemours Company

Savanna River Laboratory

Aiken, SC 29801

ATTN: R. G. Baxter

M. 0. Boersma

J. G. Glasscock

J. R. Knight

M. J. Plodinec

C. T. Randall

E. A. Jennrich

EG\&G Idaho

P.0. Box 1625

Idaho Falls, ID 83415

R. Shaw

Electric Power Research

Inst i tute

3412 Hillview Avenue

P.0. Box 10412

Palo Alto, CA 94304

7 West Valley Nuclear Services

Company

P.0. Box 191

West Valley, NY 14171

ATTN: V. S. Arakali

S. M. Barnes

C. C. Chapman

J. C. Cwynar

J. E. Krauss

S. J. Marchette

J. M. Pope 
No. of

Copies

J. L. White, Chairman

Energy Research \& Development Authority

Empire State Plaza

Albany, NY 12223

\section{ONSITE}

8 DOE Richland Operations Office

E. A. Bracken

C. E. Collantes

C. R. DeLannoy

N. T. Karagianes

J. M. Peterson

J. L. Rhoades

M. W. Shupe

J. D. White

10 Westinghouse Hanford Company

T. E. Dabrowski/W. J. Kyriazis

J. M. Henderson

R. E. Lerch

R. D. Prosser

J. L. Scott

J. D. Wat rous

D. D. Wodrich

R. D. Wojtasek

B. A. Wolfe

File Copy
No. of

Copies

50 Pacific Northwest Laboratory

C. R. Allen

W. W. Ballard, Jr.

W. F. Bonner

D. J. Bradley

R. A. Brouns

G. H. Bryan

H. C. Burkholder

J. R. Carrell (2)

T. T. Claudson

D. G. Coles

R. D. Dierks

D. W. Faletti

R. W. Goles

D. E. Knowlton

R. S. Kemper

W. L. Kuhn

W. W. Laity

L. T. Lakey

D. E. Larson

J. L. MeElroy

J. E. Mendel/M. R. Kreiter

J. E. Minor

R. K. Nakaoka

J. M. Perez, Jr.

M. E. Peterson

M. A. Reimus

P. W. Reimus (10)

W. A. Ross

K. J. Schneider

S. C. Slate

G. J. Sevigny

D. H. Si emens

J. H. Westsik, Jr. Publishing Coordination (2)

Technical Report Files (5) 


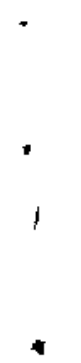

